Carlos Eduardo Baldo Carlomagno

\title{
INFLUÊNCIA DA MONITORIZAÇÃO DA MECÂNICA RESPIRATÓRIA SOBRE A EFICÁCIA DO ENSINO DA VENTILAÇÃO MANUAL DE MÉDICOS RESIDENTES DE NEONATOLOGIA
}

\author{
Dissertação apresentada à Faculdade \\ Israelita de Ciências da Saúde Albert \\ Einstein para obtenção do Título de Mestre \\ em Ciências da Saúde.
}

São Paulo 
Carlos Eduardo Baldo Carlomagno

\title{
INFLUÊNCIA DA MONITORIZAÇÃO DA MECÂNICA RESPIRATÓRIA SOBRE A EFICÁCIA DO ENSINO DA VENTILAÇÃO MANUAL DE MÉDICOS RESIDENTES DE NEONATOLOGIA
}

\author{
Dissertação apresentada à Faculdade \\ Israelita de Ciências da Saúde Albert \\ Einstein para obtenção do Título de Mestre \\ em Ciências da Saúde.
}

Orientador: Prof. Dr. Celso Moura Rebello

São Paulo

2019 
Carlomagno, Carlos Eduardo Baldo

Influência da monitorização da mecânica respiratória sobre a eficácia do ensino da ventilação manual de médicos residentes de Neonatologia / Carlos Eduardo Baldo Carlomagno. -- São Paulo, 2019. xiii, $39 \mathrm{f}$.

Dissertação (Mestrado) - Faculdade Israelita de Ciências da Saúde Albert Einstein. Instituto Israelita de Ensino e Pesquisa Albert Einstein. Programa de Pós-Graduação em Ciências da Saúde.

Título em inglês: Influence of monitoring mechanical ventilation on the efficacy of teaching manual ventilation for Neonatal residents.

1. Respiração artificial. 2. Volume de ventilação pulmonar. 3. Avaliação educacional. 4. Internato e residência. 5. Neonatologia/educação.

NLM - WF 145

\section{Elaborada pelo Sistema Einstein Integrado de Bibliotecas}


FACULDADE ISRAELITA DE CIÊNCIAS DA SAÚDE ALBERT EINSTEIN

Coordenador do Curso de Pós-Graduação: Prof. Dr. Luiz Vicente Rizzo 
Carlos Eduardo Baldo Carlomagno

\section{INFLUÊNCIA DA MONITORIZAÇÃO DA MECÂNICA RESPIRATÓRIA SOBRE A EFICÁCIA DO ENSINO DA VENTILAÇÃO MANUAL DE MÉDICOS RESIDENTES DE NEONATOLOGIA}

Presidente da banca: Prof. Dr. Celso Moura Rebello

BANCA EXAMINADORA

Membros titulares:

Profa. Dra. Cléa Rodrigues Leone

Profa. Dra. Lilian dos Santos Rodrigues Sadeck

Prof. Dr. Paulo Roberto Pacchi

Membros suplentes:

Profa. Dra. Ana Cristina Zanon Yagui

Profa. Dra. Marta Maria Galli Bozzo Mataloun

Aprovada em: 09/12/2019. 


\section{Dedicatória}

À minha família, aos meus amigos e aos pacientes que encontrei ao longo da minha trajetória. Todos foram e são a minha fonte de inspiração e motivação. 


\section{Agradecimentos}

Aos meus avós, por terem incentivado meus pais a estudarem. Agradecimento especial à vó Alzira por acompanhar até hoje a minha trajetória, sempre com amor e carinho.

Aos meus pais por priorizarem os meus estudos e por me incentivarem a almejar novas conquistas. Obrigado por acreditarem em mim e pelos contínuos exemplos de fortaleza e resiliência.

Ao meu marido por ser meu porto seguro, por cuidar de mim e por compreender a minha ausência em diversos momentos. Obrigado por me ajudar a priorizar o que realmente é importante na vida.

À minha irmã e sobrinho por assumirem diversos cuidados familiares enquanto estava ocupado. Obrigado por dividirem essas responsabilidades comigo e por sempre me apoiarem.

Aos meus sogros por nos ajudarem e apoiarem, permitindo que pudesse me dedicar aos estudos.

Aos amigos e colegas de trabalho pelas inúmeras trocas de plantão, sem as quais não poderia ter realizado essa Pós-Graduação. Obrigado também por me fazerem rir nos plantões.

Aos residentes que se dispuseram a participar deste projeto.

A Laudiceia e a Jaciele por todo o apoio. Agradeço aos professores pelos conhecimentos transmitidos e aos colegas de curso por compartilharem essa trajetória comigo.

A Elivane, Claudia Nora, Letícia da Costa, Edna Rother, Sheila Silveira, Priscila Souza e toda equipe do Núcleo de Apoio ao Pesquisador da instituição pela ajuda imensurável na realização deste trabalho.

Meus agradecimentos ao Dr. João Cesar, por nos receber em seu laboratório e colaborar ativamente neste projeto. Aos Drs. Maurício e Pedro Alexandre, obrigado pela cooperação e liberação de seus residentes.

Finalmente, agradeço ao Dr. Celso e a Dra. Renata por me guiarem ao longo de todo esse processo. Obrigado por serem exemplos de profissionais e seres humanos a seguir. 


\section{Sumário}

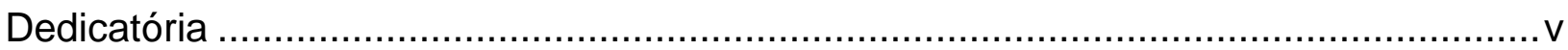

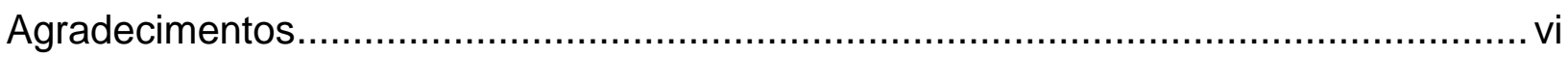

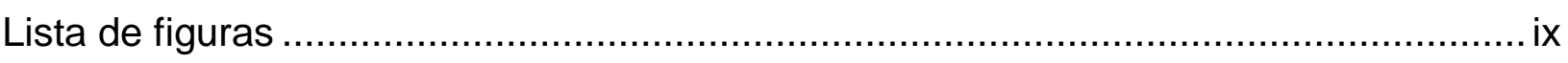

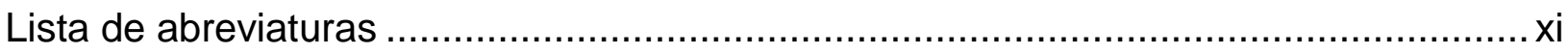

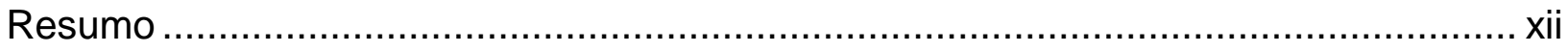

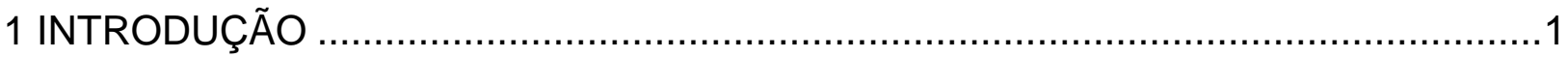

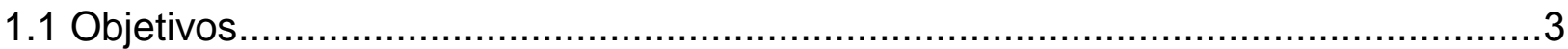

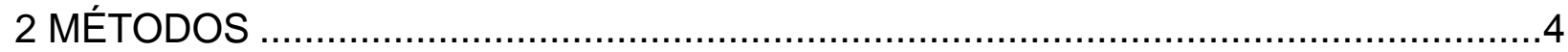

2.1 Tipo de estudo e população-alvo...............................................................4

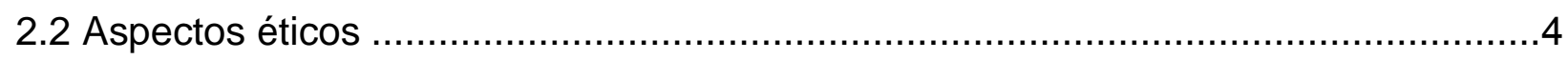

2.3 Delineamento do estudo....................................................................... 4

2.3.1 Dia zero (Questionário + Primeira ventilação + Treinamento + Segunda ventilação

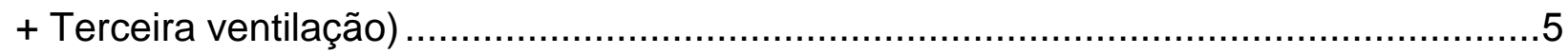

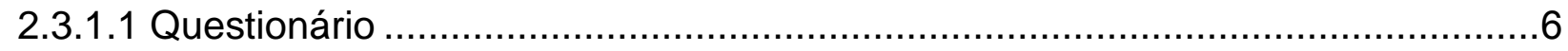

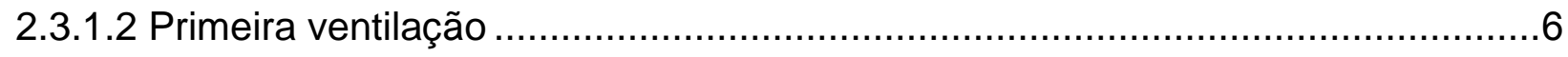

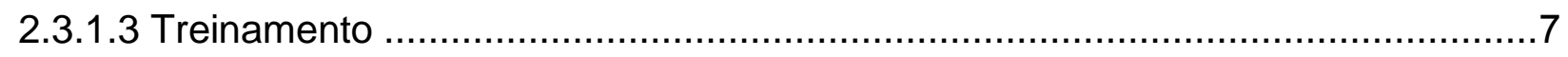

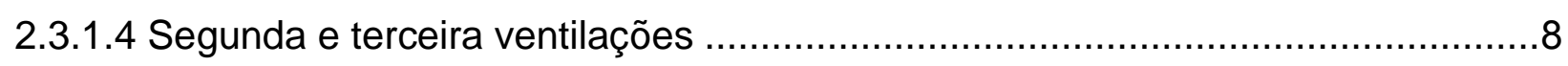

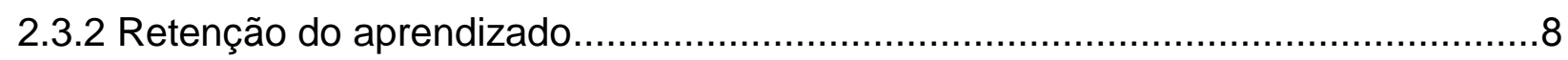

2.4 Aquisição de dados de monitorização respiratória ..........................................9

2.5 Criação de escores para volume corrente e vazamento.......................................11

2.6 Análise estatística............................................................................................. 11

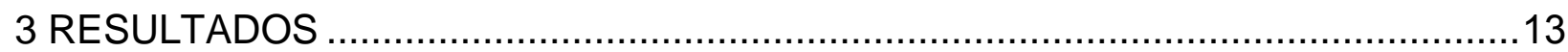

3.1 Dados demográficos dos residentes ...................................................... 13

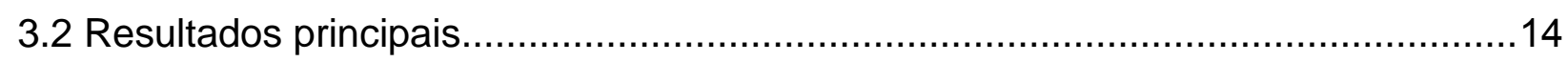

3.2.1 Volume corrente expiratório por quilo ..................................................... 14

3.2.2 Escore de volume corrente expiratório por quilo .........................................15

3.2.3 Vazamento ao redor da máscara facial .........................................................15

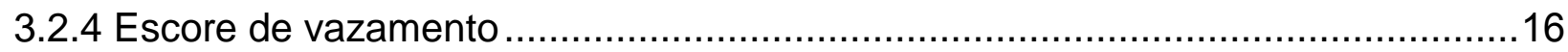

3.2.5 Uso de válvula de pressão positiva ao final da expiração acoplada ao balão

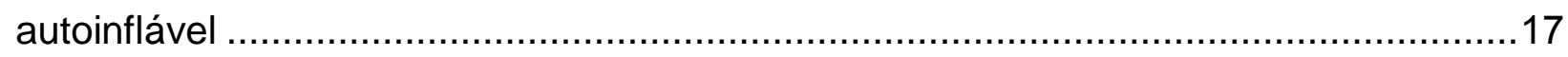

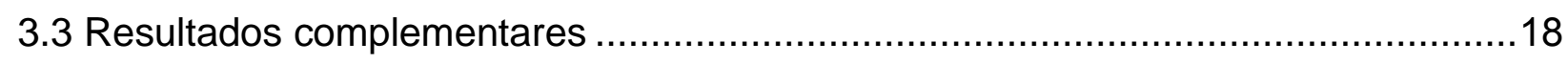

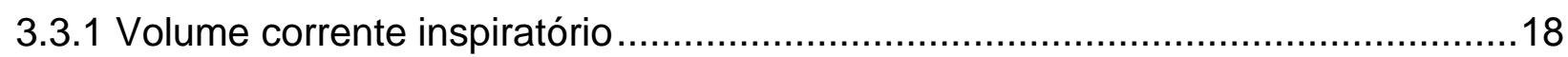




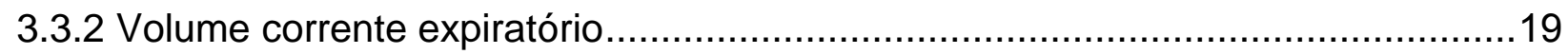

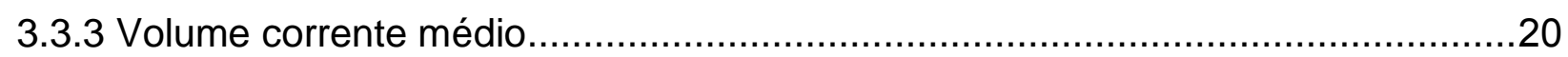

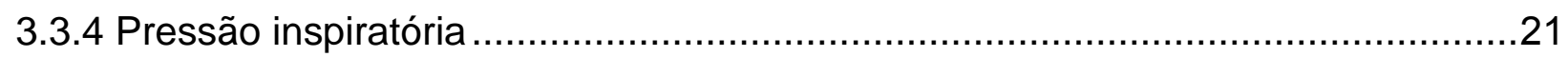

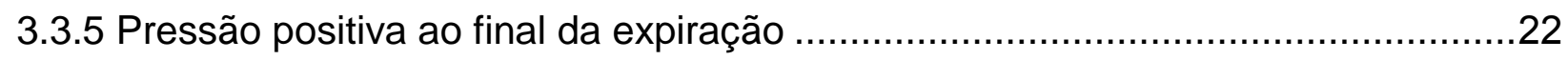

3.3.6 Frequência respiratória..........................................................................2

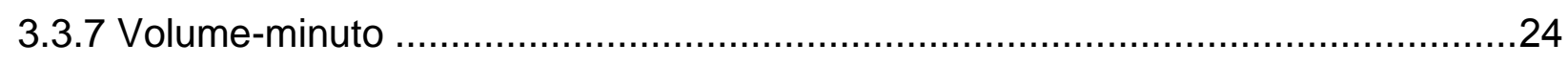

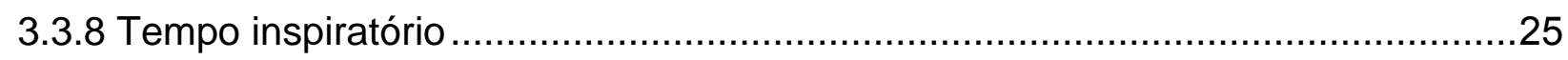

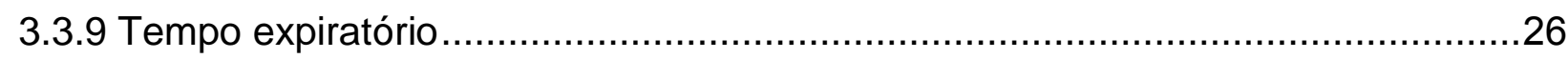

4 DISCUSSÃO

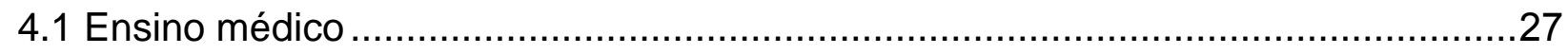

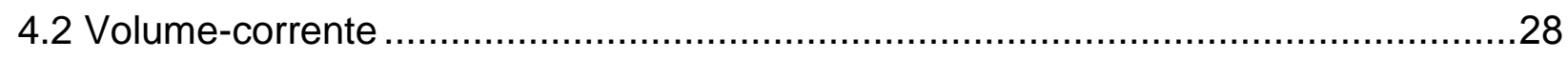

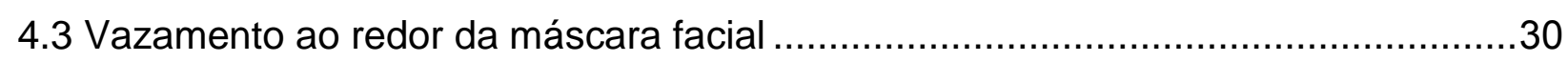

4.4 Pressões e uso da válvula de pressão positiva ao final da expiração acoplada ao

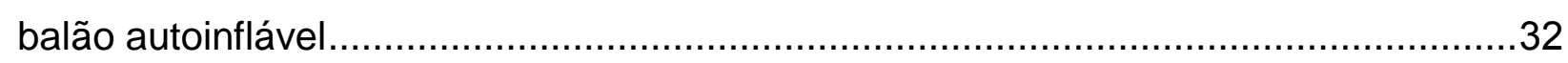

4.5 Frequência respiratória, tempo inspiratório e volume-minuto .................................33

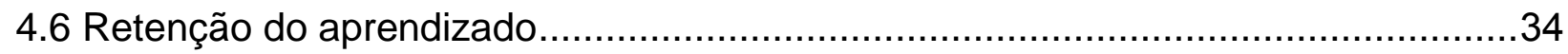

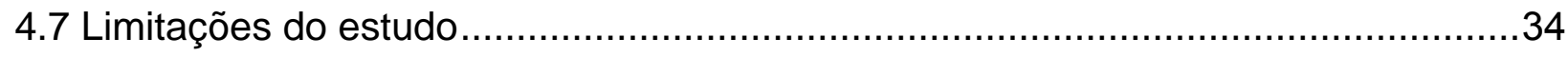

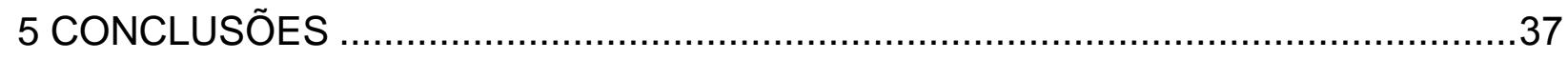

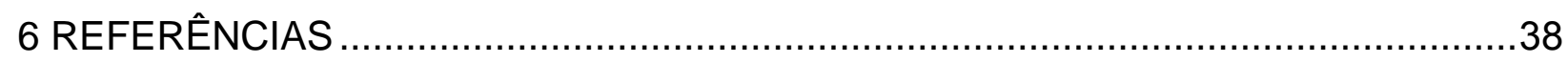

Abstract

Apêndices 


\section{Lista de figuras}

Figura 1. Esquema do dia zero de treinamento e suas respectivas atividades 5

Figura 2. Curva fluxo/tempo do monitor de função respiratória sem vazamento .............7

Figura 3. Curva fluxo/tempo do monitor de função respiratória com vazamento .............7

Figura 4. Volume corrente expresso numericamente em mililitros no monitor.................8

Figura 5. Esquema dos dias 30 e 90 após o treinamento e suas atividades ..................9

Figura 6. Foto do manequim utilizado e do monitor de função respiratória ao fundo ...10 Figura 7. Valores da média do volume corrente expiratório (mililitros por quilo), segundo momento e equipamento

Figura 8. Valores da média do escore de volume corrente expiratório, segundo momento e equipamento 15

Figura 9. Valores da média do vazamento ao redor da máscara (porcentagem), segundo momento e equipamento 16

Figura 10. Valores da média do escore vazamento ao redor da máscara, segundo momento e equipamento

Figura 11. Valores da porcentagem de uso de válvula de pressão positiva ao final da expiração no balão autoinflável segundo os momentos de ventilação. 18

Figura 12. Valores da média do volume corrente inspiratório (mililitros), segundo momento e equipamento 19

Figura 13. Valores da média do volume corrente expiratório (mililitros), segundo momento e equipamento

Figura 14. Valores da média do volume corrente médio (mililitros), segundo momento e equipamento.

Figura 15. Valores da média da pressão positiva inspiratória $(\mathrm{cmH} 2 \mathrm{O})$, segundo momento e equipamento .22

Figura 16. Valores da média da pressão positiva ao final da expiração (cmH2O), segundo momento e equipamento .23

Figura 17. Valores da média da frequência respiratória (ventilações por minutos), segundo momento e equipamento

Figura 18. Valores da média do volume minuto (mililitros por minuto), segundo momento e equipamento 
Figura 19. Valores do tempo inspiratório (segundos), de acordo com momento e

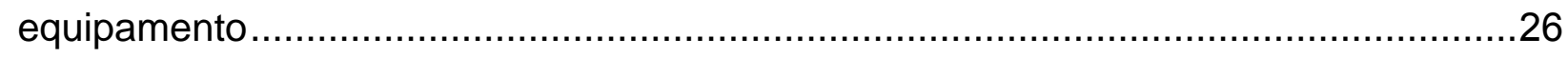

Figura 20. Valores do tempo expiratório (segundos), de acordo com momento e equipamento. .26 


\section{Lista de abreviaturas}

BAI Balão autoinflável

CRF Capacidade residual funcional

FR Frequência respiratória

MFR Monitor de função respiratória

Peça-T Ventilador mecânico manual em $T$

PEEP Pressão positiva ao final da expiração

PIP Pressão positiva inspiratória

RN Recém-nascido

TCLE Termo de Consentimento Livre e Esclarecido

Tex Tempo da fase expiratória

Tins Tempo da fase inspiratória

VC Volume corrente

VC exp Volume corrente da fase expiratória

VC ins Volume corrente da fase inspiratória

VM Volume-minuto

VPP Ventilação com pressão positiva 


\section{Resumo}

Introdução: Aproximadamente $10 \%$ dos recém-nascidos de baixo risco precisam de auxílio para iniciar ou manter a respiração na sala de parto. A ventilação manual é o procedimento mais eficaz para reverter a asfixia perinatal. A expansibilidade torácica é um marcador impreciso da ventilação pulmonar. A monitorização da mecânica respiratória pode ser uma ferramenta no ensino da ventilação manual para residentes de neonatologia. Objetivos: Avaliar a influência do monitor de função respiratória como estratégia de ensino da ventilação manual com balão autoinflável e ventilador mecânico manual em $\mathrm{T}$, baseado na otimização do volume-corrente, redução do vazamento ao redor da máscara, frequência de uso da válvula de pressão positiva ao final da expiração associada ao balão autoinflável e na retenção do aprendizado após 1 e 3 meses. Métodos: Estudo experimental onde 23 residentes de 4 programas ventilaram um manequim simulando um recém-nascido a termo (peso estimado: $2,5 \mathrm{~kg}$ ) durante 4 minutos com cada equipamento baseados na expansão torácica, visando volumecorrente alvo de 4-6mL/kg e vazamento de até 20\% (V1). Após treinamento com o monitor, realizaram nova ventilação com os dados de monitorização (V2), seguida de ventilação sem os dados (V3). A retenção foi avaliada após 1 (V4) e 3 meses (V5), sem acesso aos dados de monitorização. Os dados de volume-corrente, vazamento e pressão positiva ao final da expiração foram adquiridos por um sistema informatizado. Análise estatística (SPSS 3) utilizou ajuste de modelos mistos lineares para comparações entre os momentos e equipamentos. Resultados: Foram avaliados 23 residentes, com média de idade de 29 anos, $91,3 \%$ do sexo feminino e $60,9 \%$ do primeiro ano. Todos atuavam em sala de parto, eram familiarizados com ambos equipamentos, realizaram o curso de reanimação neonatal e 34,8\% o de reanimação do prematuro. O monitor de função respiratória reduziu significativamente o volumecorrente com o uso do balão autoinflável em todas as mensurações após o treinamento, sendo elevado em V1 (10,28mL/kg [IC95\% 9,05-11,51]), com redução nas demais ventilações ( $p<0,001)$, equiparando-se ao ventilador mecânico manual em T em V3-V5. O volume-corrente permaneceu no alvo em todas as ventilações com ventilador mecânico manual em T. O vazamento ao redor da máscara foi elevado em todas as ventilações com ambos equipamentos, não sendo observada influência do monitor. Houve acréscimo da frequência de uso de válvula de pressão positiva ao final da expiração de $21,7 \%$ para $88,4 \%$ após o treinamento $(p<0,001)$. Conclusões: $O$ monitor 
de função respiratória influenciou no volume-corrente, não influenciou o vazamento ao redor da máscara, aumentou a frequência do uso de válvula de pressão positiva ao final da expiração associada ao balão autoinflável, havendo retenção do aprendizado após 1 e 3 meses do treinamento.

Descritores: Respiração artificial; Volume da ventilação pulmonar; Reanimação; Avaliação educacional; Internato e residência; Neonatologia/educação 


\section{INTRODUÇÃO}

Estima-se que no Brasil 300.000 recém-nascidos (RN) necessitem, anualmente, de auxílio para iniciar e manter a respiração ao nascimento, e a vasta maioria dos prematuros de baixo peso requerem assistência ventilatória manual na sua adaptação ao ambiente extra-uterino. ${ }^{(1,2)}$

A reanimação imediata ao nascimento é uma importante estratégia para diminuir a morbi-mortalidade neonatal. A mortalidade neonatal precoce (entre $0 \mathrm{a}$ 7 dias de vida) relacionada à asfixia perinatal em $\mathrm{RN}$ de baixo risco (peso ao nascimento $>2500 \mathrm{~g}$ e sem malformações) ainda é elevada no Brasil, correspondendo a cerca de 6 óbitos ao dia. ${ }^{(1)}$ O sucesso na reanimação do RN asfixiado depende primordialmente de uma adequada ventilação com pressão positiva (VPP) manual, realizada com máscara facial. ${ }^{(3,4)} \mathrm{O}$ objetivo da VPP é aumentar a capacidade residual funcional (CRF), oferecer volume corrente (VC) adequado para facilitar a troca de gases e estimular a respiração, uma vez que busca minimizar a lesão pulmonar. ${ }^{(5)}$

A ventilação manual é comumente aplicada através de diferentes dispositivos, podendo ser realizada na sala de reanimação, nas unidades de terapia intensiva neonatal e pediátrica, assim como no transporte destes pacientes. Entre os dispositivos mais frequentemente utilizados estão o balão autoinflável (BAl) e o ventilador mecânico manual em $\mathrm{T}$ (Peça-T). Este último funciona com fluxo constante de gás fornecendo fração inspirada de oxigênio, pressão positiva inspiratória (PIP Positive Inspiratory Pressure) e pressão positiva ao final da expiração (PEEP - Positive End Expiratory Pressure) conhecidas e ajustáveis de acordo com a necessidade. O BAI quando acoplado a uma fonte de oxigênio oferece concentrações de oxigênio próximas a $100 \%$, sem ofertar PEEP e em contrapartida, gerando PIP e VC muito elevados. Isto resulta em lesão pulmonar por diversos mecanismos, incluindo exposição a elevadas concentrações de oxigênio (biotrauma e liberação de radicais livres) e volutrauma ${ }^{(6,7)}$ (com risco de hiperdistensão alveolar, hiperventilação, hipocapnia, desencadeamento da cascata inflamatória e displasia broncopulmonar). A Peça-T é superior ao BAI no fornecimento de pressões controladas (PIP e PEEP) durante a ventilação manual. ${ }^{(7)}$

Embora a adequação da ventilação pulmonar seja frequentemente avaliada pela expansibilidade torácica, este é um marcador ruim, pois não se relaciona adequadamente aos VC administrados, aumentando o risco de lesão pulmonar. ${ }^{(3)}$ 
Vazamentos de ar ao redor da máscara facial resultam em perda de VC. A melhor forma de medir o VC oferecido aos pulmões é através do VC expirado. ${ }^{\left({ }^{8)}\right.}$ Grandes vazamentos pela máscara (próximos a 75\%) geram volumes insuficientes para expandirem alvéolos, reduzindo a CRF próximo ao volume de fechamento alveolar, diminuindo assim a troca de gases, gerando atelectotrauma, hipoxemia, hipercapnia e falha na transição da circulação fetal-neonatal. ${ }^{(7)}$

Estudos demonstram que os operadores não conseguem avaliar adequadamente o grau de vazamento e o VC ofertado durante a VPP, tendendo a subestimar o grau de escape de ar através da máscara facial, ${ }^{(4,9)}$ independente do grau de experiência, tempo de profissão ou familiaridade com os equipamentos. Somente através da monitorização da função respiratória é possível reconhecer vazamentos e corrigir rapidamente a técnica para otimizar a entrega de pressões e VC..$^{(9,10)}$

Vários estudos demonstram que o uso do monitor de função respiratória (MFR) é uma excelente ferramenta para auxiliar no treinamento da ventilação manual, ajudando a ensinar o correto posicionamento da máscara facial reduzindo vazamentos ${ }^{(6,9,11)}$ que atrasariam a recuperação do $R N$ na sala de parto.

Cada habilidade médica tem a sua própria curva de aprendizado e risco de deterioração através do tempo. Algumas tentativas de medir o tempo de retenção de aprendizado após treinamento com o MFR mostraram que as habilidades adquiridas se mantiveram até 1 mês após o treinamento. ${ }^{(6,12)}$

A Residência Médica é um importante momento da formação do médico. Aprender a ventilar corretamente em sala de parto é uma habilidade indispensável a ser adquirida na formação do residente em Neonatologia. As estratégias de ensino devem conter fundamento teórico atualizado, mas também proporcionar treinamentos práticos que simulem situações da rotina profissional.

Fizemos a hipótese de que o MFR é uma ferramenta que contribui para o aprendizado a curto e médio prazo dos Residentes de Neonatologia para adquirirem a adequada técnica de ventilação manual com máscara facial, reconhecendo vazamentos ao fluxo e corrigindo a técnica para obterem ventilações com VC adequados, tanto no BAl quanto na Peça-T. Acreditávamos, também, que a ventilação manual com Peça-T teria a menor variabilidade da mecânica respiratória entre os participantes. 


\subsection{Objetivos}

1. Avaliar, em um modelo experimental utilizando um manequim neonatal, a influência do monitor de função respiratória como estratégia de ensino de residentes em Neonatologia quanto à adequada ventilação manual com máscara facial, utilizando balão autoinflável e ventilador mecânico manual em $T$, representada pela otimização do volume corrente ofertado em limites protetores e redução do vazamento de ar ao redor da máscara facial;

2. Conscientizar os residentes sobre a importância do uso da válvula de pressão positiva ao final da expiração acoplada ao balão autoinflável para garantir capacidade residual funcional;

3. Verificar se houve retenção deste aprendizado após 1 e 3 meses do treinamento. 


\section{MÉTODOS}

\subsection{Tipo de estudo e população-alvo}

Foi realizado um estudo prospectivo e experimental, utilizando um manequim neonatal (140 RN, Simulacare, São Paulo) e incluindo residentes escolhidos por conveniência de acordo com cálculo amostral de quatro diferentes programas de Residência Médica em neonatologia: 3 residentes do Hospital Israelita Albert Einstein, 5 da Faculdade de Ciências Médicas da Santa Casa de São Paulo, 8 da Universidade Estadual Paulista (UNESP) de Botucatu e 7 do Hospital e Maternidade Vila Nova Cachoeirinha.

\subsection{Aspectos éticos}

O estudo foi aprovado pelos Comitês de Ética em Pesquisa de todos os centros participantes (Parecer Consubstanciado número 1.922.133).

Os residentes foram convidados a participar neste estudo pelo pesquisador responsável de cada hospital de origem, por conveniência, sem nenhuma imposição ou prejuízo.

Todos os residentes assinaram o Termo de Consentimento Livre e Esclarecido (TCLE), concordando em participar voluntariamente no estudo.

Garantimos sigilo ao não divulgarmos dados e resultados que pudessem ser vinculados aos respectivos residentes, respeitando anonimato.

\subsection{Delineamento do estudo}

A coleta de dados ocorreu em momentos diferentes em cada centro (Tabela 1), respeitando, porém, os intervalos estipulados para avaliar a retenção do aprendizado e garantido o mesmo rigor metodológico em todos os locais e momentos. Os residentes do Hospital Israelita Albert Einstein, Faculdade de Ciências Médicas da Santa Casa de São Paulo e Hospital e Maternidade Vila Nova Cachoeirinha colheram 
dados em laboratório localizado no Instituto Butantã (São Paulo) e os residentes da UNESP em laboratório dentro da Faculdade em Botucatu.

Tabela 1. Datas e intervalos das coletas de dados em cada instituição

\begin{tabular}{lccc}
\hline Instituições & $\begin{array}{c}\text { Primeira a terceira } \\
\text { ventilações }\end{array}$ & Quarta ventilação & Quinta ventilação \\
\hline UNESP Botucatu & $16 / 08 / 2017$ & $20 / 09 / 2017$ & $05 / 11 / 2017$ \\
Hospital Israelita Albert Einstein & $17 / 08 / 2017$ & $21 / 09 / 2017$ & $23 / 11 / 2017$ \\
Santa Casa de São Paulo & $17 / 08 / 2017$ & $21 / 09 / 2017$ & $23 / 11 / 2017$ \\
Maternidade Vila Nova Cachoeirinha & $27 / 09 / 2017$ & $25 / 10 / 2017$ & $20 / 12 / 2017$ \\
\hline
\end{tabular}

UNESP: Universidade Estadual Paulista.

\subsubsection{Dia zero (Questionário + Primeira ventilação + Treinamento + Segunda ventilação + Terceira ventilação)}

O primeiro dia de atividades com os residentes, denominado dia zero, era composto por 5 atividades diferentes (Figura 1) que buscavam situar os conhecimentos prévios dos participantes sobre ventilação manual e posterior treinamento com o MFR.

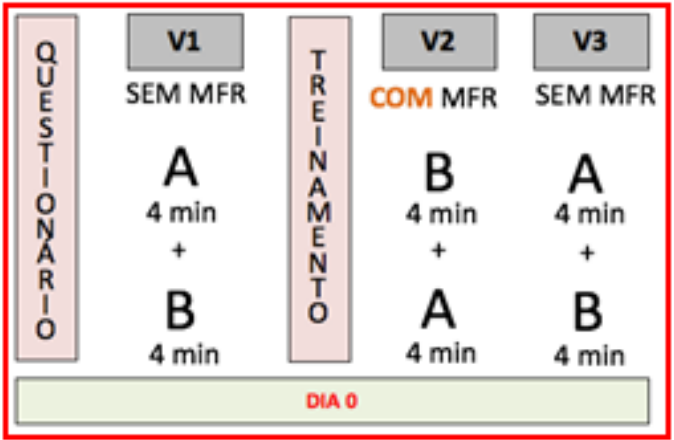

MFR - Monitor de Função Respiratória

A - Balão auto-inflável (com ou sem PEEP)

B - Peça-T

V1: primeira ventilação sem dados de monitor de função respiratória; V2: segunda ventilação com dados do monitor de função respiratória; V3: terceira ventilação sem dados do monitor de função respiratória; V4: quarta ventilação sem dados do monitor de função respiratória após 1 mês do treinamento; V5: quinta ventilação sem dados do monitor de função respiratória após 3 meses do treinamento; MFR: monitor de função respiratória.

Figura 1. Esquema do dia zero de treinamento e suas respectivas atividades 


\subsubsection{Questionário}

Antes de iniciar as atividades, os residentes responderam individualmente a um questionário (Apêndice 1), contendo informações relevantes, tais como: idade, ano de residência em Neonatologia, atuação em sala de parto, participação em cursos de reanimação neonatal, familiarização com os diferentes dispositivos de ventilação manual (BAI e Peça-T) e conhecimento prévio sobre o MFR.

O propósito deste documento era obter dados demográficos dos residentes participantes e estabelecer o grau de conhecimento prévio que o grupo apresentava sobre a reanimação neonatal.

\subsubsection{Primeira ventilação}

Após preencherem o questionário, os residentes foram submetidos a um cenário hipotético onde um manequim neonatal simulava um $\mathrm{RN}$ a termo, de peso estimado em 2,5kg, que nascia hipotônico, em apneia e com bradicardia (<100bpm), estando indicado ser reanimado dentro dos primeiros 60 segundos de vida com VPP (minuto de ouro).

Pedimos que realizassem a técnica de ventilação manual da maneira como estavam acostumados a realizá-la, em 2 períodos de 4 minutos cada (ora usando BAI e ora Peça-T), baseando-se unicamente na expansibilidade torácica do manequim e sem ter acesso aos dados de monitorização pulmonar.

O BAI (LIFESAVER ${ }^{\circledR}$ Neonate Manual Ressuscitator, Teleflex Medical Research Triangle Park, Estados Unidos) possui válvula limitadora de pressão a $40 \mathrm{cmH}_{2} \mathrm{O}$ e fluxo de oxigênio a $5 \mathrm{~L} / \mathrm{min}$. A Peça-T (BabyPuff ${ }^{\circledR}$, Fanem LTDA, Brasil) funciona com fluxo constante, neste estudo definido em $7 \mathrm{~L} / \mathrm{min}$, sendo possível limitar a pressão inspiratória e expiratória final.

A escolha do primeiro equipamento a ser utilizado por cada indivíduo foi feita randomicamente através da seleção de envelopes opacos. O uso ou não da válvula de PEEP acoplada ao $\mathrm{BAI}$, assim como as pressões inspiratórias e expiratórias utilizadas na Peça-T foram decididos pelos residentes.

Nomeamos esta ventilação inicial de primeira ventilação (V1). 


\subsubsection{Treinamento}

Ao término de $\mathrm{V} 1$, os residentes receberam treinamento teórico em ambiente separado da coleta de dados, abrangendo os dados mais relevantes da monitorização respiratória. Este treinamento foi realizado de igual maneira para todos os residentes, apesar de ocorrer em dias e momentos distintos.

Consistiu em uma breve aula apresentada por meio de PowerPoint em laptop e ministrada pelo mesmo pesquisador com experiência em monitorização da mecânica pulmonar. Esta aula durava aproximadamente 15 minutos e participavam somente os residentes que já haviam realizado a primeira ventilação. Os grupos variavam de 1 a 3 residentes, dependendo do avanço da coleta e os residentes podiam fazer perguntas sobre 0 assunto $e$ as mesmas foram respondidas durante 0 treinamento pelo mesmo pesquisador.

Os principais ensinamentos transmitidos neste treinamento incluíram:

1. Observação da curva fluxo/tempo para diagnosticar e corrigir vazamentos (Figuras 2 e 3 ).

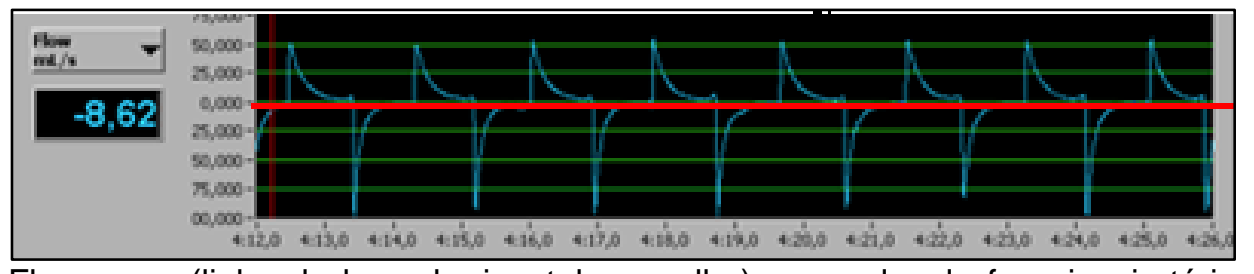

Fluxo zera (linha de base horizontal vermelha) ao mudar da fase inspiratória (positivo) para a fase expiratória (negativo).

Figura 2. Curva fluxo/tempo do monitor de função respiratória sem vazamento

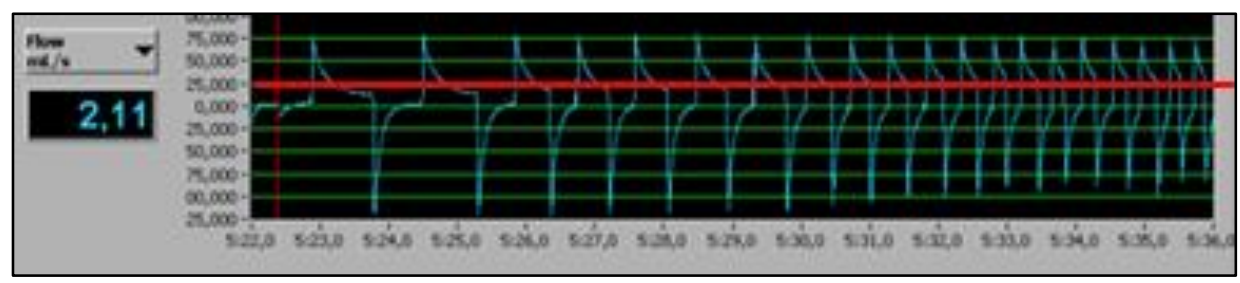

Fluxo inspiratório permanece com linha de base horizontal vermelha positiva antes de mudar para a fase expiratória (negativo).

Figura 3. Curva fluxo/tempo do monitor de função respiratória com vazamento 
2. Manutenção do VC no alvo protetor de 4 a $6 \mathrm{~mL} / \mathrm{kg}$, que para 0 peso estimado do cenário escolhido foi de 10 a 15mL (Figura 4).

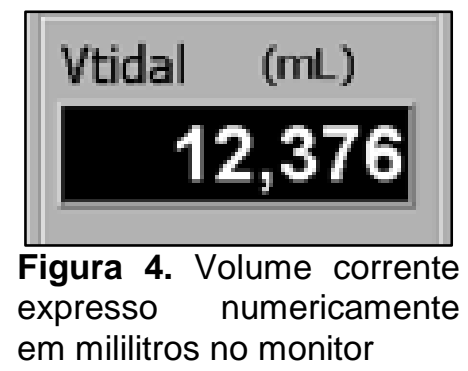

Buscávamos que com essas informações também pudessem correlacionar a influência da PIP, PEEP, tempo inspiratório (Tins), tempo expiratório (Tex) e da frequência respiratória (FR) sob o VC obtido e que corrigissem a técnica de ventilação manual para reduzir vazamentos e manter VC dentro do alvo definido.

Enfatizou-se a importância do uso de válvula de PEEP ao ventilar com BAI, buscando assim, manter o pulmão recrutado ao término de cada expiração.

\subsubsection{Segunda e terceira ventilações}

Ao término do treinamento, os residentes ventilaram novamente 0 manequim por mais 4 minutos com cada dispositivo (na ordem inversa de V1), com acesso às informações geradas pelo MFR. Esta etapa foi chamada de $2^{\underline{a}}$ ventilação (V2) e é a única ventilação onde os residentes tiveram acesso aos dados de MFR.

Logo após, os residentes repetiram a ventilação com ambos equipamentos por 4 minutos cada (na ordem inversa de V2), novamente sem acesso aos dados do MFR. Esta etapa foi chamada de $3^{\text {a }}$ ventilação (V3).

\subsubsection{Retenção do aprendizado}

A retenção do aprendizado foi avaliada com nova ventilação com ambos equipamentos, por 4 minutos cada, após aproximadamente 1 mês (V4) e 3 meses (V5) do treinamento, sem que os residentes tivessem acesso aos dados do monitor (Figura 5). 

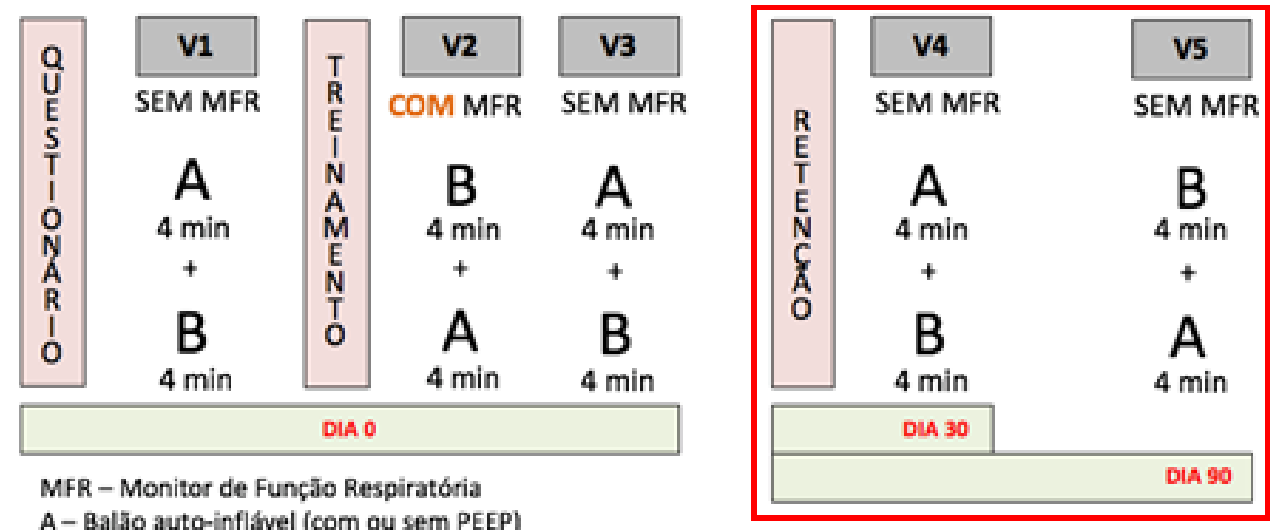

A - Balão auto-inflável (com ou sem PEEP)

B-Peça-T

V1: primeira ventilação sem dados de monitor de função respiratória; V2: segunda ventilação com dados do monitor de função respiratória; V3: terceira ventilação sem dados do monitor de função respiratória; V4: quarta ventilação sem dados do monitor de função respiratória após 1 mês do treinamento; V5: quinta ventilação sem dados do monitor de função respiratória após 3 meses do treinamento; MFR: monitor de função respiratória.

Figura 5. Esquema dos dias 30 e 90 após o treinamento e suas atividades

\subsection{Aquisição de dados de monitorização respiratória}

Durante a ventilação manual, o manequim estava conectado a um sistema informatizado de aquisição de dados (Figura 6), sendo a leitura da pressão ventilatória realizada através de um sensor de pressão (Validyne, modelo DP45-24) e o volume calculado através de um pneumotacógrafo (Hans Rudolph Inc., Kansas City, Estados Unidos), ambos previamente calibrados e conectados a um software de aquisição contínua de dados (Lab VIEW 5.1, National Instruments) desenvolvido especificamente para este fim (R. A. Eletro Sistemas LTDA, Campinas, Brasil). 


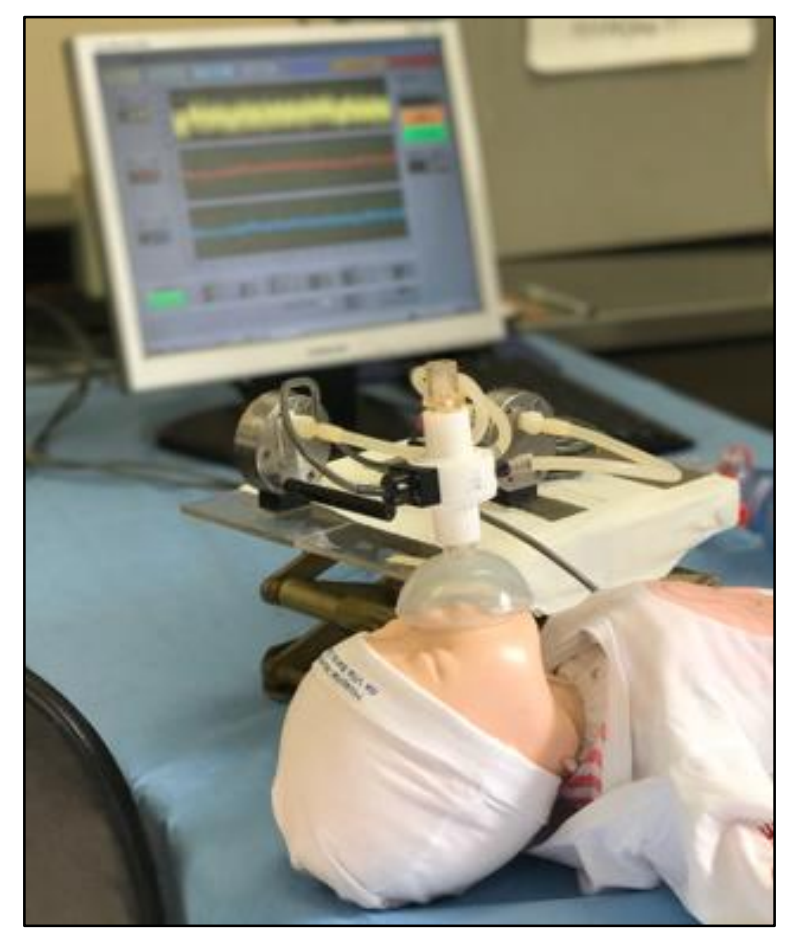

Figura 6. Foto do manequim utilizado e do monitor de função respiratória ao fundo

O cálculo de VC vem da integração dos dados de fluxo obtidos pelo pneumotacógrafo e de tempo. A leitura dos parâmetros da mecânica ventilatória (VC, vazamento de ar, PIP, PEEP, FR, volume-minuto, Tins e Tex) ocorreu continuamente a partir do início das manobras de reanimação até o seu término, no quarto minuto.

Paralelo aos dados obtidos automaticamente pelo software, os dados também foram registrados manualmente pelo investigador principal a cada 30 segundos, em caso de perda indevida de dados pelo programa.

O vazamento pela máscara facial foi calculado pela quantidade de ar que não voltou do pulmão do manequim para o sensor de fluxo durante a expiração, através da fórmula:

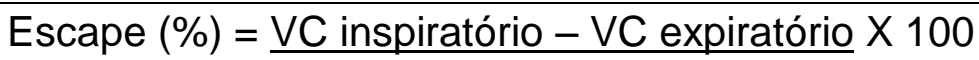
VC inspiratório 


\subsection{Criação de escores para volume corrente e vazamento}

Criamos um escore de VC expiratório por quilo (Quadro 1) para diferenciar as diferentes ventilações. Idealmente os residentes deveriam estar no escore 3 (VC expiratório por quilo em níveis protetores de 4 a $6 \mathrm{~mL} / \mathrm{kg}$ ).

Quadro 1. Escore de volume corrente por quilo

\begin{tabular}{|lc|}
\hline Escore & Valor \\
\hline 5 - Muito alto & $>8,1 \mathrm{~mL} / \mathrm{kg}$ \\
4 - Alto & 8 a $6,1 \mathrm{~mL} / \mathrm{kg}$ \\
3 - Adequado & 6 a $4 \mathrm{~mL} / \mathrm{kg}$ \\
2 - Baixo & $3,9 \mathrm{a} 2 \mathrm{~mL} / \mathrm{kg}$ \\
1 - Muito baixo & $<2 \mathrm{~mL} / \mathrm{kg}$ \\
\hline
\end{tabular}

Também elaboramos um escore de vazamento (Quadro 2) com a mesma finalidade. Idealmente os residentes deveriam estar no escore 1 (vazamento $\leq 20 \%)$.

Quadro 2. Escore de vazamento ao redor da máscara

\begin{tabular}{|lc|}
\hline Escore & Valor \\
\hline 5 - Muito alto & $\geq 51 \%$ \\
4 - Alto & 50 a $21 \%$ \\
3 - Adequado & $\leq 20 \%$ \\
\hline
\end{tabular}

\subsection{Análise estatística}

A análise estatística deste trabalho foi realizada pelos especialistas estatísticos do Núcleo de Apoio ao Pesquisador do Hospital Israelita Albert Einstein.

O tamanho amostral desde estudo foi de 23 residentes, similar ao correspondente a uma turma de treinamento realizado pelo Programa de Reanimação Neonatal da Sociedade Brasileira de Pediatria. Com este número amostral é possível utilizar um teste pareado para detectar uma diferença de $17 \%$ entre as ventilações sem e com MFR utilizando Peça-T e de 12,5\% entre as ventilações sem e com MFR com BAl, assumindo poder de $80 \%$ e nível de significância de 0,05 .

As medidas obtidas com os diferentes equipamentos, condições e momentos, foram descritas através de médias e desvios padrão, medianas e valores 
mínimos e máximos. As comparações entre os momentos e equipamentos foram realizadas por meio do ajuste de modelos mistos lineares, considerando a dependência entre as medidas de um mesmo residente ao longo do tempo e com diferentes equipamentos. A avaliação de adequação do ajuste foi feita por meio dos resíduos dos modelos.

Para avaliar as alterações quanto à utilização de válvula de PEEP com BAI (sim ou não), foi utilizado o teste de Cochran.

As análises foram realizadas com o auxílio do pacote estatístico SPSS (3) e considerando nível de significância em 0,05. 


\section{RESULTADOS}

\subsection{Dados demográficos dos residentes}

Avaliamos 23 residentes de neonatologia, cujos dados demográficos estão detalhados na tabela 2.

Tabela 2. Características demográficas dos 23 residentes participantes do estudo

\begin{tabular}{lc}
\hline Dados demográficos & Resultados \\
\hline Idade (média / mín - máx) & $29(24-35)$ anos \\
Sexo n(\%) & $21(91,3)$ \\
$\quad$ Feminino & $2(8,7)$ \\
$\quad$ Masculino & \\
Local residência n(\%) & $8(34,8)$ \\
$\quad$ Universidade Estadual Paulista - Botucatu & $7(30,4)$ \\
$\quad$ Hospital e Maternidade Vila Nova Cachoeirinha & $5(21,7)$ \\
$\quad$ Faculdade de Ciências Médicas Santa Casa de São Paulo & $3(13,1)$ \\
$\quad$ Hospital Israelita Albert Einstein & \\
Ano de residência em neonatologia n(\%) & $14(60,9)$ \\
$\quad$ Primeiro & $9(39,1)$ \\
$\quad$ Segundo & \\
Cursos realizados n(\%) & $23(100)$ \\
$\quad$ Reanimação neonatal & $8(34,8)$ \\
Reanimação prematuro <34 sem & $8(34,8)$ \\
$\quad$ Transporte recém-nascido de risco & \\
Familiarização com equipamento n(\%) & $23(100)$ \\
$\quad$ Balão autoinflável & $23(100)$ \\
$\quad$ Ventilador mecânico manual em T & $3(13)$ \\
$\quad$ Monitor função respiratória &
\end{tabular}

A maioria dos residentes participaram integralmente das 5 diferentes ventilações (V1 a V5) propostas. Tivemos, porém, algumas perdas nos períodos de reavaliação de retenção de aprendizagem (V4 e V5), principalmente por estarem em programas de estágios fora da cidade de coleta de dados. As perdas foram consideradas nas análises estatísticas.

$$
\begin{aligned}
& V 1+V 2+V 3=23 \text { residentes }(100 \%) ; 0 \text { perdas. } \\
& V 4=17 \text { residentes }(73,9 \%) ; 6 \text { perdas }(26,1 \%) . \\
& V 5=18 \text { residentes }(78,3 \%) ; 5 \text { perdas }(21,7 \%) .
\end{aligned}
$$




\subsection{Resultados principais}

\subsubsection{Volume corrente expiratório por quilo}

O alvo de VC expiratório por quilo (VC exp/kg) era de 4 a $6 \mathrm{~mL} / \mathrm{kg}$, considerado protetor e representado na figura 7 por linhas horizontais verdes.

A média do $\mathrm{VC}$ exp/kg reduziu com o treinamento apenas para o BAl, mantendo-se estável e dentro de parâmetros protetores na Peça-T desde antes do treinamento $(3,53 \mathrm{~mL} / \mathrm{kg}[2,25-4,82]$ a $5,75 \mathrm{~mL} / \mathrm{kg}[4,3-7,18])$.

Os residentes ventilaram com VC excessivos no BAl em V1 $(10,43 \mathrm{~mL} / \mathrm{kg}[9,15$ - 11,72] $\mathrm{p}<0,001)$, porém ventilaram dentro do alvo protetor em todas as ventilações subsequentes $(3,37$ a $5,95 \mathrm{~mL} / \mathrm{kg})$. De V3 a $\mathrm{V} 5$, os residentes obtiveram VC exp/kg equiparáveis com ambos equipamentos (Figura 7).

$O$ detalhamento numérico de todos os valores pode ser encontrado no apêndice 2 (médias) e apêndice 3 (desvios-padrão).

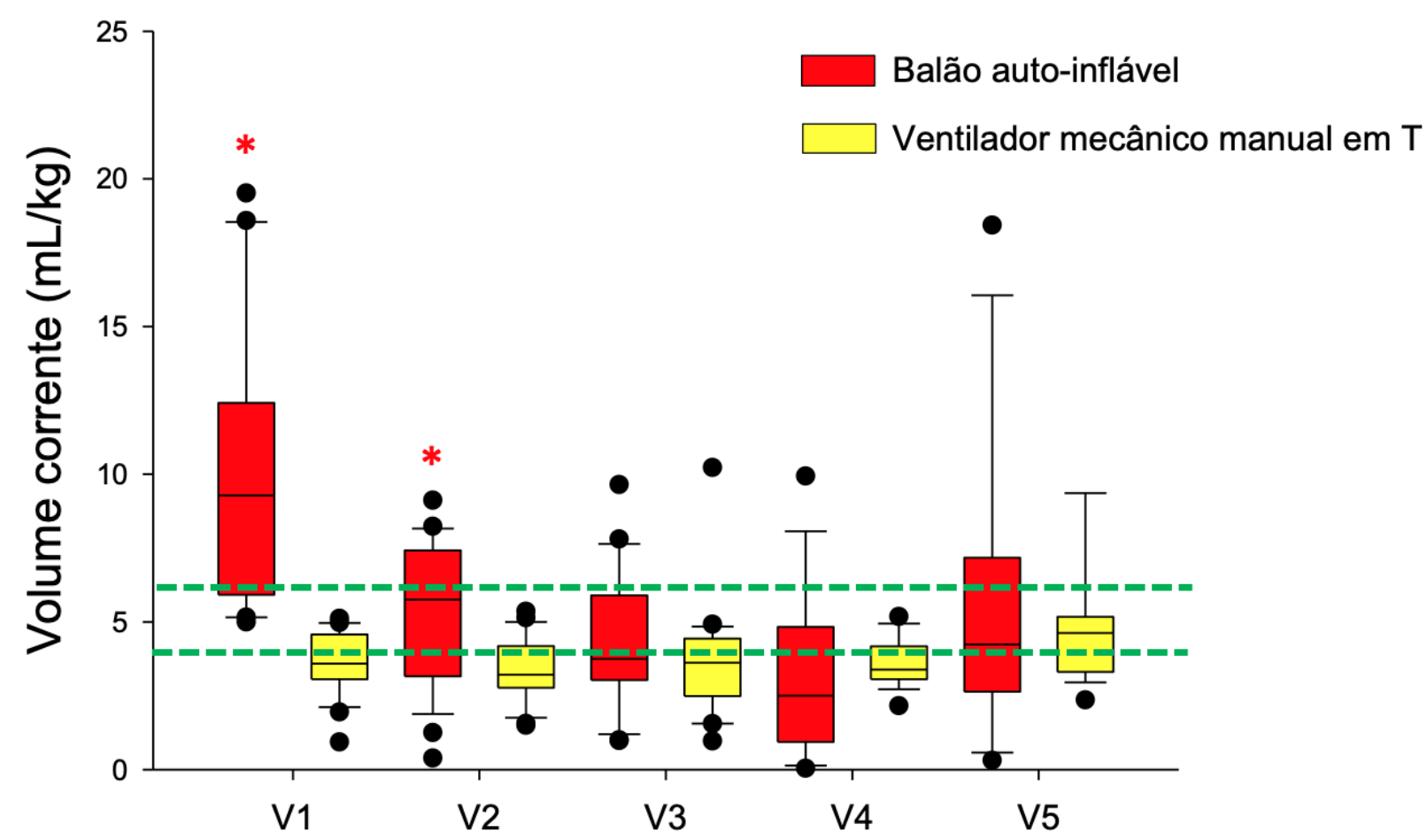

${ }^{*} \mathrm{p}<0,05$ versus BAI e Peça-T. Valores mostrados em média obtidos por modelos mistos. Valores- $\mathrm{p}$ corrigidos pelo método de Bonferroni para comparações múltiplas.

Figura 7. Valores da média do volume corrente expiratório (mililitros por quilo), segundo momento e equipamento 


\subsubsection{Escore de volume corrente expiratório por quilo}

Criamos um escore de VC exp/kg (Quadro 1) - 1: muito baixo $(<2 \mathrm{~mL} / \mathrm{kg}$ ); 2: baixo (2 a 3,9mLkg); 3: adequado (4 a $6 \mathrm{~mL} / \mathrm{kg}) ; 4$ : alto $(6,1$ a $8 \mathrm{~mL} / \mathrm{kg}) ; \mathrm{e}$ 5: muito alto $(>8,1 \mathrm{mLkg})$. Idealmente os residentes deveriam estar no escore 3 (VC expiratório por quilo em níveis protetores de $4 \mathrm{a} 6 \mathrm{~mL} / \mathrm{kg}$ ). Cada escore é representado por uma linha colorida diferente (Figura 8).

Nota-se, na figura 8, que inicialmente os residentes ventilavam com VC excessivos no BAI em V1 (média de escore de 4,34), porém com VC abaixo do alvo após o treinamento (escore de 3,04 [V2] a 2,89 [V5]).

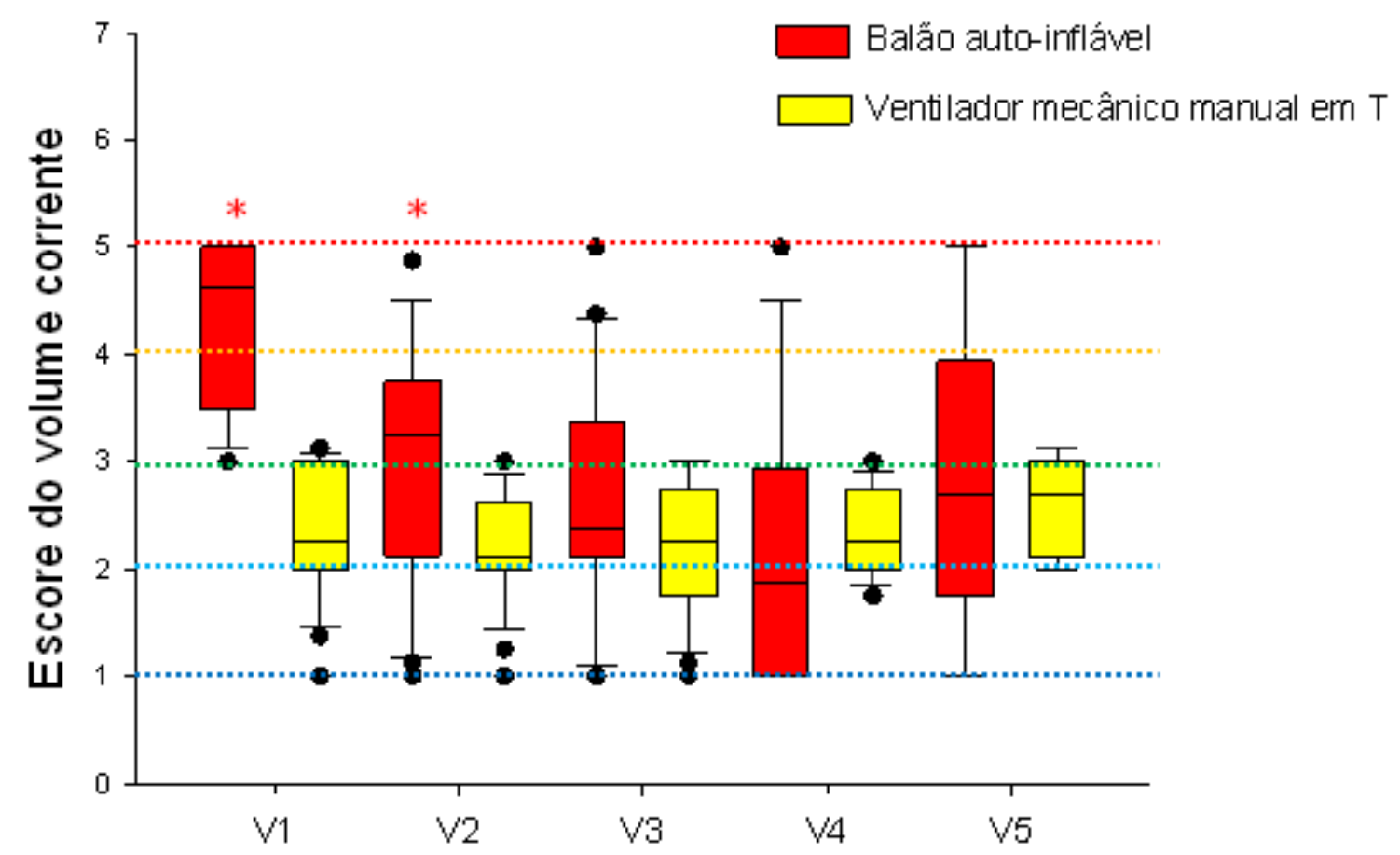

${ }^{*} \mathrm{p}<0,05$ versus BAI e Peça-T. Valores mostrados em média obtidos por modelos mistos. Valores-p corrigidos pelo método de Bonferroni para comparações múltiplas.

Figura 8. Valores da média do escore de volume corrente expiratório, segundo momento e equipamento

\subsubsection{Vazamento ao redor da máscara facial}

A porcentagem de vazamento ao redor da máscara facial é calculada através da fórmula:

[(VC inspiratório - VC expiratório) / VC inspiratório] X 100 
O vazamento manteve-se acima do alvo de até $20 \%$ (representada por linhas horizontais verdes na figura 9) em todas as ventilações e independente do tipo de equipamento.

As médias de vazamento ao redor da máscara facial na Peça-T variaram de $36 \%$ [24,26 - 47,74] em V1 a 47,8\% [36,07 - 59,55] em V3. No BAl variou de $31,7 \%$ [19,99 - 43,47] em V1 a 50,1 [36,55 - 63,61] em V4, sendo estatisticamente significante $p=0,047$ (Figura 9).

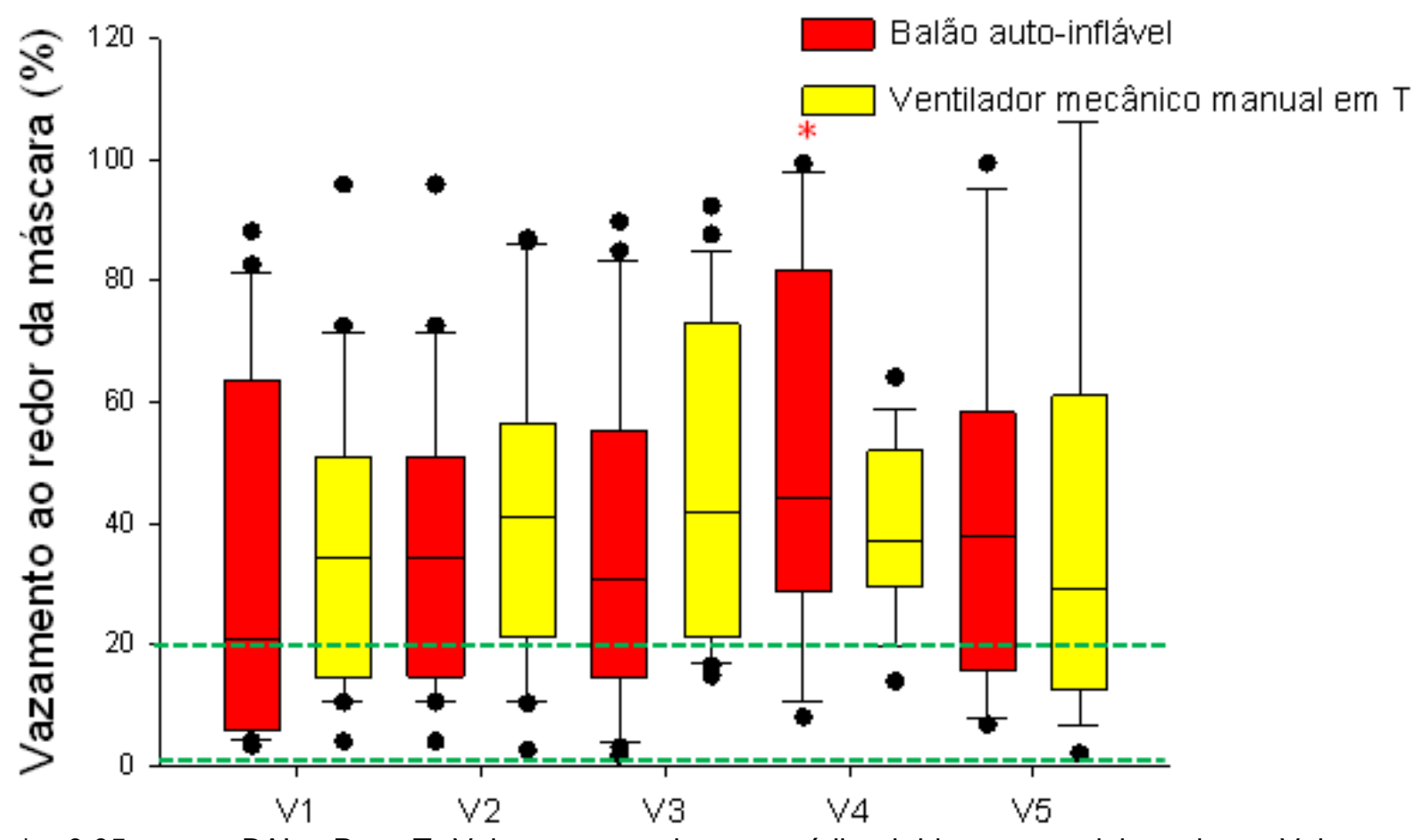

${ }^{*} p<0,05$ versus BAl e Peça-T. Valores mostrados em média obtidos por modelos mistos. Valores- $p$ corrigidos pelo método de Bonferroni para comparações múltiplas.

Figura 9. Valores da média do vazamento ao redor da máscara (porcentagem), segundo momento e equipamento

\subsubsection{Escore de vazamento}

Criamos um escore de vazamento (Quadro 2) - 1: adequado (<20\%); 2: alto (21 a 50\%); e 3: muito alto (>50\%). Idealmente os residentes que ventilassem com boa vedação da máscara facial deveriam estar no escore 1. Cada escore é representado por uma linha colorida diferente (Figura 10).

Os residentes ventilaram com grande vazamento em todas as ventilações e com ambos equipamentos. Além disso, aumentaram a média do escore de vazamento em V5 com BAI (2,61), mostrando que não apenas não conseguiram 
usar o MFR para reconhecer o vazamento pela curva fluxo-tempo, como tampouco souberam corrigir a sua técnica de ventilação para reduzir o vazamento e pioraram a vedação ao redor da máscara com o passar dos meses.

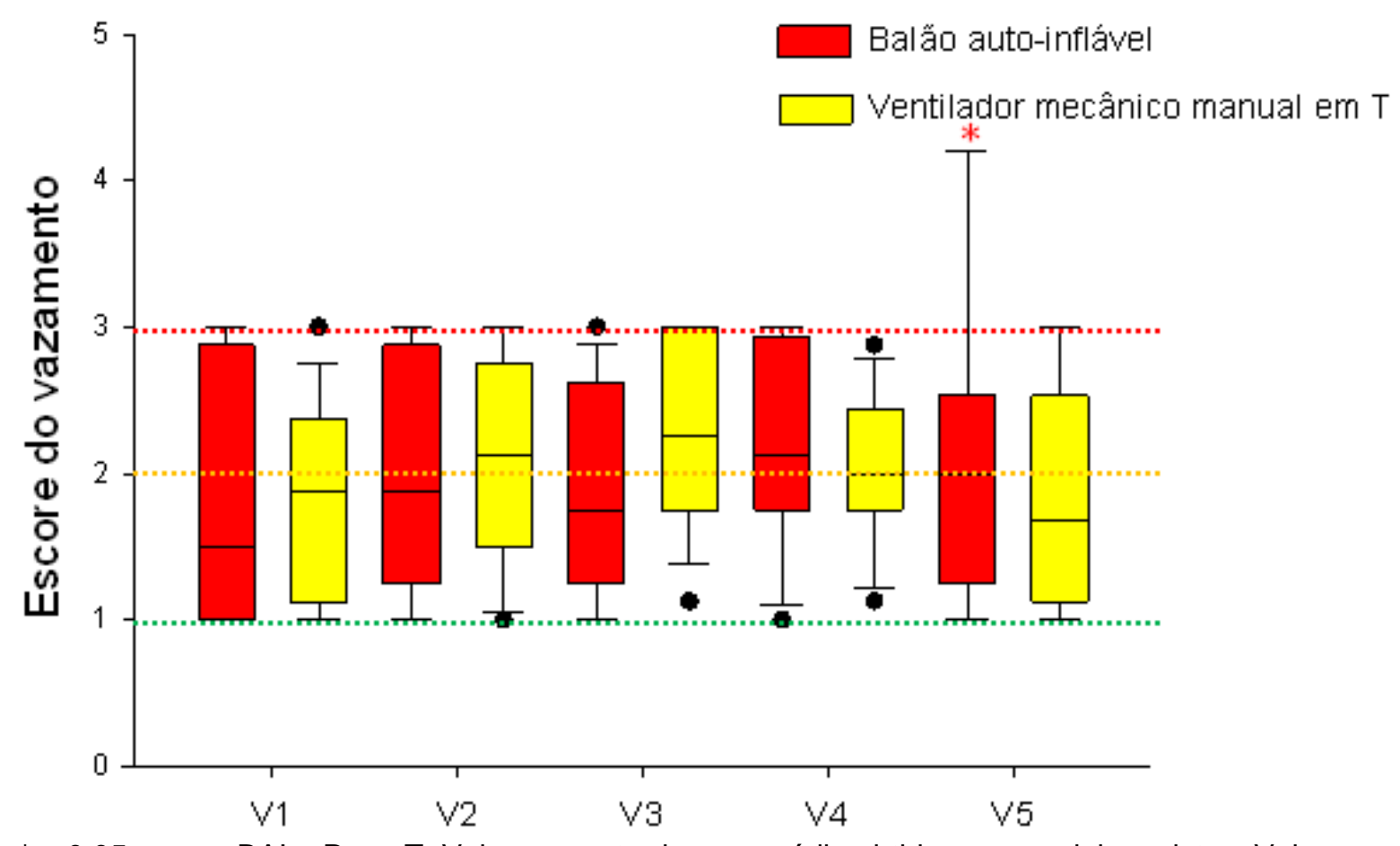

${ }^{*} p<0,05$ versus $B A I$ e Peça-T. Valores mostrados em média obtidos por modelos mistos. Valores- $p$ corrigidos pelo método de Bonferroni para comparações múltiplas.

Figura 10. Valores da média do escore vazamento ao redor da máscara, segundo momento e equipamento

\subsubsection{Uso de válvula de pressão positiva ao final da expiração acoplada ao balão autoinflável}

Apenas $5(22 \%)$ residentes conheciam a válvula de PEEP acoplada ao BAI antes do treinamento (Figura 11). Esse recurso foi amplamente divulgado durante o treinamento, com tendência de aumento de seu uso nas ventilações posteriores (até $89 \%$ em V5). 


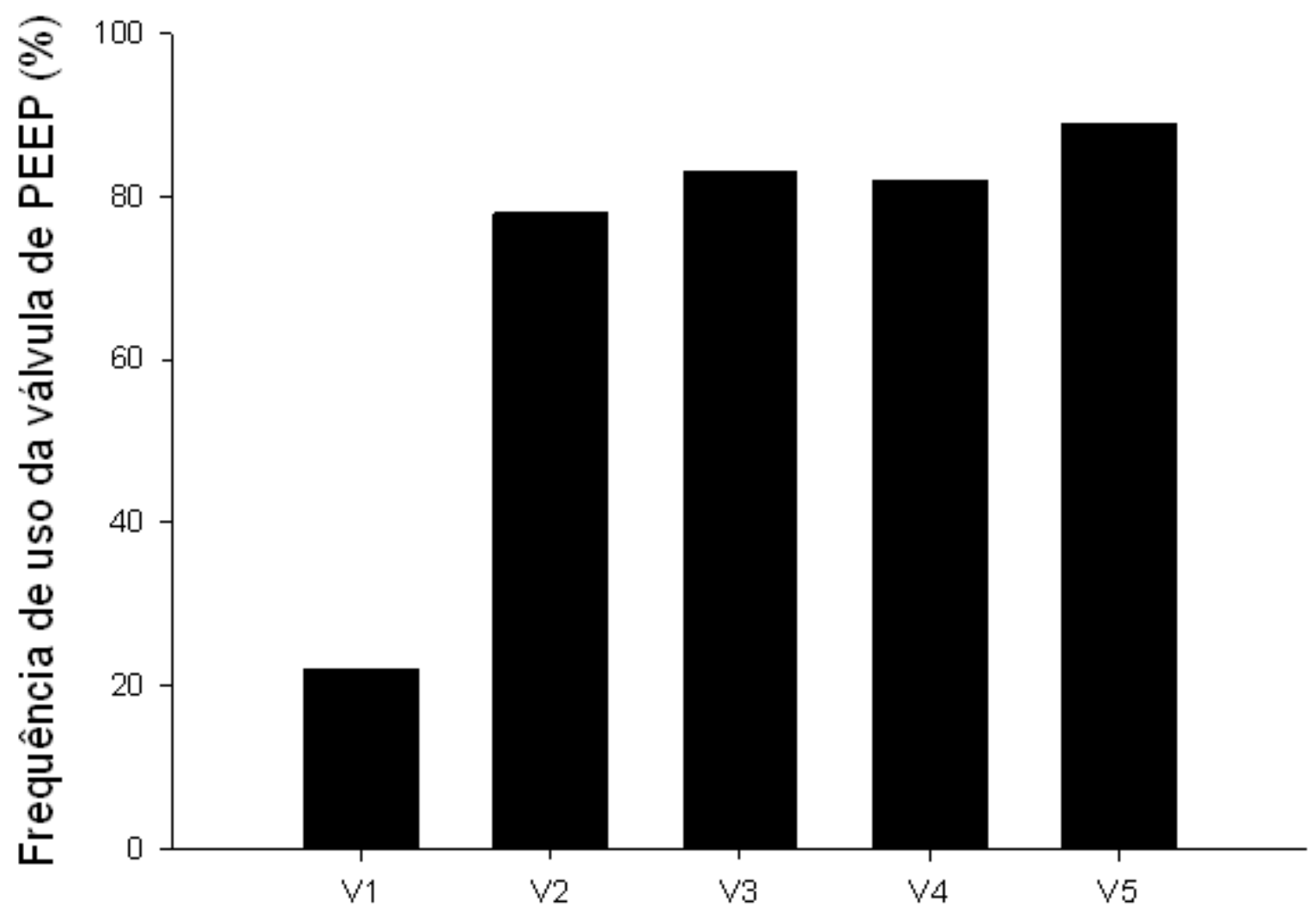

Valores mostrados em porcentagens com teste de Cochran para tendência em proporções $(p<0,001)$. PEEP: Pressão positiva ao final da expiração.

Figura 11. Valores da porcentagem de uso de válvula de pressão positiva ao final da expiração no balão autoinflável segundo os momentos de ventilação

\subsection{Resultados complementares}

\subsubsection{Volume corrente inspiratório}

A média do VC inspiratório reduziu com o treinamento em todos os momentos apenas para o BAI, conforme mostrado na figura 12 (máxima de 47,3mL em V1 e mínima de $21,6 \mathrm{~mL}$ em V3), mostrando que os residentes ventilaram com menores VC ins até 3 meses do treinamento com MFR.

Apesar da média do VC ins em V5 ser menor do que V1 (29,1 e $47,3 \mathrm{~mL}$ respectivamente), aumentou-se comparado as demais ventilações sem diferença estatística com V1, sugerindo que os residentes começaram a ventilar com maior VC ins após 3 meses do treinamento.

Houve diferença entre os equipamentos em todas as ventilações, exceto em V3, mostrando que imediatamente após o treinamento com MFR, os residentes conseguiram manter VC ins iguais com BAI e Peça-T. 
O VC ins manteve-se estável em todas as ventilações com Peça-T (valor mínimo de $16,8 \mathrm{~mL}$ em V4 e máximo de $22,3 \mathrm{~mL}$ em V3), sem diferença estatística entre elas.

O alvo de VC inspiratório era de 10 a $15 \mathrm{~mL}$, considerado protetor e representado por linhas horizontais verdes na figura 12.

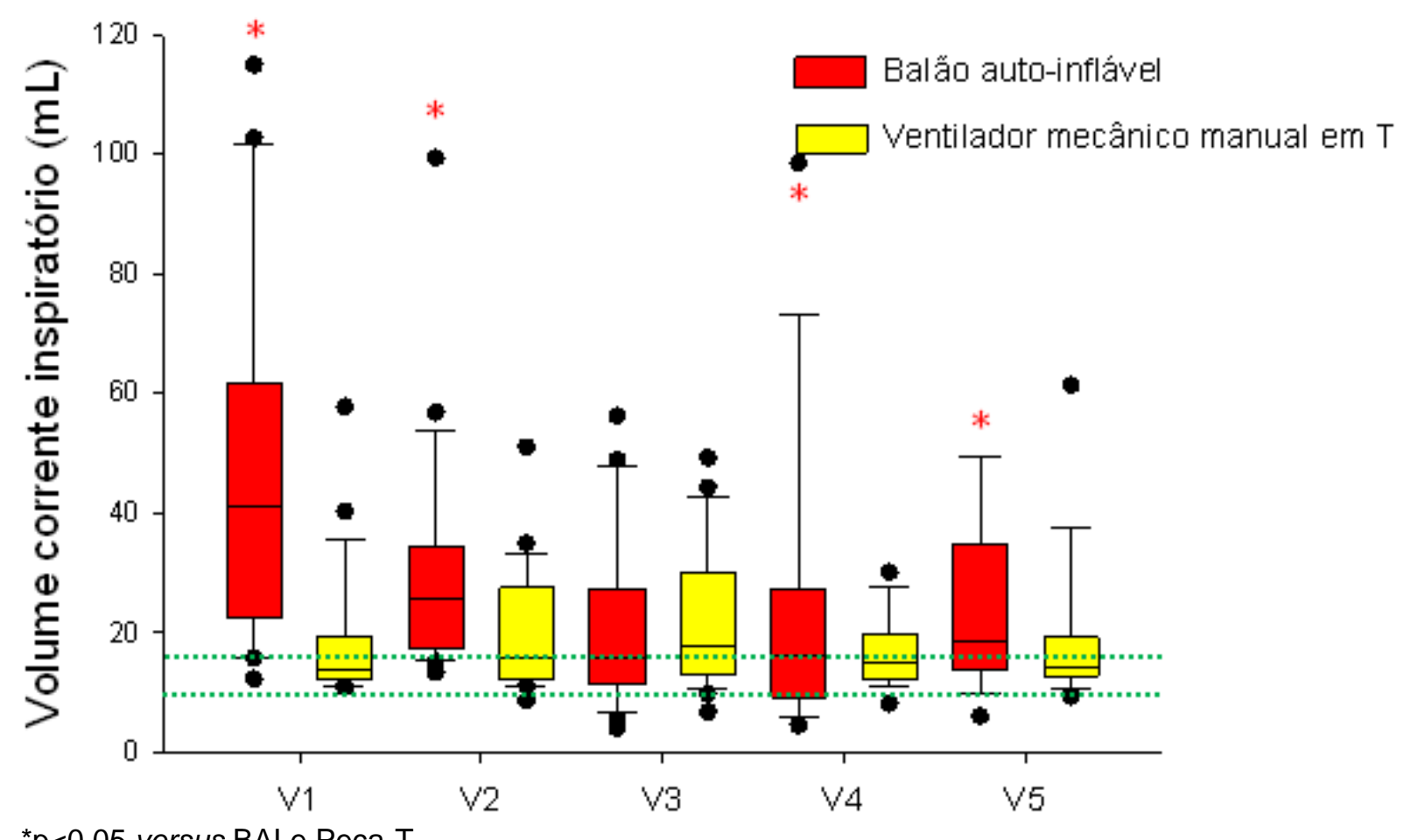

${ }^{*} \mathrm{p}<0,05$ versus $\mathrm{BAl}$ e Peça-T

Valores mostrados em média obtidos por modelos mistos. Valores-p corrigidos pelo método de Bonferroni para comparações múltiplas.

Figura 12. Valores da média do volume corrente inspiratório (mililitros), segundo momento e equipamento

\subsubsection{Volume corrente expiratório}

O treinamento com MFR reduziu os valores da média do VC exp em todos os momentos com o BAI, caindo de $26,07 \mathrm{~mL}$ em V1 até $8,42 \mathrm{~mL}$ em V4. As mensurações do BAl em V1 e V2 foram significativamente mais elevadas quando comparadas aos valores da Peça-T (valor máximo de 26,07mL com BAI em V1 e mínimo de 8,82mL na Peça-T em V2).

Porém, obtiveram valores muito próximos com os 2 equipamentos e sem diferença estatística entre V3, V4 e V5. Estes achados mostram que os residentes aprenderam a controlar a força de insuflação do BAl até 3 meses após o treinamento. 
Porém, a média do VC exp com ambos equipamentos aumentou em V5 $(14,36 \mathrm{~mL}$ com a Peça-T e $14,76 \mathrm{~mL}$ com o BAI), sugerindo que com 3 meses do treinamento, os residentes começaram a ventilar com menor destreza.

$\mathrm{O}$ alvo de VC expiratório era de 10 a $15 \mathrm{~mL}$, considerado protetor e representado por linhas horizontais verdes na figura 13.

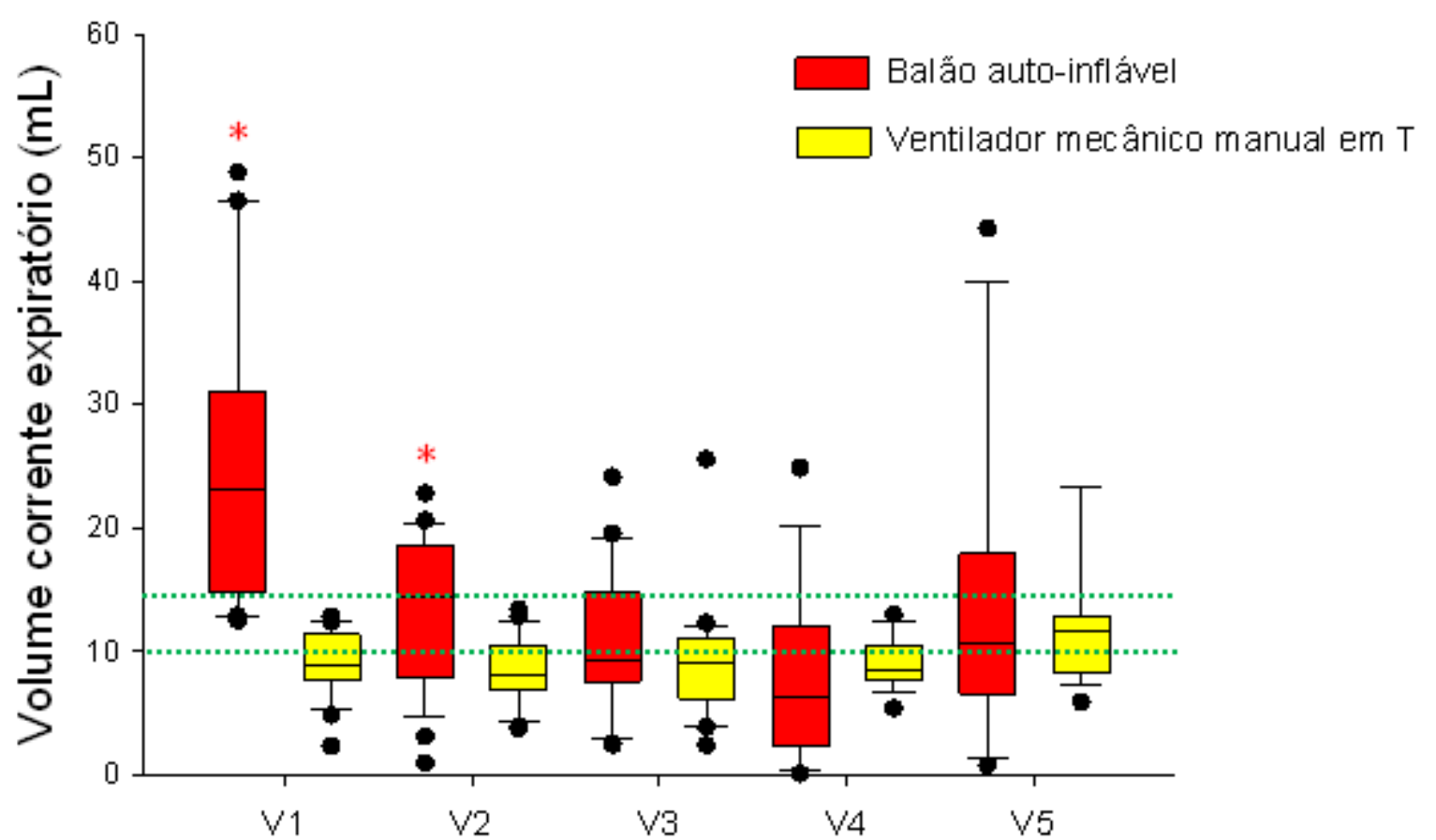

${ }^{*} \mathrm{p}<0,05$ versus BAl e Peça-T. Valores mostrados em média obtidos por modelos mistos. Valores- $p$ corrigidos pelo método de Bonferroni para comparações múltiplas.

Figura 13. Valores da média do volume corrente expiratório (mililitros), segundo momento e equipamento

\subsubsection{Volume corrente médio}

O VC médio é calculado através da fórmula:

$(\mathrm{VC}$ ins $+\mathrm{VC} \exp ) / 2$

O treinamento com MRF reduziu o VC médio obtido em todas as ventilações posteriores com BAl (valor máximo de $36,73 \mathrm{~mL}$ em V1 e mínimo de $16,20 \mathrm{~mL}$ em V4).

Além disso, em V3, não houve diferença significativa no VC médio obtido entre Peça-T e BAl, mostrando que após serem treinados com o MRF, os 
residentes conseguiram ventilar de forma mais protetora com o BAI, equiparável à Peça-T.

$\mathrm{O}$ alvo de VC médio era de 10 a $15 \mathrm{~mL}$, considerado protetor e representado por linhas horizontais verdes na figura 14 .

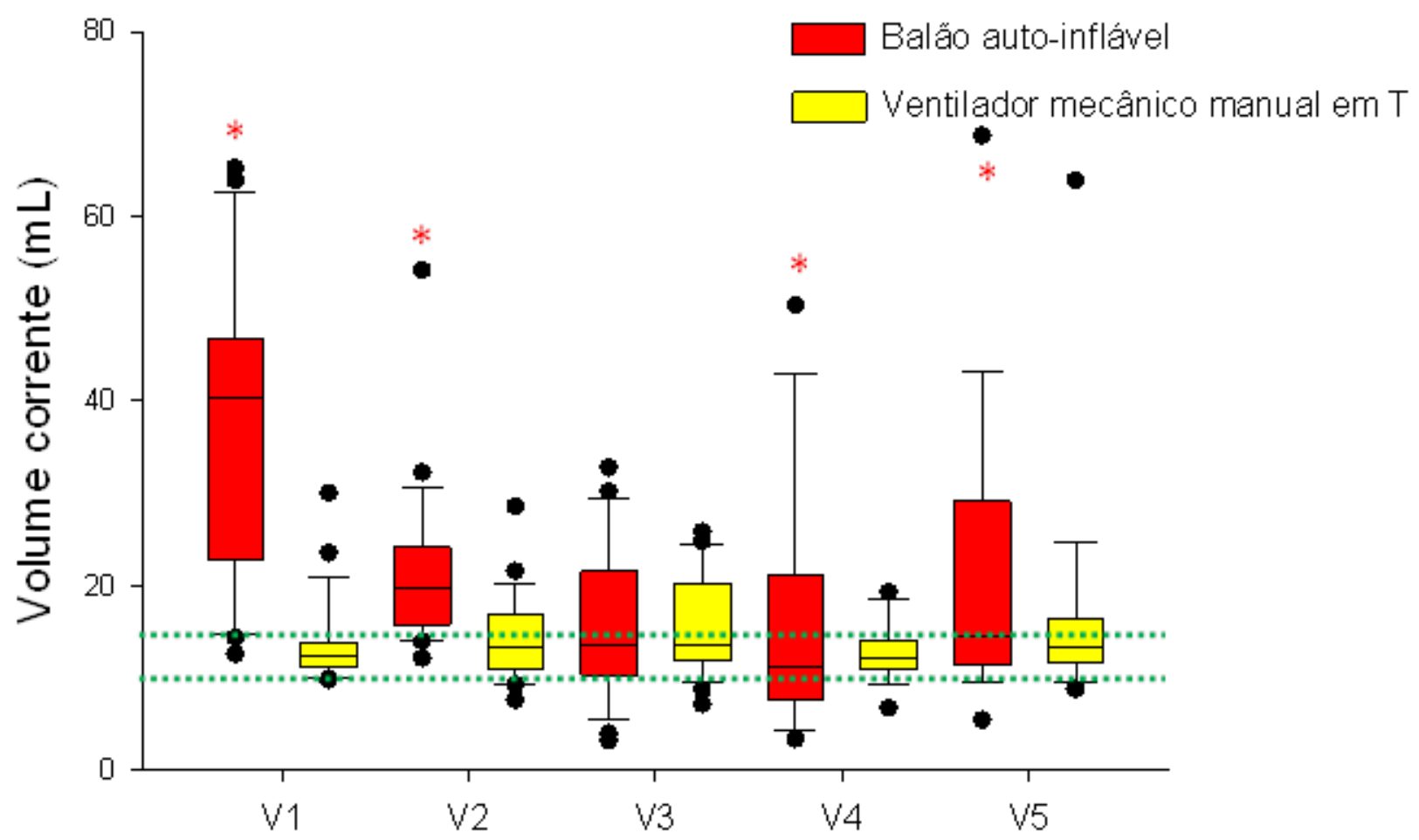

${ }^{*} p<0,05$ versus $\mathrm{BAl}$ e Peça-T. Valores mostrados em média obtidos por modelos mistos. Valores- $\mathrm{p}$ corrigidos pelo método de Bonferroni para comparações múltiplas.

Figura 14. Valores da média do volume corrente médio (mililitros), segundo momento e equipamento

\subsubsection{Pressão inspiratória}

$\mathrm{O}$ alvo de PIP era de 20 a $25 \mathrm{cmH}_{2} \mathrm{O}$, considerado protetor e representado por linhas horizontais verdes na figura 15.

Os residentes ventilaram com médias de PIP excessivas em V1 e BAl $\left(28,98 \mathrm{cmH}_{2} \mathrm{O}\right)$, sendo esses valores lesivos aos pulmões dos recém-nascidos. Durante e após o treinamento, reduziram a média de PIP em BAl a partir de V2 para valores equiparáveis à Peça-T $\left(17,06\right.$ a $\left.20,03 \mathrm{cmH}_{3} \mathrm{O}\right)$ mais próximos dos $20 \mathrm{cmH}_{2} \mathrm{O}$ preconizados pelo manual de reanimação da Sociedade Brasileira de Pediatria. 


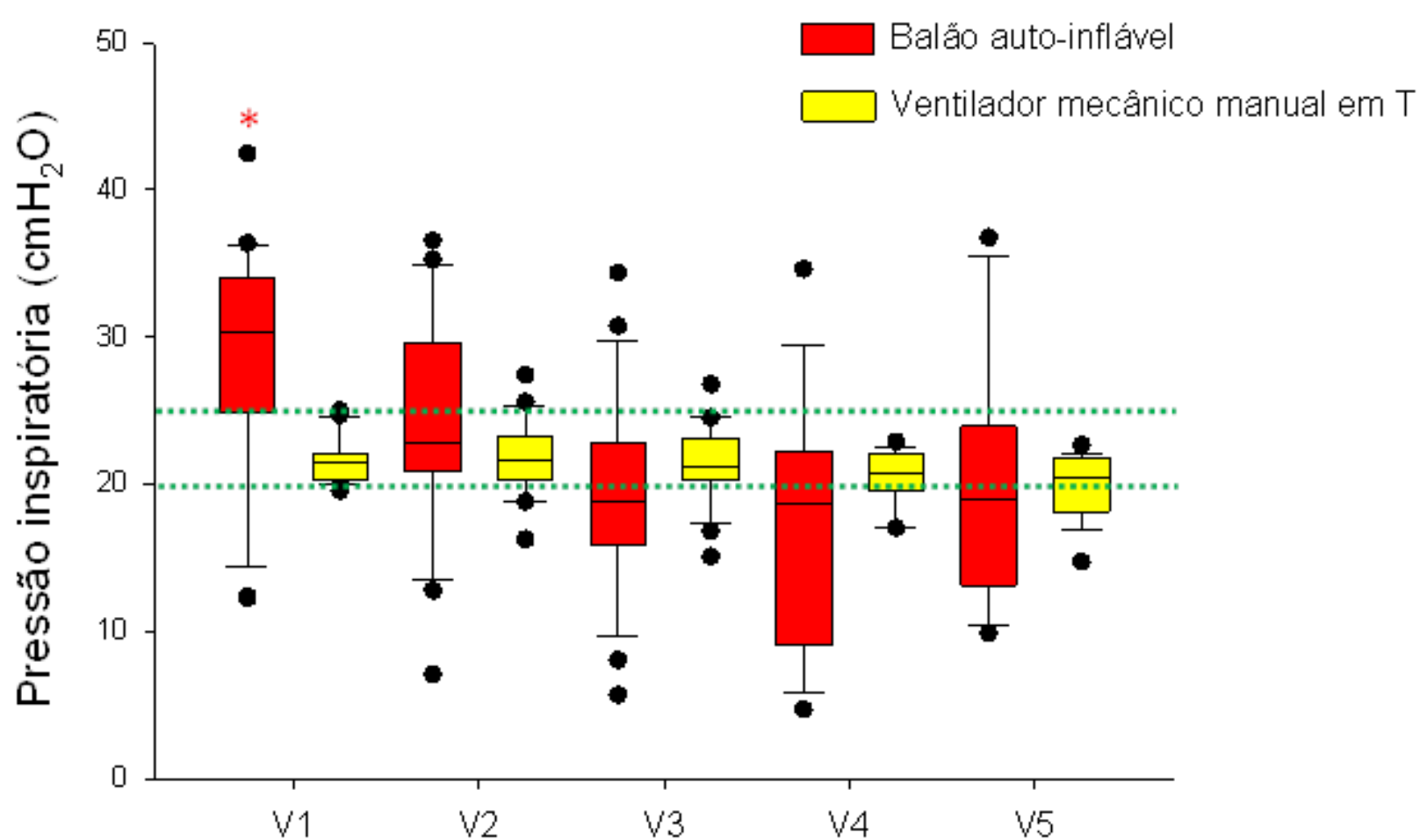

${ }^{*} p<0,05$ versus BAl e Peça-T. Valores mostrados em média obtidos por modelos mistos. Valores- $p$ corrigidos pelo método de Bonferroni para comparações múltiplas.

Figura 15. Valores da média da pressão positiva inspiratória $(\mathrm{cmH} 2 \mathrm{O})$, segundo momento e equipamento

\subsubsection{Pressão positiva ao final da expiração}

Os residentes conseguiram manter PEEP constantes e previamente determinadas em todas as ventilações utilizando a Peça- $\mathrm{T}$, geralmente na ordem de 5 a $7 \mathrm{cmH}_{2} \mathrm{O}$, representado por linhas horizontais verdes na figura 16. A maioria dos residentes não tinha conhecimento do uso de válvula de PEEP no BAI antes do treinamento, porém, mesmo utilizando esse recurso, obtiveram médias de valores de PEEP muito baixas em todas as ventilações com o BAI (mínimo de $0,77 \mathrm{cmH}_{2} \mathrm{O}$ em V1 e máximo de $2,57 \mathrm{cmH}_{2} \mathrm{O}$ em $\mathrm{V} 3$ ). $\mathrm{O}$ efeito do treinamento ocorreu apenas para o $\mathrm{BAI}$ em V2 e V3, com discreta melhora nas médias de PEEP, porém, ainda abaixo do recomendado para recrutar adequadamente os pulmões em sala de parto (Figura 16). 


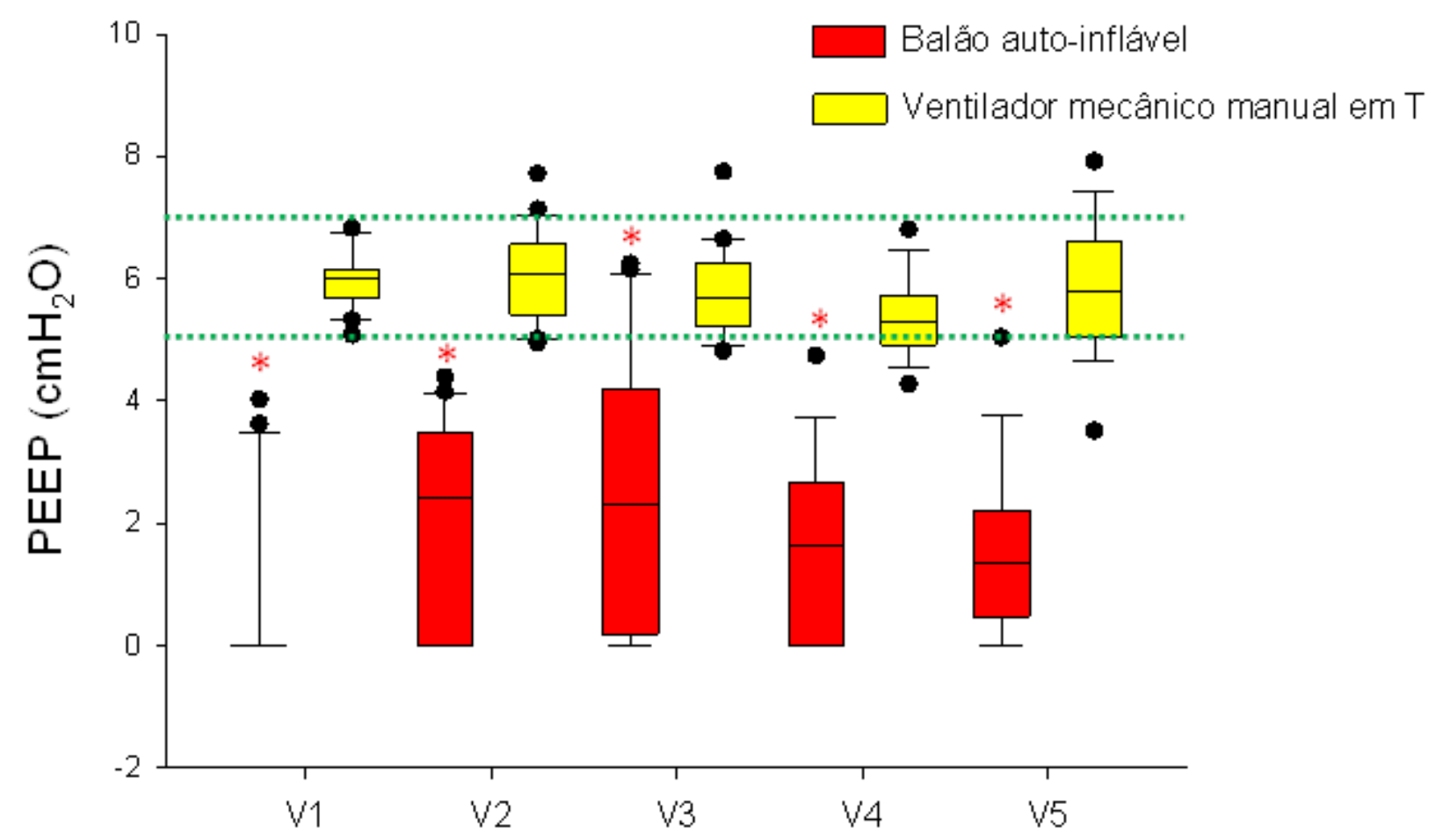

${ }^{*} \mathrm{p}<0,05$ versus BAI e Peça-T. Valores mostrados em média obtidos por modelos mistos. Valores- $\mathrm{p}$ corrigidos pelo método de Bonferroni para comparações múltiplas.

Figura 16. Valores da média da pressão positiva ao final da expiração $(\mathrm{cmH} 2 \mathrm{O})$, segundo momento e equipamento

\subsubsection{Frequência respiratória}

O alvo de FR era de 40 a 60 ventilações por minuto (conforme preconizado pela Sociedade Brasileira de Pediatria), representado por linhas horizontais verdes na figura 17.

As mensurações das médias de FR não se modificaram com o treinamento.

Em cada momento, contudo, as medidas obtidas por BAI foram significativamente maiores que as obtidas por Peça-T (45,76 a 51,13 ventilações por minuto em BAI versus 33,02 a 40,41 ventilações por minuto em Peça-T). Isto está relacionado ao funcionamento de cada equipamento. Para ofertar PIP predeterminada com Peça-T é necessário ocluir a Peça-T, de modo que prolonga o Tins e reduz a FR. Já o BAI, precisa de FR aumentadas para manter PEEP quando do uso de válvula. 


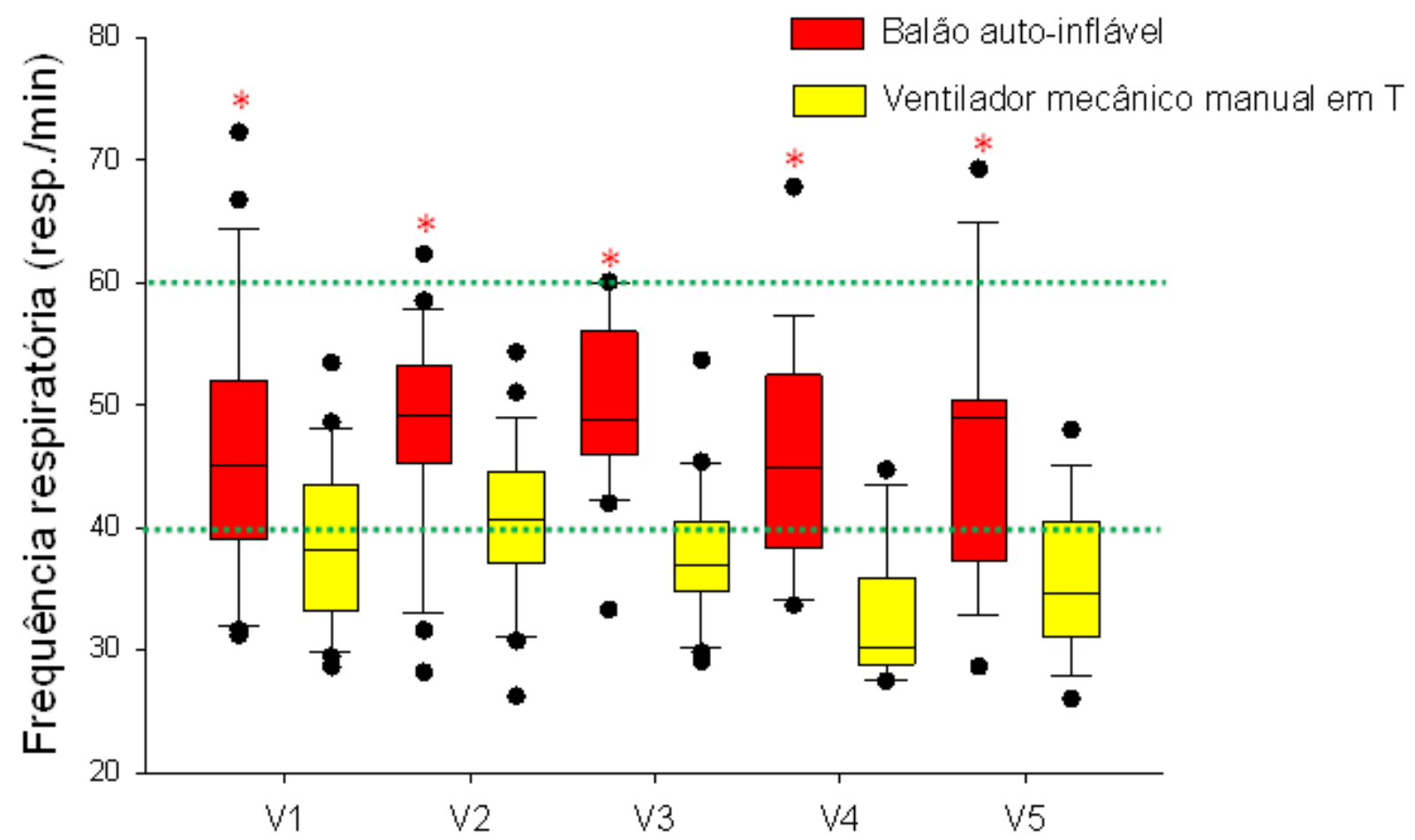

${ }^{*} p<0,05$ versus BAI e Peça-T. Valores mostrados em média obtidos por modelos mistos. Valores- $p$ corrigidos pelo método de Bonferroni para comparações múltiplas.

Figura 17. Valores da média da frequência respiratória (ventilações por minutos), segundo momento e equipamento

\subsubsection{Volume-minuto}

O volume-minuto (VM) é igual ao VC multiplicado pela FR.

As mensurações das médias de VM foram mais elevadas no BAI, visto que os residentes ventilaram com maiores VC e FR neste equipamento do que com a Peça-T (máximo de 575,66mL/min em V5 com Peça-T e de 1751,44mL/min em V1 com BAl). Houve, porém, redução do VM com o BAI após o treinamento (máximo de $1045,71 \mathrm{~mL} / \mathrm{min}$ em V2 e mínimo de $712,51 \mathrm{~mL} / \mathrm{min}$ em V3), por queda do VC no BAI (Figura 18). 


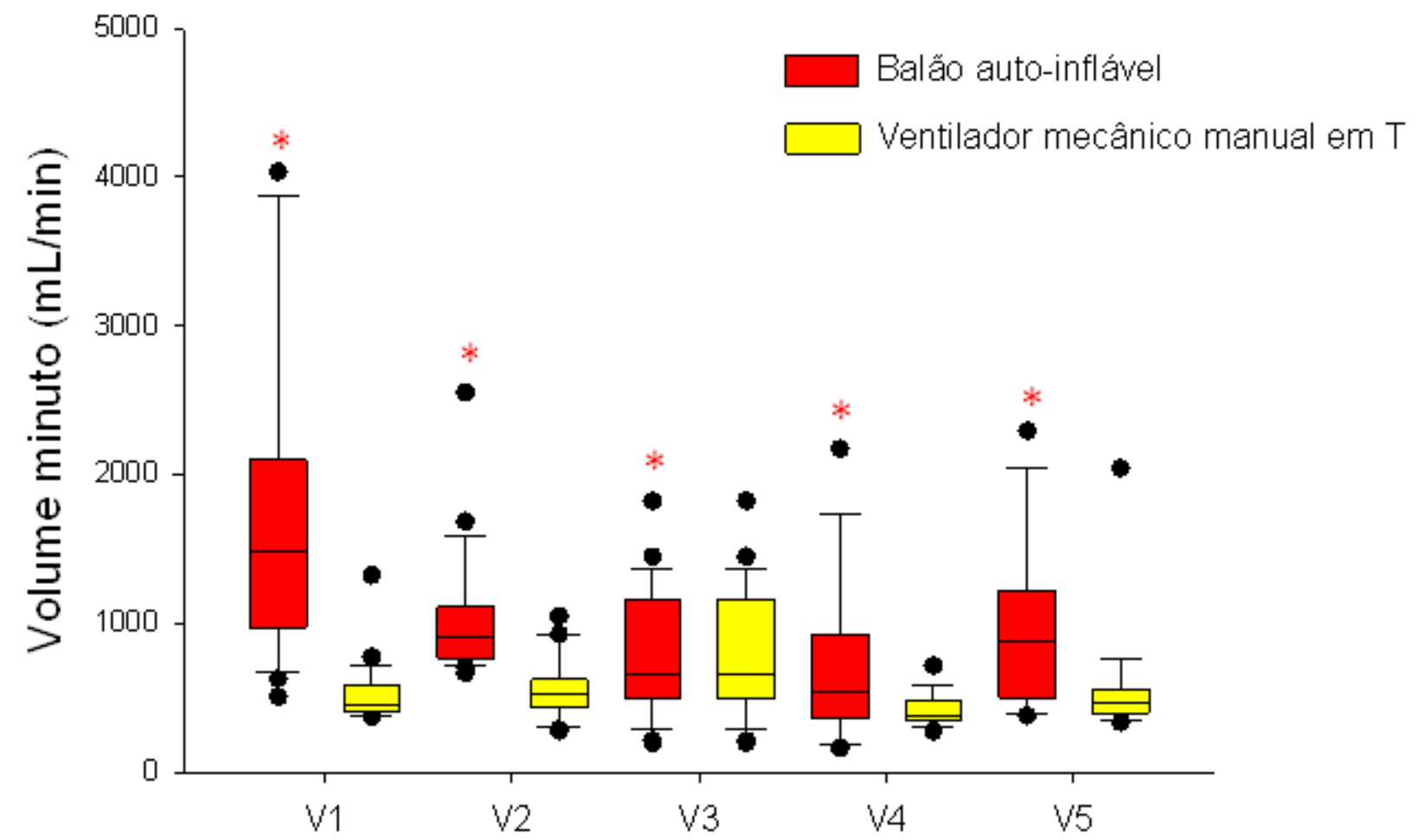

${ }^{*} \mathrm{p}<0,05$ versus $\mathrm{BAl}$ e Peça-T. Valores mostrados em média obtidos por modelos mistos. Valores- $\mathrm{p}$ corrigidos pelo método de Bonferroni para comparações múltiplas.

Figura 18. Valores da média do volume minuto (mililitros por minuto), segundo momento e equipamento

\subsubsection{Tempo inspiratório}

O alvo para o Tins era de 0,35 a 0,45 segundos, representado por linhas horizontais verdes na figura 19.

Para o Tins médio, notou-se aumento dos valores em V3 e V4 quando usada a Peça-T, mostrando que os residentes entenderam que a oclusão da Peça-T é necessária para manter a PIP com este equipamento. Para BAI, houve aumento dos valores do Tins em V4 e V5, sem significado clínico. Além disso, em cada momento, notou-se que o BAI apresentou valores significativamente mais baixos que a Peça-T, visto que requer FR elevadas para manter PEEP, quando do uso da válvula específica. 


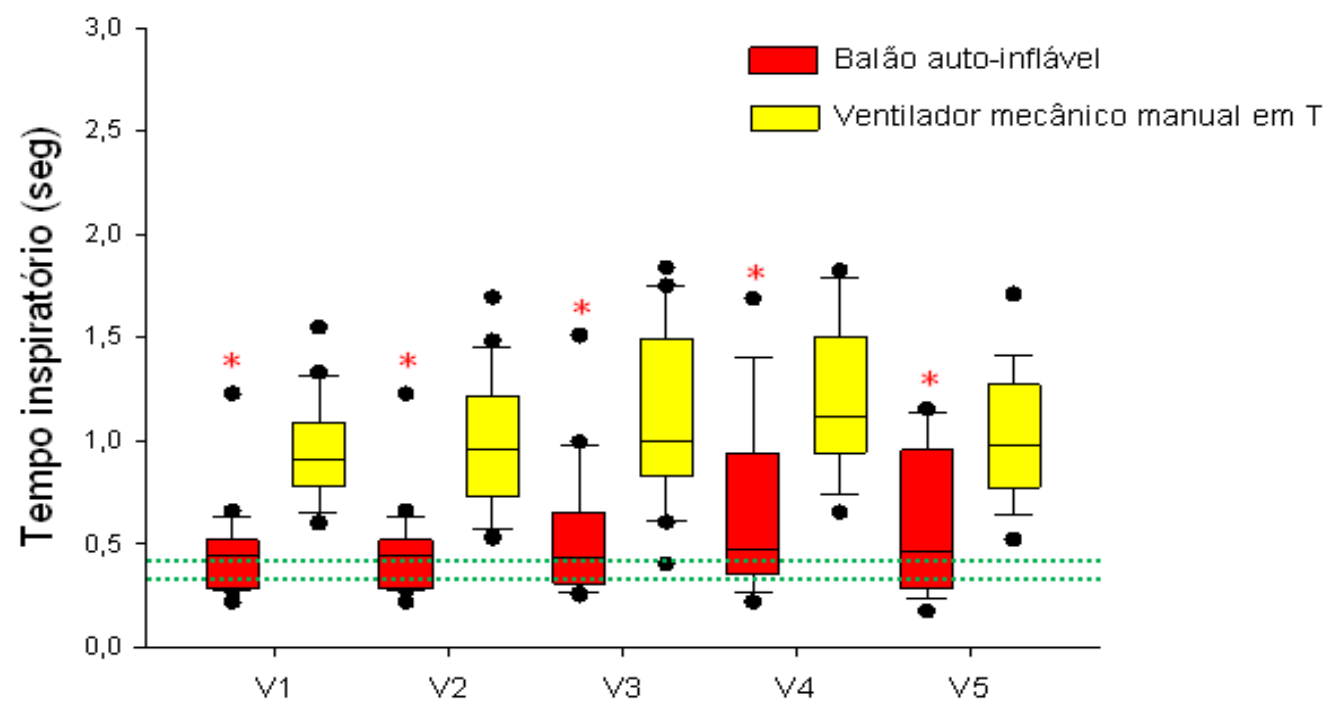

${ }^{*} \mathrm{p}<0,05$ versus $\mathrm{BAl}$ e Peça-T. Valores mostrados em média obtidos por modelos mistos. Valores-p corrigidos pelo método de Bonferroni para comparações múltiplas.

Figura 19. Valores do tempo inspiratório (segundos), de acordo com momento e equipamento

\subsubsection{Tempo expiratório}

O Tex médio reduziu após o treinamento em todos os momentos quando o BAI foi utilizado, visto que requer FR aumentadas para manter PEEP quando no uso da válvula específica. No caso da Peça-T, observou-se redução dos valores em V2 e V3, já que requer Tins elevados para obter a PIP estabelecida. Não foi identificada diferença significativa entre os equipamentos quando observamos cada momento separadamente (Figura 20).

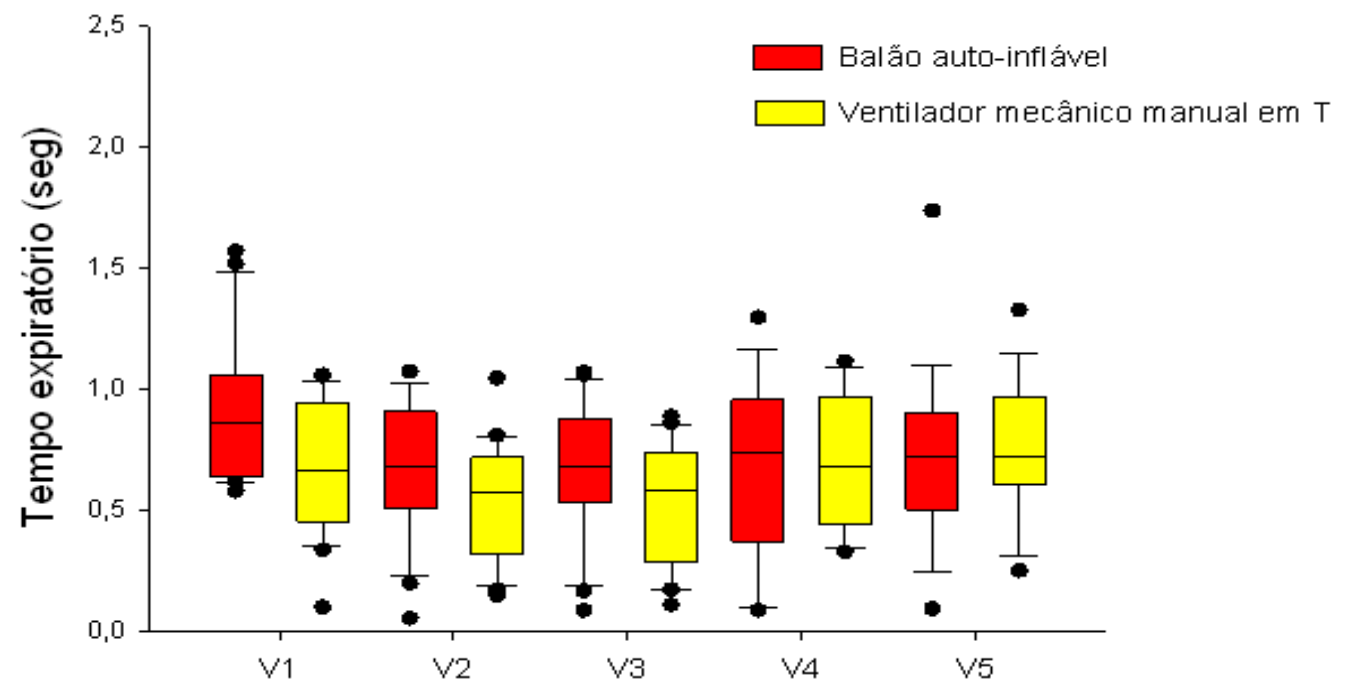

${ }^{*} \mathrm{p}<0,05$ versus BAl e Peça-T. Valores mostrados em média obtidos por modelos mistos. Valores-p corrigidos pelo método de Bonferroni para comparações múltiplas.

Figura 20. Valores do tempo expiratório (segundos), de acordo com momento e equipamento 


\section{DISCUSSÃO}

\subsection{Ensino médico}

Este estudo mostrou que o MFR é uma ferramenta útil no ensino de residentes de Neonatologia quanto a adequada técnica de ventilação manual. A escolha de treinar residentes vem da importância de promover estratégias de aprendizado duradouras, visto que são anos de extremo desenvolvimento profissional. Dentre as muitas habilidades que devem ser aprimoradas durante a residência em neonatologia, a ventilação manual é indubitavelmente uma das mais importantes e quiçá uma das mais difíceis de ensinar na ausência de dados objetivos.

Ericsson descreveu o conceito de treinamento deliberado para o ensino de habilidades médicas. ${ }^{(13)}$ Nele, reforçava a importância de estabelecer objetivos de aprendizado bem definidos, realizar aferição precisa do desempenho, promover repetição focada dos objetivos e receber feedback da performance. Todas estas etapas foram contempladas neste trabalho. Os residentes sabiam que tinham como objetivo principal promover estratégia gentil de ventilação manual, minimizando vazamentos (<20\%) e otimizando VC $(4-6 \mathrm{~mL} / \mathrm{kg})$. Foram treinados com o MFR para garantirem estes alvos e foram objetivamente aferidos através dos dados contínuos de monitorização da mecânica pulmonar. Ventilaram com cada dispositivo por 5 vezes, totalizando 10 avaliações de 4 minutos cada e com repetições após 1 e 3 meses do treinamento. Finalmente, receberam comentários de sua performance ao longo de todo o processo, sugerindo melhorias e reforçando os seus acertos.

Ao promover estratégias de ensino mediante a simulação com manequins, retiramos o estresse inerente aos cenários da vida real, e permitimos que o ensino ocorra de forma mais leve, porém ainda assim, mais próxima da realidade. Em contrapartida, Kelm et al. ${ }^{(12)}$ reforçam que a ventilação em manequim com pulmão artificial não representa as mudanças dinâmicas da complacência pulmonar durante a transição fetal-neonatal vistas na sala de parto. Acreditamos, porém, que isso não reduz o valor deste tipo de estratégia de ensino, e que ao adquirir essas habilidades corretamente mediante o uso de manequins, o profissional estará melhor habilitado a entender e reconhecer essas mudanças dinâmicas diante de seu paciente no cenário clínico real. 


\subsection{Volume-corrente}

A fisiologia da VPP é amplamente conhecida, elevando a CRF, permitindo maior troca de gases pulmonares e otimizando as chances de iniciar e manter respiração espontânea. Adequada VPP depende da vedação e do correto posicionamento da máscara facial, devendo cobrir nariz, boca e parte superior do queixo. ${ }^{(14,15)}$ Isso gera pressões inspiratórias e expiratórias que garantem a transmissão do VC necessário para abrir alvéolos colabados logo após o nascimento e reduzir o esforço do bebê para mantê-los abertos, auxiliando na transição fetal-neonatal. Volumes correntes excessivos são responsáveis por lesionar o pulmão em desenvolvimento, aumentando o risco de doença pulmonar crônica; em contrapartida, VC baixos, são insuficientes para promover a transição fetal-neonatal. ${ }^{(13)}$ A elevação do tórax e a recuperação da frequência se correlacionam fracamente ao grau de vazamento ao redor da máscara e do VC enviado aos pulmões, ${ }^{(15-17)}$ assim como baixa relação com os valores que o operador acredita estar de fato ofertando. ${ }^{(18)}$

A adequada técnica de ventilação manual depende do controle de diversos parâmetros contínuos e simultâneos, não sendo um procedimento tão simples quanto parece. Ao utilizar a elevação do tórax como principal parâmetro da ventilação manual, operadores não reconhecem a magnitude do VC ofertado. O VC exp, aquele que retorna dos pulmões após a expiração, é o volume utilizado para estimar o volume de ar que de fato chegou aos pulmões. Conforme descrito em meta-análise publicada pela Cochrane em 2010 ${ }^{(19)}$ o alvo de VC expiratório na reanimação neonatal é de 4 a $8 \mathrm{~mL} / \mathrm{kg}$, já que seria o necessário para evitar aletectrauma (manutenção de alvéolos fechados e insucesso da transição fetal-neonatal) e/ou volutrauma (hiperdistensão pulmonar com insultos e risco de doença pulmonar crônica).

Em nosso estudo orientamos os residentes participantes a obterem VC exp de 4 a $6 \mathrm{~mL} / \mathrm{kg}$, tendo maior chance de estar em alvos protetores. Como no display do monitor utilizado em nosso estudo o VC aparece em mililitros, concordamos em buscar valores de 10 a $15 \mathrm{~mL}$, já que consideramos estarem ventilando a um bebê de $2,5 \mathrm{~kg}$. Encontramos que na primeira ventilação antes do treinamento com BAl a média de VC exp foi de 10,43mL/kg, estando muito acima de valores protetores. Imediatamente após o treinamento e com acesso aos dados de monitorização, esses 
valores caíram rapidamente dentro do alvo, e se mantiveram em níveis protetores em todas as demais ventilações com BAI, equiparando-se à Peça-T em V3, V4 e V5.

Esses valores são similares aos encontrados por Kelm et al. ${ }^{(12)} \mathrm{em}$ estudo metodologicamente similar ao nosso. Eles incluíram 37 profissionais sem treinamento prévio com MFR e ventilaram com BAI. Estudaram VC exp absoluto (sem dividirem por alvo de peso) e constataram que antes do treinamento a mediana do VC foi de $6,7 \mathrm{~mL}$ com grande variação $(4,2$ a $44 \mathrm{~mL})$, apresentando valores elevados similares aos nossos. De maneira similar, imediatamente após o treinamento com MFR o VC reduziu para 3,5mL e com menor variação $(1,8$ a 7,3mL) e se manteve estável após 1 mês do treinamento com mediana de 4,1mL e variação de 1,9 a 9,7mL. Esse estudo, ao contrário do nosso, não acompanhou os participantes além de 1 mês para verificar a retenção por um período mais prolongado, e tampouco detalhou o grau de experiência dos profissionais e nem como ocorreu o treinamento com MFR.

Quando do uso da Peça-T, nossos resultados estiveram sempre em alvos protetores, com médias de 3,53 a $5,75 \mathrm{~mL} / \mathrm{kg}$ ao longo de todas as ventilações, sem impacto do uso do MFR para esse dispositivo. Isso é esperado, visto que a PeçaT funciona com fluxo contínuo e pressões previamente controladas. A Peça-T é capaz de manter pressões e VC estáveis, especialmente se mantiver fluxo $>8 \mathrm{~L} / \mathrm{min}$, ${ }^{(18)}$ porém nós demonstramos isto com fluxo determinado em $7 \mathrm{~L} / \mathrm{min}$.

Nossos resultados foram melhores do que Poulton et al., ${ }^{(16)}$ onde equipes de reanimação habilitadas ventilaram prematuros <32 semanas somente com Peça-T. O MFR foi utilizado somente para avaliação e os participantes não tiveram acesso aos seus dados. Nesse estudo, o VC apresentou mediana de $6,4 \mathrm{~mL} / \mathrm{kg}$ e variação de 3,1 a 9,5mL/kg com a Peça-T, demonstrando novamente que a percepção do VC ofertado pela elevação do tórax é ruim e independente do tempo de experiência.

$\mathrm{O}$ excesso de VC inadvertidamente ofertado também foi confirmado no estudo de O'Currain et al., ${ }^{(20)}$ onde avaliaram 388 profissionais de saúde (47\% parteiras, $27 \%$ enfermeiros e $26 \%$ médicos) que buscaram treinamento no curso de reanimação neonatal e com aproximadamente 8 anos de experiência em neonatologia. Receberam treinamento com curvas de vazamento e alvos de VC em limiares protetores. Foram randomizados em 2 grupos: intervenção, com acesso aos dados de monitorização e controle, sem acesso aos dados. Ventilaram somente com Peça-T, antes e após o treinamento, e as duas ventilações ocorreram no mesmo dia. Houve aumento do VC ofertado no grupo com acesso aos dados de MFR de 14,9mL (variando 
de 10,7 a 18,6mL) para $18,2 \mathrm{~mL}(14,8$ a 20,6mL). O aumento do VC foi resultado da redução do vazamento ao redor da máscara de 35 para 23\% ao usar MFR, mostrando o impacto do vazamento na obtenção de VC.

Algo que não pudemos avaliar em nosso estudo é a influência das respirações espontâneas na oferta dos parâmetros ventilatórios, visto que utilizamos manequim neonatal. Em cenários reais, dificilmente podemos sincronizar as

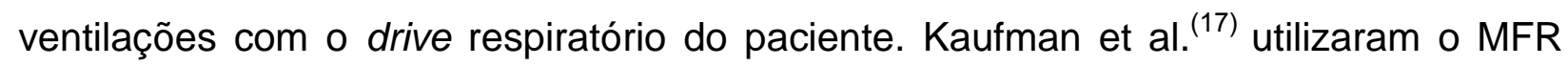
para estudar essa relação na ventilação de prematuros <32 semanas com Peça-T e perceberam que o VC espontâneo do bebê entre insuflações é da média de 3,3mL/kg, mas que quando a VPP coincide com a respiração espontânea, essas se somam e geram VC da ordem de 9,3mL/kg (com variação de 4,5 a 12,9mL/kg). É sabido que volumes acima de $10 \mathrm{~mL} / \mathrm{kg}$ aumentam o risco de volutrauma, lesão pulmonar e doença pulmonar crônica. Somente com dados de monitorização será possível verificar o efeito somatório da VPP com a ventilação espontânea e ajustar a ventilação para adequar o VC em níveis protetores.

\subsection{Vazamento ao redor da máscara facial}

A média de vazamento antes do treinamento com MFR foi de $31,7 \%$ com BAl e 36\% com Peça-T. Os residentes não reconheceram e consequentemente não reduziram a porcentagem de vazamento ao longo dos treinamentos com ambos dispositivos, chegando a médias máximas de 50,1\% com BAI em V4 e 45,7\% com a Peça-T em V5 (aumentos de 58 e 27\% após 1 e 3 meses de treinamento, respectivamente). Nosso treinamento foi insuficiente para que os residentes compreendessem a curva fluxo/tempo e reconhecessem quando ela demonstra vazamento. Uma próxima abordagem deveria realizar treinamentos mais longos e se possível incluindo o próprio MFR para otimizar a compreensão desta importante curva na monitorização.

Nossos dados divergem com o descrito em outros estudos. Wood et al. ${ }^{(14)}$ demonstraram utilizando manequim neonatal e dados de MFR que vazamentos são grandes e variáveis durante a ventilação manual e independem do grau de experiência do operador (média de 10 anos) e do tipo de máscara facial utilizada. Operadores não percebem a magnitude do vazamento e não corrigem a técnica a 
tempo. A média de vazamento encontrada por Wood foi de $26,6 \%$ antes de usar o MFR e de $11,2 \%$ ao utilizar os dados da monitorização, representando uma queda de $58 \%$ do vazamento.

Esses dados divergem dos encontrados em outros estudos. Schmölzer et al. ${ }^{(15)}$ conduziram um estudo experimental aonde uma equipe experiente reanimava prematuros de extremo baixo peso (<1000 gramas) em sala de parto. Os operadores não tinham acesso aos dados da monitorização e foram randomizados na escolha do equipamento a ser utilizado, BAI ou Peça-T. Encontraram que $42 \%$ das ventilações com Peça-T e 56\% com BAI apresentavam vazamentos superiores a $75 \%$, apesar de serem realizadas por profissionais experientes em reanimação e habilidosos com ambos equipamentos. Mostraram, também, que $43 \%$ desses prematuros foram intubados em sala de parto por não recuperarem frequência cardíaca (>100bpm) durante a ventilação manual. Possivelmente, tivessem tido acesso aos dados de monitorização, poderiam ter reconhecido que a manutenção da bradicardia poderia estar relacionada ao vazamento de ar ao redor da máscara, corrigido prontamente a técnica, reduzido o vazamento e conseguido recuperar a frequência cardíaca e evitado a intubação e a lesão pulmonar associada à ventilação invasiva.

Kaufman et al. ${ }^{(17)}$ fizeram estudo similar ao de Schmölzer et al., ${ }^{(15)}$ também utilizando equipe experiente para ventilar prematuros $<32$ semanas em sala de parto somente com Peça-T e sem acesso aos dados do MFR. Encontraram vazamentos da ordem de 24 a 59\%. Esses dados são similares aos encontrados por Thallinger et al.,(21) onde avaliaram 8 alunos de Medicina e 81 de Enfermagem, inexperientes e sem treinamento prévio com reanimação neonatal. Receberam treinamento individual por 10 minutos sobre a técnica de VPP com manequim e BAI e não tiveram acesso aos dados do MFR. O vazamento encontrado foi da ordem de 52,8 a $62,1 \%$, reforçando que independentemente do grau de experiência, vazamentos ocorrem de forma variável durante a VPP.

Esses estudos confirmam resultados similares aos nossos, aonde de base o vazamento é excessivo e variável. Porém, somente o estudo de O'Currain et al. ${ }^{(20)}$ utilizou o MFR como estratégia de ensino em manequim, comparando resultados sem e com dados de monitorização. Encontraram que antes do treinamento, o grupo controle apresentou mediana de vazamento de $51 \%$ (mín 22 e máx $80 \%$ ) e o grupo intervenção mediana de 63\% (mín 22 e máx 90\%). Após o treinamento, o vazamento 
caiu para 35\% no grupo controle (mín 14 e máx 67\%) e para 23\% no grupo intervenção (mín 8 e máx 41\%).

\subsection{Pressões e uso da válvula de pressão positiva ao final da expiração acoplada ao balão autoinflável}

A PIP ofertada se relaciona diretamente com o VC gerado; portanto, é esperado que aumentos da PIP ocasionem aumentos do VC. Isto foi reforçado em nosso estudo. Encontramos que na primeira ventilação antes do treinamento com BAl a média de PIP foi de $28,9 \mathrm{cmH}_{2} \mathrm{O}$ com valores máximos de até $31,3 \mathrm{cmH}_{2} \mathrm{O}$, muito acima dos $25 \mathrm{cmH} 2 \mathrm{O}$ máximos preconizados, promovendo a geração de VC excessivos nesse mesmo período. Imediatamente após o treinamento e com acesso aos dados de monitorização, esses valores caíram rapidamente dentro do alvo e se mantiveram em níveis adequados em todas as demais ventilações com BAl (de 17,06 a 23,77cmH2O), equiparando-se à Peça-T em V2 a V5.

Por ser um equipamento que funciona com fluxo contínuo e pressões pré-determinadas, todas as pressões com a Peça-T são estáveis e sem influência do MFR.

Nossos resultados são semelhantes aos encontrados no estudo de Kelm et al., ${ }^{(12)}$ onde 37 participantes de cursos de reanimação foram treinados sobre 0 MFR e ventilaram sem acesso aos dados somente com BAI. Obtiveram médias de PIP antes do treinamento de $32,3 \mathrm{cmH}_{2} \mathrm{O}$ com queda para $17,8 \mathrm{cmH}_{2} \mathrm{O}$ imediatamente após o treinamento e manutenção de $18,7 \mathrm{cmH}_{2} \mathrm{O}$ um mês após o treinamento. Neste estudo, os participantes foram treinados para focar exclusivamente no VC e PIP, sem atenção ao vazamento. Em contrapartida, pedimos aos nossos residentes que se atentassem a todos os parâmetros de monitorização pulmonar. Este estudo não reavaliou após 1 mês do treinamento, não sendo possível comparar os nossos dados posterior a este momento.

A PEEP é a responsável por aumentar a CRF e manter os alvéolos abertos, permitindo assim troca de gases e a adequada transição da circulação cardiopulmonar. A Peça-T é capaz de oferecer PEEP previamente determinada de maneira contínua e segura, mas ainda não é um dispositivo amplamente disponível em países em desenvolvimento. O BAI só é capaz de ofertar PEEP se acoplado à válvula 
de PEEP específica. A pressão ofertada é inconsistente, visto que a PEEP cai rapidamente ao diminuir a $\mathrm{FR}$, usualmente oferecendo pressões $<3 \mathrm{cmH}_{2} \mathrm{O}^{(22)}$ Obtivemos resultados similares ao já estabelecido na literatura. $A$ média de PEEP obtida por nossos residentes com BAI e válvula de PEEP variou de 0,77 a $2,57 \mathrm{cmH}_{2} \mathrm{O}$ ao longo de todo o estudo, mostrando a dificuldade em manter PEEP com esse dispositivo.

No estudo de Hartung et al., ${ }^{(23)}$ utilizaram o MFR para verificar o efeito da PIP e FR no PEEP ofertado com BAI e válvula. Verificaram que as medianas de PEEP ofertadas são inferiores às pré-estabelecidas pelas válvulas: válvula de 5 $\mathrm{cmH}_{2} \mathrm{O}$ ofertou mediana de $3,4\left(2,7\right.$ a 3,8) $\mathrm{cmH}_{2} \mathrm{O}$ e de $10 \mathrm{cmH}_{2} \mathrm{O}$ medianas de 6,1 (4,9 a 7,1$) \mathrm{cmH}_{2} \mathrm{O}$. Segundo o estudo, isso se deve principalmente à variação do fluxo na fase expiratória com BAI pelo próprio paciente e por pequenos vazamentos de ar no sistema da válvula, mantendo a oferta de PEEP instável e decrescente após cada insuflação.

A queda brusca da PEEP é compensada pelo aumento da FR, conforme demonstrado no estudo de Tracy et al., ${ }^{(22)}$ onde utilizaram o MFR para verificar o efeito da FR na PEEP originada quando a válvula de PEEP é acoplada ao BAI. Verificaram que para atingir PEEP de $5 \mathrm{cmH} 2 \mathrm{O}$ é necessário manter frequências respiratórias próximas a 60 insuflações por minuto. Também demonstraram que o uso da válvula de PEEP aumenta a PIP, já que ao acoplar a válvula ao equipamento há aumento de resistência no sistema, gerando PIP elevadas. Isso, somada à elevação da FR, contribuiu para PIP e VC elevados que poderiam contribuir a volutrauma. Isso não é um argumento forte suficiente para contraindicar o uso de PEEP quando do uso do BAI. A reanimação com PEEP é essencial para aumentar a CRF, sendo então o uso do MFR essencial para evitar PIP e VC exagerados ao usar válvula de PEEP.

\subsection{Frequência respiratória, tempo inspiratório e volume-minuto}

Cada equipamento apresenta uma relação específica com a FR e VM para o seu funcionamento. O BAI com válvula PEEP precisa de FR elevadas e por tanto VM aumentados para garantir o envio de PEEP. Em nosso estudo vimos que a FR com BAl variou de 45,76 a 51,13 ventilações por minuto (vpm). Tracy et al. ${ }^{(22)}$ já haviam confirmado com o uso de MFR que ao ventilar com BAl e válvula de PEEP, 
frequências respiratórias de 40vpm garantem $89 \%$ da oferta da PEEP enquanto FR de 60vpm garantem $98 \%$ da oferta. O VM obtido em nosso estudo foi de $712,51 \mathrm{~mL} / \mathrm{min}$ em V4 a $1751,44 \mathrm{~mL} / \mathrm{min}$ em V1, mostrando que o MFR auxilia na redução do VM por diminuição do VC e não da FR.

A Peça-T requer Tins mais longos para equilibrar pressões e ofertar a PIP desejada, reduzindo a FR. Em nosso estudo a FR variou de 33,02vpm em V4 a 40,41vpm em V2. O VM obtido foi de $424,66 \mathrm{~mL} / \mathrm{min}$ em V4 a $589,6 \mathrm{~mL} / \mathrm{min}$ em V2, sendo mais estáveis e constantes devido ao uso de fluxo contínuo e pressões préestabelecidas. Para conseguir isso, demonstramos que é importante que o operador oclua a Peça-T por cerca de 1 segundo (0,95 a 1,19seg).

\subsection{Retenção do aprendizado}

O nosso estudo destaca-se por ser, de acordo com nosso conhecimento e revisão bibliográfica, o único estudo que avaliou a retenção do aprendizado por períodos superiores a 1 mês após o treinamento com MFR. Alguns dos demais estudos previamente mencionados avaliaram retenção até somente 3 a 4 semanas. Esta é uma importante contribuição deste estudo. Demonstramos que o treinamento com MFR manteve bons resultados mesmo após 3 meses, exceto para vazamento, o que ocorreu durante todas as etapas do estudo.

Desta maneira, diante da indisponibilidade do MFR até este momento em todas as salas de parto, fica claro que treinamentos com essa tecnologia são suficientes para manter conhecimentos por pelo menos 3 meses, sendo talvez essa uma periodicidade razoável de treinamento com este instrumento.

\subsection{Limitações do estudo}

O fato de os residentes participantes terem sido selecionados por conveniência deve ser considerado um fator limitante deste estudo. Felizmente, os dados demográficos mostraram adequada representatividade dos residentes. Tivemos perdas de participação dos residentes em V4 e V5 devido participação em estágios 
fora dos locais de coleta e férias; essas perdas foram próxima de $20 \%$ e consideradas no cálculo amostral e na análise dos resultados, sem prejuízo aos resultados obtidos.

Apesar de não termos feito um estudo com grupo experimental e controle, consideramos que os dados de ventilação obtidos de cada residente em V1, antes de receberem treinamento sobre o MFR, funciona metodologicamente como grupo controle. Cada residente foi controle de si próprio ao longo do estudo, e ao parearmos os dados, aumentamos seu significado estatístico.

A maneira como fizemos o treinamento (aula de aproximadamente 15 minutos em PowerPoint) mostrou ser insuficiente para domínio de curva fluxo/tempo, resultando em vazamentos excessivos em todas as ventilações e com ambos equipamentos. Há necessidade de repensar o modo de transmitir estes conhecimentos de monitorização para que o uso do MFR não fique restrito pelo não reconhecimento das diversas curvas.

Consideramos que o display do nosso MFR era um pouco poluído e confuso para os residentes. Ele prioriza a observação do VC, que aparece de forma numérica a cada ventilação. Em contrapartida, percebemos que os residentes tinham dificuldades em compreender as curvas pressão-tempo e fluxo-tempo. Já os demais parâmetros, apareciam numericamente em tamanho reduzido. É importante reconhecer o efeito do display nos resultados obtidos. Os residentes, por exemplo, não aprenderam ao longo dos 3 meses a reconhecerem o vazamento através da curva.

Curiosamente, em estudo realizado por Katz et al., ${ }^{(24)}$ utilizaram um óculos de rastreio ocular para determinar quais eram os parâmetros do MFR mais observados pelos reanimadores. Neste estudo, os participantes se atentavam mais as curvas (33\% das vezes) e depois nos parâmetros numéricos (22\%). Os participantes deste estudo eram membros da equipe de neonatologia e tinham tempo médio de 6 anos de experiência na área. A maioria dos nossos participantes (60,9\%) estavam ainda cursando o primeiro ano de residência. Essa diferença deve explicar o fato de os participantes deste estudo focarem mais em curvas e os nossos residentes em dados numéricos.

O estudo de Takatori et al. ${ }^{(25)}$ buscou maneiras de facilitar a usabilidade do MFR. No monitor por eles propostos, o vazamento é descrito em porcentagem e não em curva, o que facilitaria o seu reconhecimento, e além disso utiliza uma cara feliz em verde quando o vazamento está $<20 \%$ e o VC $>5 \mathrm{~mL} / \mathrm{kg}$ e uma cara vermelha quando o vazamento é $>20 \%$ e o $\mathrm{VC}<5 \mathrm{~mL} / \mathrm{kg}$. Ainda não há estudos 
disponíveis utilizando este monitor, porém podemos inferir que monitores com estas particularidades podem otimizar o reconhecimento de alterações da ventilação, possibilitando correções mais imediatas da técnica de ventilação manual. 


\section{CONCLUSÕES}

1. Neste estudo experimental, o uso do monitor de função respiratória mostrou ser uma boa estratégia de ensino da ventilação manual para residentes em neonatologia, promovendo melhor adequação do volume-corrente ofertado quando utilizado balão autoinflável, mas sem impacto com a Peça-T (onde os volumes são estáveis e adequados); no entanto, o monitor de função respiratória não auxiliou no reconhecimento e correção do vazamento ao redor da máscara facial;

2. Os residentes demonstraram compreender a importância de garantir capacidade residual funcional ao se ventilar com balão autoinflável, aumentando a frequência de uso da válvula de pressão positiva ao final da expiração;

3. Houve retenção do aprendizado até pelo menos 3 meses do treinamento com monitor de função respiratória. 


\section{REFERÊNCIAS}

1. Sociedade Brasileira de Pediatria. Reanimação do recém-nascido $\geq 34$ semanas em sala de parto: diretrizes 2016 da Sociedade Brasileira de Pediatria [Internet]. São Paulo: Sociedade Brasileira de Pediatria; 2016 [citado 2019 Mar 17]. [Programa de Reanimação Neonatal]. Disponível em:

https://www.sbp.com.br/fileadmin/user_upload/DiretrizesSBPReanimacaoRNMaior34semanas2 6jan2016.pdf

2. Singh $\mathrm{Y}$, Oddie $\mathrm{S}$. Marked variation in delivery room management in very preterm infants. Resuscitation. 2013;84(11):1558-61.

3. van Vonderen JJ, Hooper SB, Krabbe VB, Siew ML, Te Pas AB. Monitoring tidal volumes in preterm infants at birth: mask versus endotracheal ventilation. Arch Dis Child Fetal Neonatal Ed. 2015;100(1):F43-6.

4. Hartung JC, te Pas AB, Fischer $\mathrm{H}$, Schmalisch $\mathrm{G}$, Roehr $\mathrm{CC}$. Leak during manual neonatal ventilation and its effect on the delivered pressures and volumes: an in vitro study. Neonatology. 2012;102(3):190-5.

5. Schmolzer GM, Morley CJ, Wong C, Dawson JA, Kamlin CO, Donath SM, et al. Respiratory function monitor guidance of mask ventilation in the delivery room: a feasibility study. J Pediatr. 2012;160(3):377-381.e2.

6. Schilleman K, Witlox RS, Lopriore E, Morley CJ, Walther FJ, te Pas AB. Leak and obstruction with mask ventilation during simulated neonatal resuscitation. Arch Dis Child Fetal Neonatal Ed. 2010;95(6):F398-402.

7. Roehr CC, Kelm M, Fischer HS, Bührer C, Schmalisch G, Proquitté H. Manual ventilation devices in neonatal resuscitation: tidal volume and positive pressure-provision. Resuscitation. 2010;81(2):202-5.

8. O'Donnell CP, Kamlin CO, Davis PG, Morley CJ. Neonatal resuscitation 1: a model to measure inspired and expired tidal volumes and assess leakage at the face mask. Arch Dis Child Fetal Neonatal Ed. 2005;90(5):F388-91.

9. Schmolzer GM, Kamlin OC, O'Donnell CP, Dawson JA, Morley CJ, Davis PG. Assessment of tidal volume and gas leak during mask ventilation of preterm infants in the delivery room. Arch Dis Child Fetal Neonatal Ed. 2010;95(6):F393-7.

10. Wood FE, Morley CJ, Dawson JA, Kamlin CO, Owen LS, Donath S, et al. Improved techniques reduce face mask leak during simulated neonatal resuscitation: study 2 . Arch Dis Child Fetal Neonatal Ed. 2008;93(3):F230-4.

11. Schmolzer GM, Kamlin OC, Dawson JA, te Pas AB, Morley CJ, Davis PG. Respiratory monitoring of neonatal resuscitation. Arch Dis Child Fetal Neonatal Ed. 2010;95(4):F295-303. Review.

12. Kelm M, Dold SK, Hartung J, Breckwoldt J, Schmalisch G, Roehr CC. Manual neonatal ventilation training: a respiratory function monitor helps to reduce peak inspiratory pressures and tidal volumes during resuscitation. J Perinat Med. 2012;40(5):583-6. 
13. Ericsson KA. Deliberate practice and the acquisition and maintenance of expert performance in medicine and related domains. Acad Med. 2004;79(10 Suppl):S70-81.

14. Wood FE, Morley CJ, Dawson JA, Davis PG. A respiratory function monitor improves mask ventilation. Arch Dis Child Fetal Neonatal Ed. 2008;93(5):F380-1.

15. Schmolzer GM, Dawson JA, Kamlin CO, O'Donnell CP, Morley CJ, Davis PG. Airway obstruction and gas leak during mask ventilation of preterm infants in the delivery room. Arch Dis Child Fetal Neonatal Ed. 2011;96(4):F254-7.

16. Poulton DA, Schmolzer GM, Morley CJ, Davis PG. Assessment of chest rise during mask ventilation of preterm infants in the delivery room. Resuscitation. 2011;82(2):175-9.

17. Kaufman J, Schmolzer GM, Kamlin CO, Davis PG. Mask ventilation of preterm infants in the delivery room. Arch Dis Child Fetal Neonatal Ed. 2013;98(5):F405-10.

18. Hartung JC, te Pas AB, Fischer H, Schmalisch G, Roehr CC. Leak during manual neonatal ventilation and its effect on the delivered pressures and volumes: an in vitro study. Neonatology. 2012;102(3):190-5.

19. Schmolzer GM, Morley CJ, Davis PG. Respiratory function monitoring to reduce mortality and morbidity in newborn infants receiving resuscitation. Cochrane Database Syst Rev. 2010;(9):CD008437.

20. O'Currain E, Thio M, Dawson JA, Donath SM, Davis PG. Respiratory monitors to teach newborn facemask ventilation: a randomised trial. Arch Dis Child Fetal Neonatal Ed. 2018;0:F15.

21. Thallinger M, Ersdal HL, Ombay C, Eilevstjonn J, Stordal K. Randomised comparison of two neonatal resuscitation bags in manikin ventilation. Arch Dis Child Fetal Neonatal Ed.

2016;101(4):F299-303.

22. Tracy M, Shah D, Priyadarshi A, Hinder M. The effectiveness of Ambu neonatal self-inflating bag to provide consistent positive end-expiratory pressure. Arch Dis Child Fetal Neonatal Ed. 2016;101(5):F439-43.

23. Hartung JC, Wilitzki S, Thio-Lluch M, te Pas AB, Schmalisch G, Roehr CC. Reliability of single-use PEEP-valves attached to self-inflating bags during manual ventilation of neonatesan in vitro study. PLoS One. 2016;11(2):e0150224.

24. Katz TA, Weinberg DD, Fishman CE, Nadkarni V, Tremoulet P, Te Pas AB, et al. Visual attention on a respiratory function monitor during simulated neonatal resuscitation: an eyetracking study. Arch Dis Child Fetal Neonatal Ed. 2019;104(3):F259-64.

25. Takatori F, Inoue S, Togo S, Yamamori S. Development of respiratory function monitor for neonates. Conf Proc IEEE Eng Med Biol Soc. 2017;2017:3719-22. 


\section{Abstract}

Introduction: Approximately $10 \%$ of low-risk newborns require support in the delivery room to initiate or sustain respiration after birth. Manual ventilation is an efficient procedure to revert perinatal asphyxia. Thoracic expansibility is a poor marker of pulmonary ventilation. Monitoring mechanical respiration can be used as a tool for teaching manual ventilation to neonatal residents. Purpose: to evaluate the influence of the respiratory function monitor as a strategy for teaching manual ventilation using selfinflating bag and a pressure limited T-piece device based on tidal volume optimization, reduce facemask air leakage, increase the use of PEEP-valve, and measurement learning retention rates after one and three months of training. Methods: This was an experimental study including 23 neonatal residents from 4 different residency programs who conducted facemask ventilation based on thoracic expansion for 4-minutes with each device (self-inflating bag and T-piece) into a neonatal manikin to simulate a terminfant weighing $2.5 \mathrm{~kg}$. Their goal was to reach a tidal volume of $4-6 \mathrm{~mL} / \mathrm{kg}$ and facemask leaking below 20\% (V1). Subsequently, residents were trained to use respiratory function monitor, they performed another 4-minute ventilation with each device, focusing on the information provided by the monitor (V2), followed by another 4-min ventilation with each device without monitor data (V3). Learning retention was assessed after one (V4) and three months (V5), without access to monitor data. Tidal-volume, air leak, and PEEP rates were collected using specific software. Linear mixed model was performed using SPSS 3 to compare ventilation times and devices. Results: A total of 23 residents were evaluated. Participants mean age was 29 years, $91.3 \%$ of them were women and $60.9 \%$ were in the first-year of residency. All residents had undergone delivery-room training, were familiarized with both self-inflating bag and T-piece devices, and had participated in neonatal resuscitation courses, in addition, 34.8\% also had training on premature resuscitation. The respiratory function monitor reduced significantly tidal volume by using self-inflating bag after training, which was elevated in V1 $(10.28 \mathrm{~mL} / \mathrm{kg}$ $[95 \% \mathrm{Cl} 9.05-11.51)$, with reduction in other ventilations $(p<0.001)$, and similar to the T-piece in V3-V5. Tidal volume remained within adequate ranges in all T-piece ventilations. Facemask air leak was high in all ventilations using both devices, no influence of monitor was seen. PEEP-valve use increased from $21.7 \%$ to $88.4 \%$ after training $(p<0.001)$. Conclusions: The respiratory function monitor improved tidal 
volume, increased PEEP-valve usage, but showed no impact on air leak rates. Learning remained after 1 and 3 months of training.

Keywords: Respiration, artificial; Tidal volume; Educational measurement; Internship and residency; Neonatology/education 


\section{Apêndices}

Apêndice 1. Questionário respondido pelos residentes participantes antes de iniciar o treinamento com MFR

Número de ordem:

Data:

Nome:

Idade: anos

Sexo: ( ) M ( ) F

E-mail:

Celular:

Telefone Residencial:

Faculdade de Medicina: Ano Formatura:

Hospital Residência Pediatria: Ano Término:

Hospital de Residência em Neonatologia:

Ano de início da Residência em Neonatologia:

Ano atual de Residência: $R$ ( $1^{\circ}$ ou $2^{\circ}$ ano de Neonatologia)

Possui curso de Reanimação Neonatal (SBP 2011/2017):

( ) $\mathrm{S}($ ) $\mathrm{N}$

Possui curso de Reanimação do Prematuro (SBP 2011/2017):

( ) S ( ) N

Possui curso de Transporte do RN de risco (SBP 2011/2017):

( ) $\mathrm{S}($ ) $\mathrm{N}$

Atua na sala de reanimação em serviço universitário:

( ) S ( ) N

Familiarizado(a) com balão autoinflável:

( ) $\mathrm{S} \quad($ ) $\mathrm{N}$

Familiarizado(a) com ventilador manual e Peça-T:

( ) $\mathrm{S}($ ) $\mathrm{N}$

Familiarizado(a) com Monitor de Função Respiratória:

( ) S ( ) N 
Apêndice 2. Detalhamento numérico das médias dos diferentes parâmetros avaliados na ordem de apresentação dos Resultados

Valores numéricos da média do volume corrente expiratório por quilo (mililitros por quilo), segundo momento e equipamento.

\begin{tabular}{|c|c|c|c|}
\hline \multirow[b]{2}{*}{ Momento da avaliação } & \multicolumn{2}{|c|}{ Equipamento } & \multirow[b]{2}{*}{$\begin{array}{l}\text { Valor-p } \\
\text { Equip. }\end{array}$} \\
\hline & $\begin{array}{c}\text { Ventilador manual } \\
\text { em Peça-T } \\
\text { Média (IC 95\%) } \\
\end{array}$ & $\begin{array}{l}\text { Balão inflável } \\
\text { Média (IC 95\%) }\end{array}$ & \\
\hline 1ª Ventilação & $3,82[2,53 ; 5,10]$ & $10,43[9,15 ; 11,72]$ & $<0,001$ \\
\hline $2^{\text {a }}$ Ventilação após trein. com monitor & $3,53[2,25 ; 4,82]$ & $5,41[4,13 ; 6,70]$ & 0,016 \\
\hline Valor-p em comparação com $1^{\underline{a}}$ & $>0,999$ & $<0,001$ & \\
\hline $3^{a}$ Ventilação após trein. sem monitor & $3,79[2,51 ; 5,08]$ & $4,52[3,23 ; 5,80]$ & 0,221 \\
\hline Valor-p em comparação com $1 \underline{\text { ạ }}$ & $>0,999$ & $<0,001$ & \\
\hline $4^{\text {a }}$ ventilação após 1 mês do trein. sem monitor & $3,79[2,31 ; 5,28]$ & $3,37[1,88 ; 4,85]$ & 0,959 \\
\hline Valor-p em comparação com $1^{\underline{a}}$ & $>0,999$ & $<0,001$ & \\
\hline $5^{a}$ ventilação após 3 meses do trein. sem monitor & $5,75[4,30 ; 7,19]$ & $5,95[4,50 ; 7,40]$ & 0,531 \\
\hline Valor-p em comparação com $1^{\mathrm{a}}$ & 0,164 & 0,001 & \\
\hline
\end{tabular}

Valores numéricos da média do escore de volume corrente expiratório por quilo, segundo momento e equipamento.

\begin{tabular}{|c|c|c|c|}
\hline \multirow[b]{2}{*}{ Momento da avaliação } & \multicolumn{2}{|c|}{ Equipamento } & \multirow[b]{2}{*}{$\begin{array}{l}\text { Valor-p } \\
\text { Equip. }\end{array}$} \\
\hline & $\begin{array}{c}\text { Ventilador manual } \\
\text { em Peça-T } \\
\text { Média (IC 95\%) }\end{array}$ & $\begin{array}{l}\text { Balão inflável } \\
\text { Média (IC 95\%) }\end{array}$ & \\
\hline $1^{a}$ Ventilação & $2,35[1,99 ; 2,71]$ & $4,34[3,98 ; 4,70]$ & $<0,001$ \\
\hline $2^{\mathrm{a}}$ Ventilação após trein. com monitor & $2,23[1,87 ; 2,59]$ & $3,04[2,67 ; 3,40]$ & 0,002 \\
\hline Valor-p em comparação com $1 \underline{\text { a }}$ & $>0,999$ & $<0,001$ & \\
\hline 3ª Ventilação após trein. sem monitor & $2,24[1,88 ; 2,60]$ & $2,66[2,30 ; 3,02]$ & 0,088 \\
\hline Valor-p em comparação com $1^{\text {a }}$ & $>0,999$ & $<0,001$ & \\
\hline 4⿳亠口了 Ventilação após 1 mês do trein. sem monitor & $2,38[1,97 ; 2,80]$ & $2,26[1,84 ; 2,67]$ & 0,794 \\
\hline Valor-p em comparação com $1^{a \underline{a}}$ & $>0,999$ & $<0,001$ & \\
\hline $5^{\mathrm{a}}$ ventilação após 3 meses do trein. sem monitor & $2,61[2,21 ; 3,02]$ & $2,89[2,48 ; 3,29]$ & 0,299 \\
\hline Valor-p em comparação com $1^{a}$ & $>0,999$ & $<0,001$ & \\
\hline
\end{tabular}

Valores médios e IC obtidos por modelos mistos. Valores-p corrigidos pelo método de Bonferroni para comparações múltiplas. trein.: Treinamento. Equip.: Equipamento. 
Valores numéricos da média do vazamento ao redor da máscara (porcentagem), segundo momento e equipamento.

\begin{tabular}{|c|c|c|c|}
\hline \multirow[b]{2}{*}{ Momento da avaliação } & \multicolumn{2}{|c|}{ Equipamento } & \multirow[b]{2}{*}{$\begin{array}{l}\text { Valor-p } \\
\text { Equip. }\end{array}$} \\
\hline & $\begin{array}{c}\text { Ventilador manual } \\
\text { em Peça-T } \\
\text { Média (IC 95\%) } \\
\end{array}$ & $\begin{array}{l}\text { Balão inflável } \\
\text { Média (IC 95\%) }\end{array}$ & \\
\hline 1a Ventilação & $36,00[24,26 ; 47,74]$ & $31,73[19,99 ; 43,47]$ & 0,585 \\
\hline $2^{\mathrm{a}}$ Ventilação após trein. com monitor & $43,89[32,15 ; 55,63]$ & $43,85[32,11 ; 55,59]$ & 0,310 \\
\hline Valor-p em comparação com 1 ạ & 0,463 & 0,144 & \\
\hline $3^{\text {a }}$ Ventilação após trein. sem monitor & $47,81[36,07 ; 59,55]$ & $35,14[23,40 ; 46,88]$ & 0,698 \\
\hline Valor-p em comparação com 1 르 & 0,158 & $>0,999$ & \\
\hline 4⿳亠口冋 Ventilação após 1 mês do trein. sem monitor & $39,11[25,57 ; 52,64]$ & $50,08[36,55 ; 63,61]$ & 0,047 \\
\hline Valor-p em comparação com 1 a & $>0,999$ & 0,033 & \\
\hline $5^{\text {a }}$ Ventilação após 3 meses do trein. sem monitor & $45,70[32,51 ; 58,89]$ & $41,04[27,85 ; 54,22]$ & 0,648 \\
\hline Valor-p em comparação com $1^{a \underline{a}}$ & 0,376 & 0,414 & \\
\hline
\end{tabular}

Valores médios e IC obtidos por modelos mistos. Valores-p corrigidos pelo método de Bonferroni para comparações múltiplas. trein.: Treinamento. Equip.: Equipamento.

Valores numéricos da média do escore de vazamento ao redor da máscara, segundo momento e equipamento.

\begin{tabular}{|c|c|c|c|}
\hline \multirow[b]{2}{*}{ Momento da avaliação } & \multicolumn{2}{|c|}{ Equipamento } & \multirow[b]{2}{*}{$\begin{array}{l}\text { Valor-p } \\
\text { Equip. }\end{array}$} \\
\hline & $\begin{array}{c}\text { Ventilador manual } \\
\text { em Peça-T } \\
\text { Média (IC 95\%) }\end{array}$ & $\begin{array}{l}\text { Balão inflável } \\
\text { Média (IC 95\%) }\end{array}$ & \\
\hline 1a Ventilação & $1,81[1,35 ; 2,28]$ & $1,77[1,31 ; 2,24]$ & 0,543 \\
\hline $2^{\mathrm{a}}$ Ventilação após trein. com monitor & $2,07[1,61 ; 2,54]$ & $2,02[1,55 ; 2,48]$ & 0,574 \\
\hline Valor-p em comparação com $1^{\underline{a}}$ & $>0,999$ & $>0,999$ & \\
\hline 3a Ventilação após trein. sem monitor & $2,22[1,76 ; 2,69]$ & $1,86[1,40 ; 2,32]$ & 0,757 \\
\hline Valor-p em comparação com $1^{a \underline{a}}$ & 0,485 & $>0,999$ & \\
\hline $4^{a}$ Ventilação após 1 mês do trein. sem monitor & $2,00[1,46 ; 2,54]$ & $2,17[1,63 ; 2,71]$ & 0,294 \\
\hline Valor-p em comparação com $1^{a}$ & $>0,999$ & 0,691 & \\
\hline $5^{\text {a }}$ Ventilação após 3 meses do trein. sem monitor & $1,83[1,30 ; 2,35]$ & $2,61[2,09 ; 3,14]$ & 0,008 \\
\hline Valor-p em comparação com $1^{\mathrm{a}}$ & $>0,999$ & 0,030 & \\
\hline
\end{tabular}


Valores numéricos da média de volume corrente inspiratório (mililitros), segundo momento e equipamento.

\begin{tabular}{|c|c|c|c|}
\hline \multirow[b]{2}{*}{ Momento da avaliação } & \multicolumn{2}{|c|}{ Equipamento } & \multirow[b]{2}{*}{$\begin{array}{l}\text { Valor-p } \\
\text { Equip. }\end{array}$} \\
\hline & $\begin{array}{c}\text { Ventilador manual } \\
\text { em Peça-T } \\
\text { Média (IC 95\%) }\end{array}$ & $\begin{array}{l}\text { Balão inflável } \\
\text { Média (IC 95\%) }\end{array}$ & \\
\hline 1' - Ventilação & $18,43[11,27 ; 25,59]$ & $47,32[40,16 ; 54,49]$ & $<0,001$ \\
\hline $2^{\mathrm{a}}$ Ventilação após trein. com monitor & $19,96[12,80 ; 27,13]$ & $30,73[23,57 ; 37,89]$ & 0,001 \\
\hline Valor-p em comparação com $1^{\mathrm{a}}$ & $>0,999$ & 0,587 & \\
\hline 3ª Ventilação após trein. sem monitor & $22,35[15,19 ; 29,51]$ & $21,59[14,43 ; 28,75]$ & 0,274 \\
\hline Valor-p em comparação com $1^{a}$ & 0,414 & 0,004 & \\
\hline 4⿳亠口冋 Ventilação após 1 mês do trein. sem monitor & $16,84[8,66 ; 25,02]$ & $23,68[15,50 ; 31,86]$ & 0,027 \\
\hline Valor-p em comparação com $1^{\text {ạ }}$ & $>0,999$ & 0,03 & \\
\hline 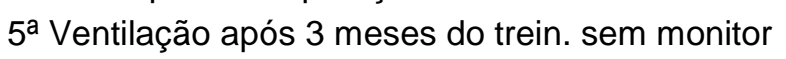 & $19,66[11,67 ; 27,65]$ & $29,10[21,11 ; 37,09]$ & 0,007 \\
\hline Valor-p em comparação com $1^{a}$ & $>0,999$ & 0,378 & \\
\hline
\end{tabular}

Valores numéricos da média de volume corrente expiratório (mililitros), segundo momento e equipamento.

\begin{tabular}{|c|c|c|c|}
\hline \multirow[b]{2}{*}{ Momento da avaliação } & \multicolumn{2}{|c|}{ Equipamento } & \multirow[b]{2}{*}{$\begin{array}{l}\text { Valor-p } \\
\text { Equip. }\end{array}$} \\
\hline & $\begin{array}{c}\text { Ventilador manual } \\
\text { em Peça-T } \\
\text { Média (IC 95\%) } \\
\end{array}$ & $\begin{array}{l}\text { Balão Inflável Média } \\
\text { (IC 95\%) }\end{array}$ & \\
\hline 1ㄹ Ventilação & $9,54[6,34 ; 12,73]$ & $26,07[22,88 ; 29,27]$ & $<0,001$ \\
\hline $2^{\mathrm{a}}$ Ventilação após trein. com monitor & $8,82[5,62 ; 12,02]$ & $13,52[10,33 ; 16,72]$ & 0,016 \\
\hline Valor-p em comparação com $1^{\text {a }}$ & $>0,999$ & $<0,001$ & \\
\hline 3ㄹ Ventilação após trein. sem monitor & $9,47[6,27 ; 12,67]$ & $11,28[8,08 ; 14,48]$ & 0,222 \\
\hline Valor-p em comparação com $1^{a}$ & $>0,999$ & $<0,001$ & \\
\hline $\begin{array}{l}\text { 4ㄹ Ventilação após } 1 \text { mês do trein. sem } \\
\text { monitor }\end{array}$ & $9,48[5,78 ; 13,17]$ & $8,42[4,72 ; 12,11]$ & 0,963 \\
\hline Valor-p em comparação com $1^{\underline{a}}$ & $>0,999$ & $<0,001$ & \\
\hline $\begin{array}{l}5^{\text {a }} \text { Ventilação após } 3 \text { meses do trein. sem } \\
\text { monitor }\end{array}$ & $14,36[10,77 ; 17,96]$ & $14,76[11,16 ; 18,36]$ & 0,558 \\
\hline Valor-p em comparação com 1aㅗ & 0,162 & 0,001 & \\
\hline
\end{tabular}

Valores médios e IC obtidos por modelos mistos. Valores-p corrigidos pelo método de Bonferroni para comparações múltiplas. trein.: Treinamento. Equip.: Equipamento. 
Valores numéricos da média do volume corrente médio (mililitros), segundo momento e equipamento.

\begin{tabular}{|c|c|c|c|}
\hline \multirow[b]{2}{*}{ Momento da avaliação } & \multicolumn{2}{|c|}{ Equipamento } & \multirow[b]{2}{*}{$\begin{array}{l}\text { Valor-p } \\
\text { Equip. }\end{array}$} \\
\hline & $\begin{array}{c}\text { Ventilador manual } \\
\text { em Peça-T } \\
\text { Média (IC 95\%) }\end{array}$ & $\begin{array}{l}\text { Balão inflável } \\
\text { Média (IC 95\%) }\end{array}$ & \\
\hline 1ª Ventilação & $13,99[10,10 ; 17,88]$ & $36,73[32,84 ; 40,62]$ & $<0,001$ \\
\hline $2^{a}$ Ventilação após trein. com monitor & $14,66[10,77 ; 18,55]$ & $21,85[17,96 ; 25,74]$ & $<0,001$ \\
\hline Valor-p em comparação com $1^{a \underline{a}}$ & 0,930 & 0,002 & \\
\hline $3^{a}$ Ventilação após trein. sem monitor & $15,93[12,04 ; 19,82]$ & $16,44[12,55 ; 20,33]$ & 0,130 \\
\hline Valor-p em comparação com $1^{a}$ & 0,367 & $<0,001$ & \\
\hline 4ª Ventilação após 1 mês do trein. sem monitor & $13,10[8,61 ; 17,60]$ & $16,20[11,71 ; 20,70]$ & 0,035 \\
\hline Valor-p em comparação com $1^{a}$ & $>0,999$ & $<0,001$ & \\
\hline $5^{\text {a }}$ Ventilação após 3 meses do trein. sem monitor & $17,23[12,85 ; 21,61]$ & $21,97[17,59 ; 26,35]$ & 0,008 \\
\hline Valor-p em comparação com $1^{\mathrm{a}}$ & 0,171 & 0,005 & \\
\hline
\end{tabular}

Valores numéricos da média da pressão inspiratória (centímetros de água), segundo momento e equipamento.

\begin{tabular}{|c|c|c|c|}
\hline \multirow[b]{2}{*}{ Momento da avaliação } & \multicolumn{2}{|c|}{ Equipamento } & \multirow[b]{2}{*}{$\begin{array}{l}\text { Valor-p } \\
\text { Equip. }\end{array}$} \\
\hline & $\begin{array}{c}\text { Ventilador manual } \\
\text { em Peça-T } \\
\text { Média (IC 95\%) }\end{array}$ & $\begin{array}{c}\text { Balão inflável } \\
\text { Média (IC 95\%) }\end{array}$ & \\
\hline $1^{\text {a }}$ Ventilação & $21,97[19,60 ; 24,33]$ & $28,98[26,62 ; 31,34]$ & $<0,001$ \\
\hline $2^{\mathrm{a}}$ Ventilação após trein. com monitor & $22,06[19,69 ; 24,42]$ & $23,77[21,41 ; 26,13]$ & 0,125 \\
\hline Valor-p em comparação com $1 \underline{\text { a }}$ & $>0,999$ & 0,177 & \\
\hline $3^{\text {a }}$ Ventilação após trein. sem monitor & $21,60[19,24 ; 23,96]$ & $19,54[17,18 ; 21,90]$ & 0,582 \\
\hline Valor-p em comparação com $1^{a}$ & $>0,999$ & $<0,001$ & \\
\hline 4" Ventilação após 1 mês do trein. sem monitor & $20,76[18,04 ; 23,47]$ & $17,06[14,34 ; 19,78]$ & 0,197 \\
\hline Valor-p em comparação com $1^{\text {a }}$ & $>0,999$ & $<0,001$ & \\
\hline $5^{\text {a }}$ Ventilação após 3 meses do trein. sem monitor & $20,33[17,68 ; 22,98]$ & $20,31[17,66 ; 22,96]$ & 0,600 \\
\hline Valor-p em comparação com 1 ạ & $>0,999$ & 0,001 & \\
\hline
\end{tabular}


Valores numéricos da média da pressão positiva ao final da expiração (centímetros de água), segundo momento e equipamento.

\begin{tabular}{|c|c|c|c|}
\hline \multirow[b]{2}{*}{ Momento da avaliação } & \multicolumn{2}{|c|}{ Equipamento } & \multirow[b]{2}{*}{$\begin{array}{l}\text { Valor-p } \\
\text { Equip. }\end{array}$} \\
\hline & $\begin{array}{c}\text { Ventilador manual } \\
\text { em Peça-T } \\
\text { Média (IC 95\%) }\end{array}$ & $\begin{array}{l}\text { Balão inflável } \\
\text { Média (IC 95\%) }\end{array}$ & \\
\hline 1a Ventilação & $6,06[5,52 ; 6,60]$ & $0,77[0,23 ; 1,31]$ & $<0,001$ \\
\hline $2^{2}$ Ventilação após trein. com monitor & $6,12[5,58 ; 6,66]$ & $1,96[1,42 ; 2,50]$ & $<0,001$ \\
\hline Valor-p em comparação com 1aㅗ & $>0,999$ & 0,020 & \\
\hline $3^{a}$ ventilação após trein. sem monitor & $5,80[5,26 ; 6,34]$ & $2,57[2,03 ; 3,11]$ & $<0,001$ \\
\hline Valor-p em comparação com $1^{a} \underline{a}$ & $>0,999$ & $<0,001$ & \\
\hline 4ª Ventilação após 1 mês do trein. sem monitor & $5,47[4,85 ; 6,09]$ & $1,61[0,99 ; 2,24]$ & $<0,001$ \\
\hline Valor-p em comparação com 1a & $>0,999$ & 0,322 & \\
\hline $5^{\text {a }}$ Ventilação após 3 meses do trein. sem monitor & $5,90[5,29 ; 6,51]$ & $1,62[1,02 ; 2,23]$ & $<0,001$ \\
\hline Valor-p em comparação com $1^{\text {a }}$ & $>0,999$ & 0,288 & \\
\hline
\end{tabular}

Valores médios e IC obtidos por modelos mistos. Valores-p corrigidos pelo método de Bonferroni para comparações múltiplas. trein.: Treinamento. Equip.: Equipamento.

Valores numéricos da média da frequência respiratória (ventilações por minuto), segundo momento e equipamento.

\begin{tabular}{|c|c|c|c|}
\hline \multirow[b]{2}{*}{ Momento da avaliação } & \multicolumn{2}{|c|}{ Equipamento } & \multirow[b]{2}{*}{$\begin{array}{l}\text { Valor-p } \\
\text { Equip. }\end{array}$} \\
\hline & $\begin{array}{c}\text { Ventilador manual } \\
\text { em Peça-T } \\
\text { Média (IC 95\%) }\end{array}$ & $\begin{array}{c}\text { Balão inflável } \\
\text { Média (IC 95\%) }\end{array}$ & \\
\hline 1a Ventilação & $38,48[34,99 ; 41,98]$ & $46,68[43,19 ; 50,18]$ & 0,004 \\
\hline $2^{\mathrm{a}}$ Ventilação após trein. com monitor & $40,41[36,91 ; 43,91]$ & $48,23[44,74 ; 51,73]$ & 0,006 \\
\hline Valor-p em comparação com $1^{\underline{a}}$ & $>0,999$ & $>0,999$ & \\
\hline 3a Ventilação após trein. sem monitor & $37,96[34,46 ; 41,46]$ & $51,13[47,63 ; 54,63]$ & $<0,001$ \\
\hline Valor-p em comparação com $1^{\text {a }}$ & $>0,999$ & $>0,999$ & \\
\hline $4^{a}$ Ventilação após 1 mês do trein. sem monitor & $33,02[29,06 ; 36,97]$ & $45,76[41,81 ; 49,72]$ & $<0,001$ \\
\hline Valor-p em comparação com 1 a & 0,276 & $>0,999$ & \\
\hline $5^{\text {a }}$ Ventilação após 3 meses do trein. sem monitor & $35,11[31,24 ; 38,98]$ & $46,97[43,10 ; 50,84]$ & $<0,001$ \\
\hline Valor-p em comparação com $1^{a \underline{a}}$ & $>0,999$ & $>0,999$ & \\
\hline
\end{tabular}


Valores numéricos da média do volume minuto (mililitros por minuto), segundo momento e equipamento.

\begin{tabular}{|c|c|c|c|}
\hline \multirow[b]{2}{*}{ Momento da avaliação } & \multicolumn{2}{|c|}{ Equipamento } & \multirow[b]{2}{*}{$\begin{array}{l}\text { Valor-p } \\
\text { Equip. }\end{array}$} \\
\hline & $\begin{array}{c}\text { Ventilador manual } \\
\text { em Peça-T } \\
\text { Média (IC 95\%) }\end{array}$ & $\begin{array}{l}\text { Balão inflável } \\
\text { Média (IC 95\%) }\end{array}$ & \\
\hline 1ª Ventilação & $531,06[338,40 ; 723,71]$ & $1751,44[1558,79 ; 1944,09]$ & $<0,001$ \\
\hline $2^{2}$ Ventilação após trein. com monitor & $572,71[380,05 ; 765,36]$ & $1045,71[853,05 ; 1238,36]$ & $<0,001$ \\
\hline Valor-p em comparação com $1^{\underline{a}}$ & $>0,999$ & 0,003 & \\
\hline $3^{a}$ Ventilação após trein. sem monitor & $589,60[396,95 ; 782,26]$ & $816,66[624,01 ; 1009,31]$ & 0,006 \\
\hline Valor-p em comparação com $1^{a}$ & 0,886 & $<0,001$ & \\
\hline $\begin{array}{l}4^{\text {a }} \text { Ventilação após } 1 \text { mês do trein. } \\
\text { sem monitor }\end{array}$ & $424,66[203,14 ; 646,18]$ & $712,51[491,00 ; 934,03]$ & 0,005 \\
\hline Valor-p em comparação com 1a & $>0,999$ & $<0,001$ & \\
\hline $\begin{array}{l}5^{\text {a }} \text { Ventilação após } 3 \text { meses do trein. } \\
\text { sem monitor }\end{array}$ & $575,66[359,67 ; 791,65]$ & $981,05[765,06 ; 1197,04]$ & $<0,001$ \\
\hline Valor-p em comparação com $1^{\underline{a}}$ & $>0,999$ & 0,001 & \\
\hline
\end{tabular}

Valores numéricos da média do tempo inspiratório (segundos), de acordo com o momento e equipamento.

\begin{tabular}{|c|c|c|c|}
\hline \multirow[b]{2}{*}{ Momento da avaliação } & \multicolumn{2}{|c|}{ Equipamento } & \multirow[b]{2}{*}{$\begin{array}{l}\text { Valor-p } \\
\text { Equip. }\end{array}$} \\
\hline & $\begin{array}{c}\text { Ventilador manual } \\
\text { em Peça-T } \\
\text { Média (IC 95\%) }\end{array}$ & $\begin{array}{l}\text { Balão inflável } \\
\text { Média (IC 95\%) }\end{array}$ & \\
\hline 1' - Ventilação & $0,95[0,82 ; 1,08]$ & $0,45[0,31 ; 0,58]$ & $<0,001$ \\
\hline $2^{\mathrm{a}}$ Ventilação após trein. com monitor & $0,98[0,85 ; 1,11]$ & $0,57[0,44 ; 0,70]$ & 0,007 \\
\hline Valor-p em comparação com $1 \underline{\underline{a}}$ & 0,699 & 0,063 & \\
\hline $3^{\text {a }}$ Ventilação após trein. sem monitor & $1,10[0,97 ; 1,23]$ & $0,53[0,40 ; 0,66]$ & $<0,001$ \\
\hline Valor-p em comparação com $1^{a}$ & 0,037 & 0,187 & \\
\hline $4^{\text {a }}$ Ventilação após 1 mês do trein. sem monitor & $1,19[1,04 ; 1,34]$ & $0,66[0,51 ; 0,81]$ & 0,001 \\
\hline Valor-p em comparação com $1^{\text {a }}$ & 0,003 & 0,006 & \\
\hline 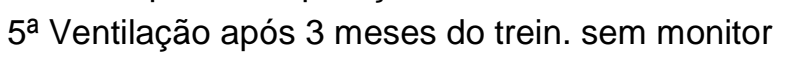 & $1,02[0,88 ; 1,17]$ & $0,62[0,47 ; 0,76]$ & 0,017 \\
\hline Valor-p em comparação com $1^{a}$ & 0,372 & 0,025 & \\
\hline
\end{tabular}

Valores médios e IC obtidos por modelos mistos. Valores-p corrigidos pelo método de Bonferroni para comparações múltiplas. trein.: Treinamento. Equip.: Equipamento. 
Valores numéricos da média do tempo expiratório (segundos), de acordo com o momento e equipamento.

\begin{tabular}{|c|c|c|c|}
\hline \multirow[b]{2}{*}{ Momento da avaliação } & \multicolumn{2}{|c|}{ Equipamento } & \multirow[b]{2}{*}{$\begin{array}{l}\text { Valor-p } \\
\text { Equip. }\end{array}$} \\
\hline & $\begin{array}{c}\text { Ventilador manual } \\
\text { em Peça-T } \\
\text { Média (IC 95\%) } \\
\end{array}$ & $\begin{array}{l}\text { Balão inflável } \\
\text { Média (IC 95\%) }\end{array}$ & \\
\hline 1ํㅡㄴ Ventilação & $0,67[0,56 ; 0,78]$ & $0,91[0,80 ; 1,02]$ & 0,148 \\
\hline $2^{\mathrm{a}}$ Ventilação após trein. com monitor & $0,53[0,42 ; 0,65]$ & $0,68[0,57 ; 0,79]$ & 0,697 \\
\hline Valor-p em comparação com 1a & 0,031 & 0,001 & \\
\hline 3a Ventilação após trein. sem monitor & $0,52[0,40 ; 0,63]$ & $0,65[0,54 ; 0,76]$ & 0,812 \\
\hline Valor-p em comparação com $1^{\text {a }}$ & 0,017 & $<0,001$ & \\
\hline 4a Ventilação após 1 mês do trein. sem monitor & $0,71[0,58 ; 0,84]$ & $0,71[0,57 ; 0,84]$ & 0,219 \\
\hline Valor-p em comparação com $1^{a}$ & $>0,999$ & 0,005 & \\
\hline 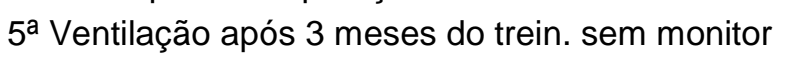 & $0,75[0,63 ; 0,88]$ & $0,72[0,59 ; 0,85]$ & 0,122 \\
\hline Valor-p em comparação com $1^{a} \underline{a}$ & $>0,999$ & 0,007 & \\
\hline
\end{tabular}


Apêndice 3. Detalhamento numérico dos desvios-padrões dos diferentes parâmetros avaliados na ordem de apresentação dos Resultados

Valores numéricos do desvio padrão do volume corrente expiratório por quilo (mililitros por quilo), segundo momento e equipamento.

\begin{tabular}{|c|c|c|c|}
\hline \multirow[b]{2}{*}{ Momento da avaliação } & \multicolumn{2}{|c|}{ Equipamento } & \multirow[b]{2}{*}{$\begin{array}{l}\text { Valor-p } \\
\text { Equip. }\end{array}$} \\
\hline & $\begin{array}{c}\text { Ventilador manual } \\
\text { em Peça-T } \\
\text { Média (IC 95\%) } \\
\end{array}$ & $\begin{array}{l}\text { Balão inflável } \\
\text { Média (IC 95\%) }\end{array}$ & \\
\hline 1ª Ventilação & $0,75[-0,69 ; 2,20]$ & $1,55[0,11 ; 3,00]$ & 0,374 \\
\hline $2^{\text {a }}$ Ventilação após trein. com monitor & $0,74[-0,71 ; 2,18]$ & $2,06[0,61 ; 3,50]$ & 0,173 \\
\hline Valor-p em comparação com $1^{a \underline{a}}$ & $>0,999$ & $>0,999$ & \\
\hline $3^{a}$ Ventilação após trein. sem monitor & $1,26[-0,18 ; 2,71]$ & $1,38[-0,07 ; 2,82]$ & 0,786 \\
\hline Valor-p em comparação com $1^{a} \underline{a}$ & $>0,999$ & $>0,999$ & \\
\hline 4" Ventilação após 1 mês do trein. sem monitor & $0,79[-0,89 ; 2,47]$ & $0,99[-0,70 ; 2,67]$ & 0,764 \\
\hline Valor-p em comparação com 1a & $>0,999$ & $>0,999$ & \\
\hline $5^{\text {a }}$ Ventilação após 3 meses do trein. sem monitor & $4,24[2,61 ; 5,88]$ & $1,45[-0,18 ; 3,09]$ & 0,035 \\
\hline Valor-p em comparação com $1^{\text {a }}$ & 0,014 & $>0,999$ & \\
\hline
\end{tabular}

Valores numéricos do desvio padrão do escore do volume corrente expiratório por quilo, segundo momento e equipamento.

\begin{tabular}{|c|c|c|c|}
\hline \multirow[b]{2}{*}{ Momento da avaliação } & \multicolumn{2}{|c|}{ Equipamento } & \multirow[b]{2}{*}{$\begin{array}{l}\text { Valor-p } \\
\text { Equip. }\end{array}$} \\
\hline & $\begin{array}{c}\text { Ventilador manual } \\
\text { em Peça-T } \\
\text { Média (IC 95\%) }\end{array}$ & $\begin{array}{l}\text { Balão inflável } \\
\text { Média (IC 95\%) }\end{array}$ & \\
\hline 1a Ventilação & $0,38[0,22 ; 0,54]$ & $0,44[0,27 ; 0,60]$ & 0,682 \\
\hline $2^{a}$ Ventilação após trein. com monitor & $0,43[0,27 ; 0,60]$ & $0,75[0,59 ; 0,91]$ & 0,091 \\
\hline Valor-p em comparação com $1^{a}$ & $>0,999$ & 0,741 & \\
\hline $3^{a}$ Ventilação após trein. sem monitor & $0,43[0,27 ; 0,59]$ & $0,60[0,44 ; 0,76]$ & 0,662 \\
\hline Valor-p em comparação com $1^{\underline{a}}$ & $>0,999$ & $>0,999$ & \\
\hline 4⿳亠口冋 Ventilação após 1 mês do trein. sem monitor & $0,37[0,18 ; 0,56]$ & $0,38[0,19 ; 0,57]$ & 0,481 \\
\hline Valor-p em comparação com 1a & $>0,999$ & $>0,999$ & \\
\hline $5^{\text {a }}$ Ventilação após 3 meses do trein. sem monitor & $0,53[0,35 ; 0,71]$ & $0,51[0,33 ; 0,69]$ & 0,342 \\
\hline Valor-p em comparação com $1^{a \underline{a}}$ & $>0,999$ & $>0,999$ & \\
\hline
\end{tabular}

Valores médios e IC obtidos por modelos mistos. Valores-p corrigidos pelo método de Bonferroni para comparações múltiplas. trein.: Treinamento. Equip.: Equipamento. 
Valores numéricos do desvio padrão do vazamento ao redor da máscara facial (porcentagem), segundo momento e equipamento.

\begin{tabular}{|c|c|c|c|}
\hline \multirow[b]{2}{*}{ Momento da avaliação } & \multicolumn{2}{|c|}{ Equipamento } & \multirow[b]{2}{*}{$\begin{array}{l}\text { Valor-p } \\
\text { Equip. }\end{array}$} \\
\hline & $\begin{array}{c}\text { Ventilador manual } \\
\text { em Pecca-T } \\
\text { Média (IC 95\%) }\end{array}$ & $\begin{array}{l}\text { Balão inflável } \\
\text { Média (IC 95\%) }\end{array}$ & \\
\hline 1a Ventilação & $14,46[4,16 ; 24,75]$ & $10,36[0,06 ; 20,65]$ & 0,53 \\
\hline $2^{\mathrm{a}}$ Ventilação após trein. com monitor & $13,78[3,49 ; 24,07]$ & $13,80[3,51 ; 24,10]$ & 0,916 \\
\hline Valor-p em comparação com 1aㅗ & $>0,999$ & $>0,999$ & \\
\hline $3^{a}$ Ventilação após trein. sem monitor & $18,19[7,90 ; 28,48]$ & $14,01[3,71 ; 24,30]$ & 0,523 \\
\hline Valor-p em comparação com $1^{a}$ & $>0,999$ & $>0,999$ & \\
\hline 4ª Ventilação após 1 mês do trein. sem monitor & $16,76[4,77 ; 28,74]$ & $10,91[-1,07 ; 22,90]$ & 0,457 \\
\hline Valor-p em comparação com $1^{a}$ & $>0,999$ & $>0,999$ & \\
\hline $5^{\text {a }}$ Ventilação após 3 meses do trein. sem monitor & $40,67[29,01 ; 52,33]$ & $20,22[8,56 ; 31,88]$ & 0,015 \\
\hline Valor-p em comparação com $1^{a}$ & 0,019 & $>0,999$ & \\
\hline
\end{tabular}

Valores médios e IC obtidos por modelos mistos. Valores-p corrigidos pelo método de Bonferroni para comparações múltiplas. trein.: Treinamento. Equip.: Equipamento.

Valores numéricos do desvio padrão do escore do vazamento ao redor da máscara facial, segundo momento e equipamento.

\begin{tabular}{|c|c|c|c|}
\hline \multirow[b]{2}{*}{ Momento da avaliação } & \multicolumn{2}{|c|}{ Equipamento } & \multirow[b]{2}{*}{$\begin{array}{l}\text { Valor-p } \\
\text { Equip. }\end{array}$} \\
\hline & $\begin{array}{c}\text { Ventilador manual } \\
\text { em Peça-T } \\
\text { Média (IC 95\%) }\end{array}$ & $\begin{array}{l}\text { Balão inflável } \\
\text { Média (IC 95\%) }\end{array}$ & \\
\hline 1ํ Ventilação & $0,46[0,33 ; 0,59]$ & $0,27[0,14 ; 0,40]$ & 0,008 \\
\hline $2^{\mathrm{a}}$ Ventilação após trein. com monitor & $0,39[0,26 ; 0,53]$ & $0,37[0,23 ; 0,50]$ & 0,274 \\
\hline Valor-p em comparação com $1^{a}$ & $>0,999$ & $>0,999$ & \\
\hline 3a Ventilação após trein. sem monitor & $0,41[0,28 ; 0,55]$ & $0,39[0,26 ; 0,52]$ & 0,275 \\
\hline Valor-p em comparação com $1 \underline{\text { a }}$ & $>0,999$ & $>0,999$ & \\
\hline 4⿳亠口冋 Ventilação após 1 mês do trein. sem monitor & $0,53[0,37 ; 0,68]$ & $0,28[0,12 ; 0,43]$ & 0,004 \\
\hline Valor-p em comparação com $1^{a}$ & $>0,999$ & $>0,999$ & \\
\hline $5^{\text {a }}$ Ventilação após 3 meses do trein. sem monitor & $0,37[0,22 ; 0,52]$ & $0,43[0,28 ; 0,58]$ & 0,844 \\
\hline Valor-p em comparação com $1 \underline{\text { a }}$ & 0,851 & $>0,999$ & \\
\hline
\end{tabular}


Valores numéricos do desvio padrão do volume corrente inspiratório (mililitros), segundo momento e equipamento.

\begin{tabular}{|c|c|c|c|}
\hline \multirow[b]{2}{*}{ Momento da avaliação } & \multicolumn{2}{|c|}{ Equipamento } & \multirow[b]{2}{*}{$\begin{array}{l}\text { Valor-p } \\
\text { Equip. }\end{array}$} \\
\hline & $\begin{array}{c}\text { Ventilador manual } \\
\text { em Peça-T } \\
\text { Média (IC 95\%) }\end{array}$ & $\begin{array}{l}\text { Balão inflável } \\
\text { Média (IC 95\%) }\end{array}$ & \\
\hline 1’a Ventilação & $4,61[1,82 ; 7,39]$ & $8,94[6,15 ; 11,72]$ & 0,008 \\
\hline $2^{\mathrm{a}}$ Ventilação após trein. com monitor & $4,64[1,85 ; 7,42]$ & $7,16[4,38 ; 9,95]$ & 0,068 \\
\hline Valor-p em comparação com $1^{a}$ & $>0,999$ & $>0,999$ & \\
\hline 3a Ventilação após trein. sem monitor & $7,98[5,19 ; 10,76]$ & $4,73[1,94 ; 7,52]$ & 0,381 \\
\hline Valor-p em comparação com $1 \underline{\underline{a}}$ & 0,210 & $>0,999$ & \\
\hline 4⿳亠口冋 Ventilação após 1 mês do trein. sem monitor & $4,28[1,04 ; 7,51]$ & $4,97[1,74 ; 8,21]$ & 0,394 \\
\hline Valor-p em comparação com $1^{\text {a }}$ & $>0,999$ & $>0,999$ & \\
\hline 5a Ventilação após 3 meses do trein. sem monitor & $5,14[1,99 ; 8,29]$ & $6,92[3,77 ; 10,07]$ & 0,183 \\
\hline Valor-p em comparação com $1^{a} \underline{a}$ & $>0,999$ & $>0,999$ & \\
\hline
\end{tabular}

Valores médios e IC obtidos por modelos mistos. Valores-p corrigidos pelo método de Bonferroni para comparações múltiplas. trein.: Treinamento. Equip.: Equipamento.

Valores numéricos do desvio padrão do volume corrente expiratório (mililitros), segundo momento e equipamento.

\begin{tabular}{|c|c|c|c|}
\hline \multirow[b]{2}{*}{ Momento da avaliação } & \multicolumn{2}{|c|}{ Equipamento } & \multirow[b]{2}{*}{$\begin{array}{l}\text { Valor-p } \\
\text { Equip. }\end{array}$} \\
\hline & $\begin{array}{c}\text { Ventilador manual } \\
\text { em Peça-T } \\
\text { Média (IC 95\%) }\end{array}$ & $\begin{array}{l}\text { Balão inflável } \\
\text { Média (IC 95\%) }\end{array}$ & \\
\hline 1a Ventilação & $1,88[-1,50 ; 5,26]$ & $3,87[0,49 ; 7,25]$ & 0,356 \\
\hline $2^{\text {a }}$ Ventilação após trein. com monitor & $1,83[-1,55 ; 5,21]$ & $5,14[1,76 ; 8,52]$ & 0,152 \\
\hline Valor-p em comparação com $1^{\mathrm{a}}$ & $>0,999$ & $>0,999$ & \\
\hline 3a Ventilação após trein. sem monitor & $3,14[-0,24 ; 6,53]$ & $3,43[0,05 ; 6,81]$ & 0,789 \\
\hline Valor-p em comparação com $1 \underline{\text { a }}$ & $>0,999$ & $>0,999$ & \\
\hline 4ª Ventilação após 1 mês do trein. sem monitor & $1,94[-1,99 ; 5,88]$ & $2,44[-1,50 ; 6,38]$ & 0,761 \\
\hline Valor-p em comparação com 1 a & $>0,999$ & $>0,999$ & \\
\hline 5a Ventilação após 3 meses do trein. sem monitor & $10,07[6,24 ; 13,90]$ & $3,59[-0,24 ; 7,42]$ & 0,035 \\
\hline Valor-p em comparação com $1^{\text {ạ }}$ & 0,014 & $>0,999$ & \\
\hline
\end{tabular}

Valores médios e IC obtidos por modelos mistos. Valores- $p$ corrigidos pelo método de Bonferroni para comparações múltiplas. trein.: Treinamento. Equip.: Equipamento. 
Valores numéricos do desvio padrão do volume corrente médio (mililitros), segundo momento e equipamento.

\begin{tabular}{|c|c|c|c|}
\hline \multirow[b]{2}{*}{ Momento da avaliação } & \multicolumn{2}{|c|}{ Equipamento } & \multirow[b]{2}{*}{$\begin{array}{l}\text { Valor-p } \\
\text { Equip. }\end{array}$} \\
\hline & $\begin{array}{c}\text { Ventilador manual } \\
\text { em Peça-T } \\
\text { Média (IC 95\%) }\end{array}$ & $\begin{array}{l}\text { Balão inflável } \\
\text { Média (IC 95\%) }\end{array}$ & \\
\hline 1’a Ventilação & $2,08[-0,33 ; 4,49]$ & $4,64[2,23 ; 7,05]$ & 0,106 \\
\hline $2^{\mathrm{a}}$ Ventilação após trein. com monitor & $3,40[0,98 ; 5,81]$ & $4,78[2,37 ; 7,20]$ & 0,325 \\
\hline Valor-p em comparação com $1^{\text {a }}$ & $>0,999$ & $>0,999$ & \\
\hline 3a Ventilação após trein. sem monitor & $4,30[1,88 ; 6,71]$ & $3,00[0,59 ; 5,42]$ & 0,642 \\
\hline Valor-p em comparação com $1^{\underline{a}}$ & $>0,999$ & $>0,999$ & \\
\hline 4ㄹ Ventilação após 1 mês do trein. sem monitor & $2,30[-0,50 ; 5,11]$ & $2,75[-0,05 ; 5,56]$ & 0,675 \\
\hline Valor-p em comparação com $1^{a}$ & $>0,999$ & $>0,999$ & \\
\hline 5ㄹ Ventilação após 3 meses do trein. sem monitor & $5,92[3,19 ; 8,65]$ & $4,13[1,40 ; 6,86]$ & 0,508 \\
\hline Valor-p em comparação com $1^{\underline{a}}$ & 0,233 & $>0,999$ & \\
\hline
\end{tabular}

Valores médios e IC obtidos por modelos mistos. Valores-p corrigidos pelo método de Bonferroni para comparações múltiplas. trein.: Treinamento. Equip.: Equipamento.

Valores numéricos do desvio padrão da pressão inspiratória (centímetros de água), segundo momento e equipamento.

\begin{tabular}{|c|c|c|c|}
\hline \multirow[b]{2}{*}{ Momento da avaliação } & \multicolumn{2}{|c|}{ Equipamento } & \multirow[b]{2}{*}{$\begin{array}{l}\text { Valor-p } \\
\text { Equip. }\end{array}$} \\
\hline & $\begin{array}{c}\text { Ventilador manual } \\
\text { em Peça-T } \\
\text { Média (IC 95\%) }\end{array}$ & $\begin{array}{l}\text { Balão inflável } \\
\text { Média (IC 95\%) }\end{array}$ & \\
\hline $1^{\text {a }}$ Ventilação & $1,02[0,39 ; 1,65]$ & $2,31[1,67 ; 2,94]$ & 0,006 \\
\hline $2^{\mathrm{a}}$ Ventilação após trein. com monitor & $1,80[1,16 ; 2,43]$ & $3,71[3,08 ; 4,34]$ & $<0,001$ \\
\hline Valor-p em comparação com $1^{a}$ & 0,690 & 0,022 & \\
\hline $3^{a}$ Ventilação após trein. sem monitor & $0,98[0,35 ; 1,61]$ & $2,46[1,83 ; 3,09]$ & 0,002 \\
\hline Valor-p em comparação com $1^{a}$ & $>0,999$ & $>0,999$ & \\
\hline 4ㄹ Ventilação após 1 mês do trein. sem monitor & $1,25[0,52 ; 1,99]$ & $2,77[2,03 ; 3,50]$ & 0,005 \\
\hline Valor-p em comparação com $1 \underline{\underline{a}}$ & $>0,999$ & $>0,999$ & \\
\hline $5^{\text {a }}$ Ventilação após 3 meses do trein. sem monitor & $1,16[0,45 ; 1,88]$ & $2,51[1,79 ; 3,22]$ & 0,010 \\
\hline Valor-p em comparação com 1aㅗ & $>0,999$ & $>0,999$ & \\
\hline
\end{tabular}


Valores numéricos do desvio padrão da pressão positiva ao final da expiração (centímetros de água), segundo momento e equipamento.

\begin{tabular}{|c|c|c|c|}
\hline \multirow[b]{2}{*}{ Momento da avaliação } & \multicolumn{2}{|c|}{ Equipamento } & \multirow[b]{2}{*}{$\begin{array}{l}\text { Valor-p } \\
\text { Equip. }\end{array}$} \\
\hline & $\begin{array}{c}\text { Ventilador manual } \\
\text { em Peça-T } \\
\text { Média (IC 95\%) }\end{array}$ & $\begin{array}{c}\text { Balão inflável } \\
\text { Média (IC 95\%) }\end{array}$ & \\
\hline 1a Ventilação & $0,32[0,10 ; 0,54]$ & $0,22[0,00 ; 0,43]$ & 0,273 \\
\hline $2^{\mathrm{a}}$ Ventilação após trein. com monitor & $0,45[0,24 ; 0,67]$ & $0,72[0,50 ; 0,93]$ & 0,271 \\
\hline Valor-p em comparação com $1^{a}$ & $>0,999$ & 0,093 & \\
\hline $3^{a}$ Ventilação após trein. sem monitor & $0,37[0,15 ; 0,59]$ & $0,40[0,18 ; 0,62]$ & 0,767 \\
\hline Valor-p em comparação com $1^{a}$ & $>0,999$ & $>0,999$ & \\
\hline $4^{a}$ Ventilação após 1 mês do trein. sem monitor & $0,27[0,01 ; 0,52]$ & $0,39[0,14 ; 0,65]$ & 0,796 \\
\hline Valor-p em comparação com 1a & $>0,999$ & $>0,999$ & \\
\hline $5^{\text {a }}$ Ventilação após 3 meses do trein. sem monitor & $0,26[0,01 ; 0,50]$ & $0,59[0,34 ; 0,83]$ & 0,174 \\
\hline Valor-p em comparação com $1^{\underline{a}}$ & $>0,999$ & 0,797 & \\
\hline
\end{tabular}
comparações múltiplas. trein.: Treinamento. Equip.: Equipamento.

Valores numéricos do desvio padrão da frequência respiratória (ventilações por minuto), segundo momento e equipamento.

\begin{tabular}{|c|c|c|c|}
\hline \multirow[b]{2}{*}{ Momento da avaliação } & \multicolumn{2}{|c|}{ Equipamento } & \multirow[b]{2}{*}{$\begin{array}{l}\text { Valor-p } \\
\text { Equip. }\end{array}$} \\
\hline & $\begin{array}{c}\text { Ventilador manual } \\
\text { em Peça-T } \\
\text { Média (IC 95\%) }\end{array}$ & $\begin{array}{l}\text { Balão inflável } \\
\text { Média (IC 95\%) }\end{array}$ & \\
\hline 1ํ Ventilação & $3,85[2,12 ; 5,58]$ & $2,89[1,16 ; 4,62]$ & 0,196 \\
\hline $2^{\mathrm{a}}$ Ventilação após trein. com monitor & $3,93[2,20 ; 5,66]$ & $5,00[3,27 ; 6,73]$ & 0,810 \\
\hline Valor-p em comparação com $1^{\mathrm{a}}$ & $>0,999$ & $>0,999$ & \\
\hline 3a Ventilação após trein. sem monitor & $4,17[2,44 ; 5,90]$ & $7,67[5,94 ; 9,40]$ & 0,038 \\
\hline Valor-p em comparação com $1^{a}$ & $>0,999$ & 0,019 & \\
\hline $4^{a}$ Ventilação após 1 mês do trein. sem monitor & $3,23[1,23 ; 5,23]$ & $5,82[3,81 ; 7,82]$ & 0,223 \\
\hline Valor-p em comparação com $1^{a}$ & $>0,999$ & 0,995 & \\
\hline $5^{\text {a }}$ Ventilação após 3 meses do trein. sem monitor & $3,51[1,55 ; 5,46]$ & $4,88[2,93 ; 6,83]$ & 0,673 \\
\hline Valor-p em comparação com $1 \underline{\text { a }}$ & $>0,999$ & $>0,999$ & \\
\hline
\end{tabular}


Valores numéricos do desvio padrão do volume minuto (mililitros por minuto), segundo momento e equipamento.

\begin{tabular}{|c|c|c|c|}
\hline \multirow[b]{2}{*}{ Momento da avaliação } & \multicolumn{2}{|c|}{ Equipamento } & \multirow[b]{2}{*}{$\begin{array}{l}\text { Valor-p } \\
\text { Equip }\end{array}$} \\
\hline & $\begin{array}{c}\text { Ventilador manual em } \\
\text { Peça-T } \\
\text { Média (IC 95\%) }\end{array}$ & $\begin{array}{l}\text { Balão inflável } \\
\text { Média (IC 95\%) }\end{array}$ & \\
\hline 1a Ventilação & $79,56[-14,68 ; 173,80]$ & $274,67[180,43 ; 368,91]$ & 0,001 \\
\hline $2^{\mathrm{a}}$ Ventilação após trein. com monitor & $76,68[-17,56 ; 170,92]$ & $205,42[111,18 ; 299,65]$ & 0,021 \\
\hline Valor-p em comparação com $1^{\text {a }}$ & $>0,999$ & $>0,999$ & \\
\hline $3^{a}$ Ventilação após trein. sem monitor & $121,66[27,42 ; 215,90]$ & $154,97[60,73 ; 249,21]$ & 0,326 \\
\hline Valor-p em comparação com $1^{\mathfrak{a}}$ & $>0,999$ & $>0,999$ & \\
\hline $\begin{array}{l}4^{\text {a }} \text { Ventilação após } 1 \text { mês do trein. } \\
\text { sem monitor }\end{array}$ & $67,74[-41,37 ; 176,85]$ & $115,08[5,97 ; 224,20]$ & 0,299 \\
\hline Valor-p em comparação com $1^{a}$ & $>0,999$ & 0,910 & \\
\hline $\begin{array}{l}5^{\text {a }} \text { Ventilação após } 3 \text { meses do trein. } \\
\text { sem monitor }\end{array}$ & $160,99[54,73 ; 267,26]$ & $216,73[110,46 ; 322,99]$ & 0,242 \\
\hline Valor-p em comparação com 1 ạ & 0,953 & $>0,999$ & \\
\hline
\end{tabular}

Valores numéricos do desvio padrão do tempo inspiratório (segundos), de acordo com momento e equipamento.

\begin{tabular}{|c|c|c|c|}
\hline \multirow[b]{2}{*}{ Momento da avaliação } & \multicolumn{2}{|c|}{ Equipamento } & \multirow[b]{2}{*}{$\begin{array}{l}\text { Valor-r } \\
\text { Equip }\end{array}$} \\
\hline & $\begin{array}{c}\text { Ventilador manual } \\
\text { em Peça-T } \\
\text { Média (IC 95\%) }\end{array}$ & $\begin{array}{l}\text { Balão inflável } \\
\text { Média (IC 95\%) }\end{array}$ & \\
\hline 1ํ Ventilação & $0,12[0,07 ; 0,16]$ & $0,07[0,03 ; 0,12]$ & 0,270 \\
\hline $2^{\mathrm{a}}$ Ventilação após trein. com monitor & $0,18[0,14 ; 0,23]$ & $0,10[0,06 ; 0,14]$ & 0,017 \\
\hline Valor-p em comparação com $1^{a}$ & 0,236 & $>0,999$ & \\
\hline 3ㄹ Ventilação após trein. sem monitor & $0,19[0,15 ; 0,24]$ & $0,12[0,07 ; 0,16]$ & 0,033 \\
\hline Valor-p em comparação com $1^{\text {a }}$ & 0,111 & $>0,999$ & \\
\hline $4^{a}$ Ventilação após 1 mês do trein. sem monitor & $0,17[0,12 ; 0,22]$ & $0,10[0,05 ; 0,15]$ & 0,094 \\
\hline Valor-p em comparação com $1^{\underline{a}}$ & 0,807 & $>0,999$ & \\
\hline $5^{\text {a }}$ Ventilação após 3 meses do trein. sem monitor & $0,17[0,12 ; 0,22]$ & $0,14[0,09 ; 0,19]$ & 0,549 \\
\hline Valor-p em comparação com $1^{a}$ & 0,854 & 0,343 & \\
\hline
\end{tabular}

Valores médios e IC obtidos por modelos mistos. Valores-p corrigidos pelo método de Bonferroni para comparações múltiplas. trein.: Treinamento. Equip.: Equipamento. 
Valores numéricos do desvio padrão do tempo expiratório (segundos), de acordo com momento e equipamento.

\begin{tabular}{|c|c|c|c|}
\hline \multirow[b]{2}{*}{ Momento da avaliação } & \multicolumn{2}{|c|}{ Equipamento } & \multirow[b]{2}{*}{$\begin{array}{l}\text { Valor-p } \\
\text { Equip. }\end{array}$} \\
\hline & $\begin{array}{c}\text { Ventilador manual } \\
\text { em Peça-T } \\
\text { Média (IC 95\%) } \\
\end{array}$ & $\begin{array}{l}\text { Balão inflável } \\
\text { Média (IC 95\%) }\end{array}$ & \\
\hline 1' Ventilação & $0,14[0,09 ; 0,18]$ & $0,09[0,05 ; 0,14]$ & 0,071 \\
\hline $2^{\mathrm{a}}$ Ventilação após trein. com monitor & $0,13[0,09 ; 0,17]$ & $0,16[0,12 ; 0,20]$ & 0,786 \\
\hline Valor-p em comparação com $1^{\text {a }}$ & $>0,999$ & $>0,999$ & \\
\hline $3^{\text {a }}$ Ventilação após trein. sem monitor & $0,13[0,09 ; 0,17]$ & $0,15[0,10 ; 0,19]$ & 0,956 \\
\hline Valor-p em comparação com $1^{a}$ & $>0,999$ & $>0,999$ & \\
\hline 4⿳亠口冋 Ventilação após 1 mês do trein. sem monitor & $0,12[0,07 ; 0,17]$ & $0,16[0,11 ; 0,21]$ & 0,602 \\
\hline Valor-p em comparação com 1 a & $>0,999$ & $>0,999$ & \\
\hline 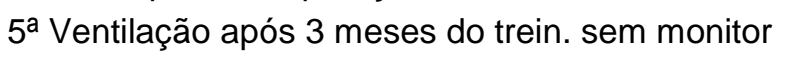 & $0,22[0,17 ; 0,27]$ & $0,17[0,12 ; 0,22]$ & 0,047 \\
\hline Valor-p em comparação com $1^{\underline{a}}$ & 0,382 & 0,861 & \\
\hline
\end{tabular}

